André Francisco Bucci

Efeitos de morfotipos do fitoplâncton no comportamento espectral da absorção da luz, e possíveis implicações para a determinação de carbono particulado por sensoriamento remoto

\author{
Dissertação apresentada ao Instituto \\ Oceanográfico da Universidade de São \\ Paulo, como parte dos requisitos para \\ obtenção do título de Mestre em Ciências, \\ Programa de Oceanografia, área de \\ Oceanografia Biológica.
}

Orientadora: Profa. Dra. Áurea Maria Ciotti

São Paulo 


\author{
Universidade de São Paulo \\ Instituto Oceanográfico
}

\title{
Efeitos de morfotipos do fitoplâncton no comportamento espectral da absorção da luz, e possíveis implicações para a determinação de carbono particulado por sensoriamento remoto
}

\author{
André Francisco Bucci
}

\section{Versão Corrigida}

Dissertação apresentada ao Instituto Oceanográfico da Universidade de São Paulo, como parte dos requisitos para obtenção do título de Mestre em Ciências, Programa de Oceanografia, área de Oceanografia Biológica.

Julgado em

1

Profa. Dra. Áurea Maria Ciotti

Conceito

Profa. Dra. Sônia Maria Flores Gianesella

Conceito

Profa. Dra. Clarisse Odebrecht

Conceito 


\section{Sumário}

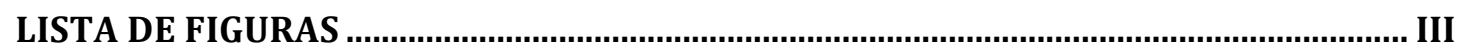

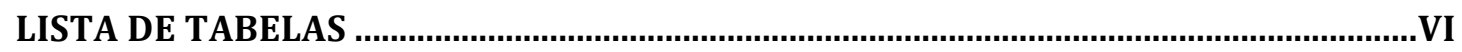

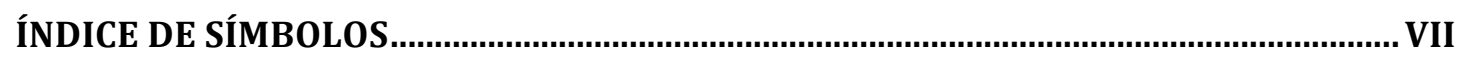

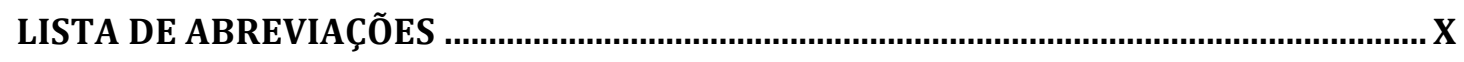

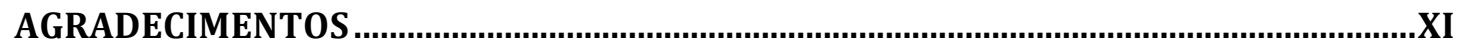

RESUMO_............................................................................................................

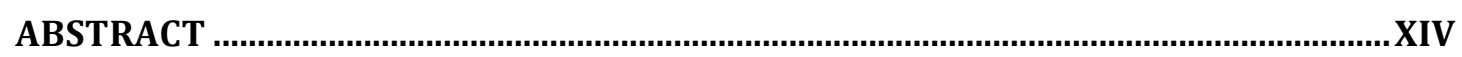

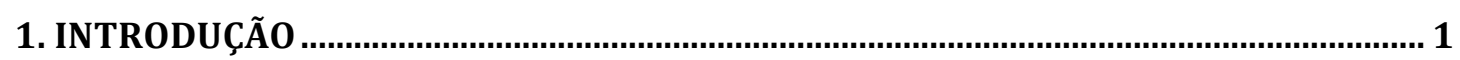

1.1. DETERMINAÇÃO DA BIOMASSA DO FITOPLÂNCTON MARINHO ………………………………….... 1

1.2. ABSORÇÃO DE LUZ PELO FITOPLÂNCTON ………………................................................................ 3

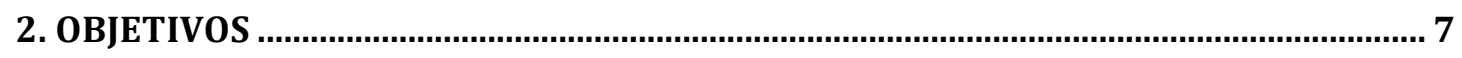

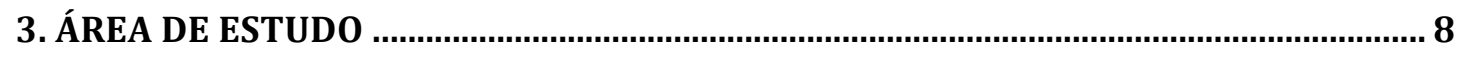

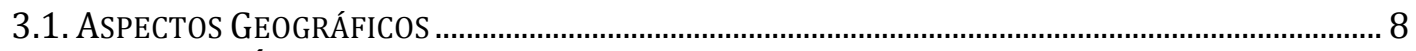

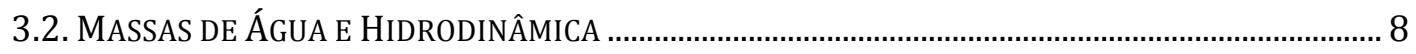

3.3. FEIÇÕES OCEANOGRÁFICAS DE MESO-ESCALA........................................................................ 9

3.4. CLIMATOLOGIA DAS CORRENTES OCEÂNICAS E CONDIÇÕES METEOROLÓGICAS...........................10

3.5. ASPECTOS BIOLÓGICOS DAS COMUNIDADES FITOPLANCTÔNICAS................................................11

3.5. CARACTERÍSTICAS BIO-ÓTICAS E COR DO OCEANO ……........................................................

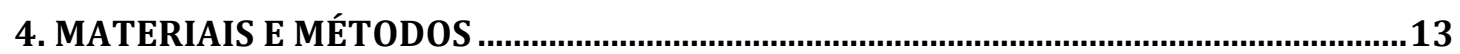

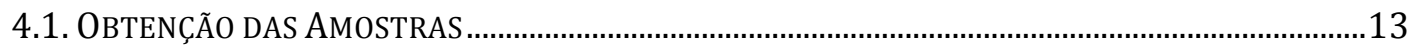

4.2. PROCESSAMENTO DAS AMOSTRAS ………………………………………........................ 14

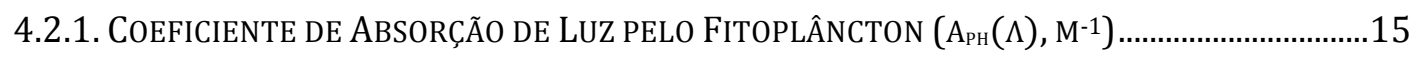

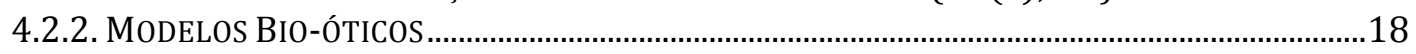

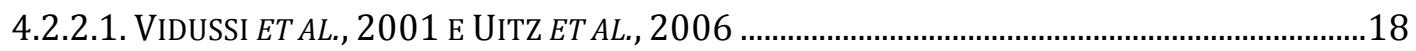

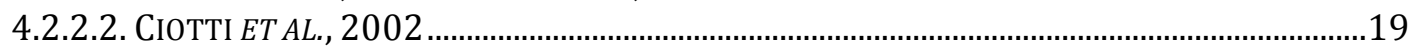

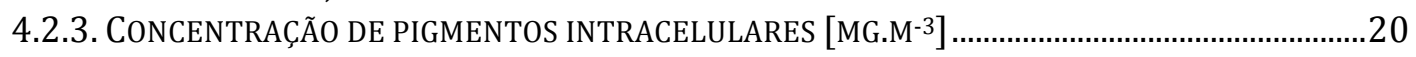

4.2.4. ABUNDÂNCIA DE ORGANISMOS FITOPLANCTÔNICOS [CÉLULAS.L ${ }^{-1}$ ] .....................................21

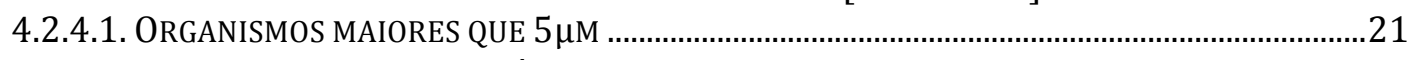

4.2.4.1.1. CONTAGEM EM MICROSCÓPIO INVERTIDO ………........................................................2

4.2.4.1.2. CÁLCULO DO NÚMERO DE CÉLULAS POR CADEIA .............................................................23

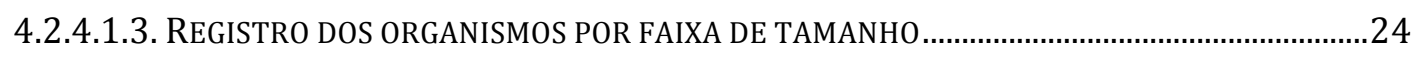

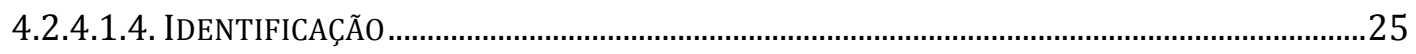

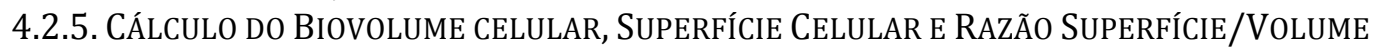

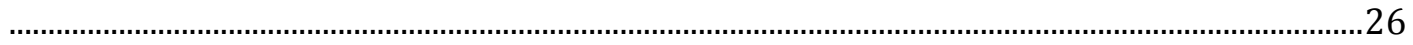

4.2.5.1 - DEFINIÇÃO DE MORFOTIPOS GEOMÉTRICOS E MEDIDAS LINEARES.....................................26

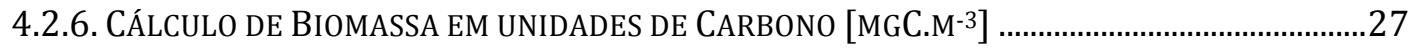

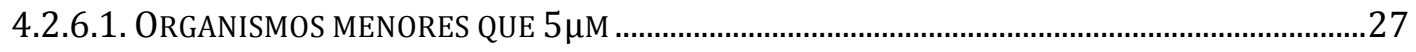

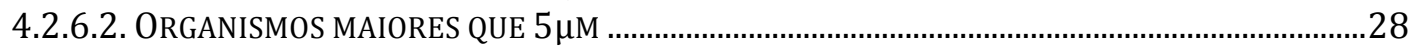

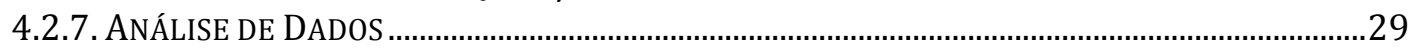

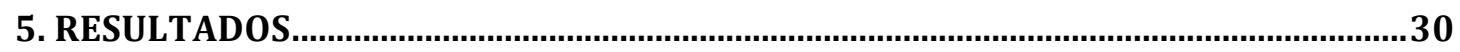

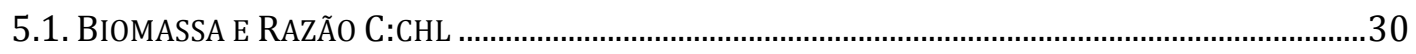

5.2. CLASSIFICAÇÃo DA COMUNIDADE FITOPLANCTÔNICA.................................................................33

5.3. DESCRITORES DE COMUNIDADE E TAMANHO PONDERADO …………...........................................

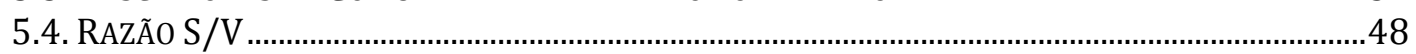

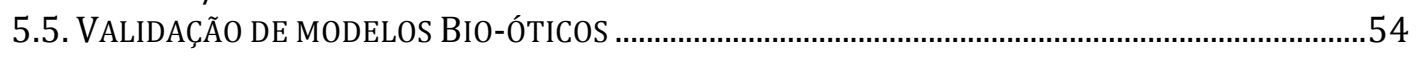


5.5.1 - VIDUSSI ET AL. (2001) E UITZ ET AL. (2006) ………...........................................................5

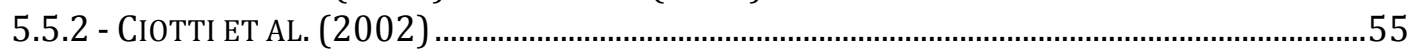

5.6. COEFICIENTE DE ABSORÇÃO DA LUZ PELO FITOPLÂNCTON …………….......................................57

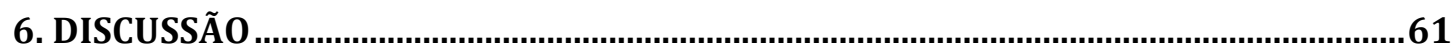

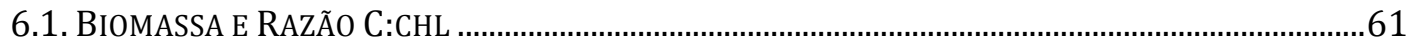

6.2. CLASSIFICAÇÃO DA COMUNIDADE FITOPLANCTÔNICA...............................................................63

6.3. DESCRITORES DE COMUNIDADE E TAMANHO PONDERADO …...................................................64

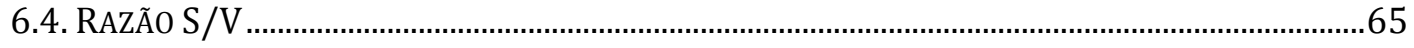

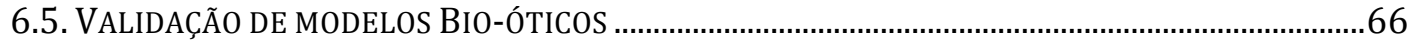

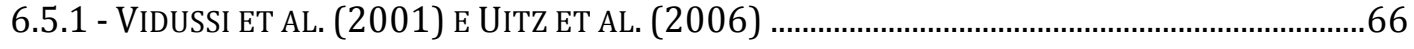

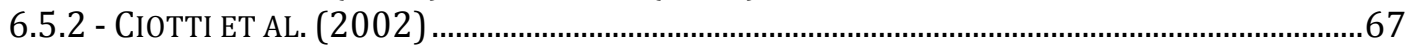

6.6. COEFICIENTE DE ABSORÇÃO DA LUZ PELO FITOPLÂNCTON ……………………….....................68

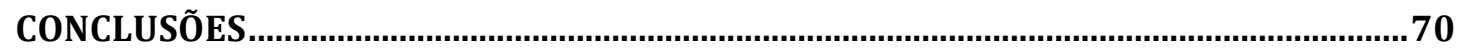

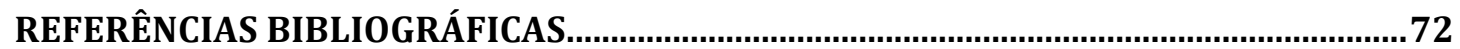

ANEXOS

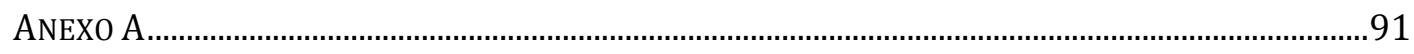

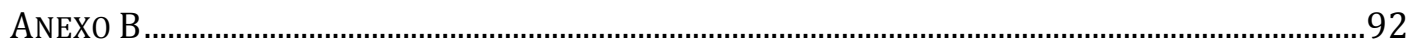

CONDIÇÕES OCEANOGRÁFICAS E ESTADO TRÓFICO …………...........................................................

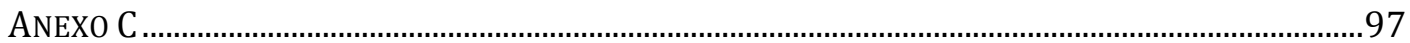




\section{Lista de Figuras}

Figura 1: Localização da área de estudo e estações de coleta de amostras de água com as estações utilizadas neste trabalho em destaque $(\Theta)$. A) Distribuição espacial da malha amostral dos dois cruzeiros oceanográficos MCT-1 e MCT-2, destacados, respectivamente, em linha pontilhada e linha contínua. B) Estações oceanográficas realizadas pelo cruzeiro MCT-1 em julho de 2010. C) Distribuição das estações oceanográficas do cruzeiro MCT-2 de dezembro de 2010 para a plataforma continental sul. D) Estações oceanográficas do MCT-2 na plataforma continental sudeste brasileira.

Figura 2: Comparação entre o uso de fórmulas de conversão de volume para biomassa. A) Biomassa representada por espécie dentro de cada amostra e B) Biomassa total da comunidade fitoplanctônica. Superescritos "a" e "b" representam diferença estatística (Teste $t$-student pareado, $p<0.001, n=2011$ ). Não estão representados os outliers em ambos os gráficos.

Figura 3: Relação entre a biomassa do fitoplâncton $(B)$ e a concentração de clorofila-a ([chl]).

Figura 4: Distribuição da biomassa e da razão C:chl entre Superfície e PFMC de toda a comunidade fitoplanctônica ( $A$ e B) e excluindo o ultra e picoplâncton (C e D). As denotações "a" e "b" representam diferença estatística entre os grupos de dados em cada gráfico (ANOVA, $p<0.05$, $\mathrm{n}=49$ ). 33

Figura 5: Distribuição das estações oceanográficas alinhadas de acordo com a biomassa total da comunidade fitoplanctônica para a Superfície. A) Biomassa $\left[\mathrm{mgC} \cdot \mathrm{m}^{-3}\right]$; $\quad$ B) [chl] [mg. $\left.\mathrm{m}^{-3}\right]$ em escala logarítmica $\left.\left(\log _{10}\right) ; \mathrm{C}\right)$ Comprimento Total ponderado pela Biomassa $\left(\mathrm{CT}^{\mathrm{B}}\right)$.

Figura 6: Distribuição das estações oceanográficas alinhadas de acordo com a biomassa total da comunidade fitoplanctônica para a PFMC. A) Biomassa $\left[\mathrm{mgC} . \mathrm{m}^{-3}\right]$; B) [chl] [mg. $\left.\mathrm{m}^{-3}\right]$ em escala logarítmica $\left(\log _{10}\right)$; C) Comprimento Total ponderado pela Biomassa $\left(\mathrm{CT}^{\mathrm{B}}\right)$.

Figura 7: Relação entre o $C T^{B}$ e a Biomassa (A) e a [chl] (B). Todos os eixos estão em escala logarítmica.

Figura 8: Distribuição da Biomassa celular entre os diferentes grupos taxonômicos na superfície (A) e na PFMC (B). Valores de biomassa em escala logarítmica.

Figura 9: Distribuição da Biomassa celular entre os diferentes morfotipos celulares na superfície (A) e na PFMC (B). A organização dos morfotipos está de acordo com sua razão $S / N$, seguindo os valores de superfície, aumentando da esquerda para a direita do gráfico. Valores de biomassa em escala logarítmica.

Figura 10: Distribuição da biomassa fitoplanctônica $\left[\mathrm{mg}^{-3} \mathrm{~m}^{-3}\right.$ d dividida entre os grupos taxonômicos encontrados em cada estação oceanográfica na superfície - notar diferença de escalas. As estações (eixo x) estão alinhadas de acordo com a biomassa total da estação, ou seja, da estação com menor biomassa (esquerda) para a estação com maior biomassa (direita). 
Figura 11: Distribuição da biomassa fitoplanctônica $\left[\mathrm{mg} \cdot \mathrm{m}^{-3}\right.$ ] dividida entre os grupos taxonômicos encontrados em cada estação oceanográfica na PFMC - notar diferença de escalas. As estações (eixo x) estão alinhadas de acordo com a biomassa total da estação, ou seja, da estação com menor biomassa (esquerda) para a estação com maior biomassa (direita).

Figura 12: Distribuição da biomassa fitoplanctônica $\left[\mathrm{mg} \cdot \mathrm{m}^{-3}\right.$ ] dividida entre os morfotipos encontrados em cada estação oceanográfica na superfície. As estações (eixo $\mathrm{x}$ ) estão alinhadas de acordo com a biomassa total da estação, ou seja, da estação com menor biomassa (esquerda) para a estação com maior biomassa (direita) - notar diferença de escalas. 45

Figura 13: Continuação da Figura 8. Mantido o mesmo enunciado. - notar diferença de escalas.

Figura 14: Distribuição da biomassa fitoplanctônica $\left[\mathrm{mg} \cdot \mathrm{m}^{-3}\right]$ dividida entre os morfotipos encontrados em cada estação oceanográfica na PFMC. As estações (eixo x) estão alinhadas de acordo com a biomassa total da estação, ou seja, da estação com menor biomassa (esquerda) para a estação com maior biomassa (direita). - notar diferença de escalas. ...... 47

Figura 15: Continuação da Figura 9a. O mesmo enunciado mantido. - notar diferença de escalas

Figura 16: Relação S/V hipotética entre os morfotipos fitoplanctônicos encontrados. As equações de cada morfotipo seguiram o apresentado por Sun e Liu (2003) e foram calculadas em um gradiente de CT de 5 a $100 \mu \mathrm{m}$ em intervalos de $0.1 \mu \mathrm{m}$. A largura e profundidade de cada forma foram estipulados como sendo metade do comprimento total e 1/3 do comprimento total, respectivamente. Morfotipos com múltiplas formas geométricas mantiveram a mesma proporção entre dimensões. O CT (eixo $x$ ) está demonstrado em escala logarítmica $\left(\log _{10}\right)$

Figura 17: Relação entre a razão S/V [ $\left.\mu^{-1}\right]$ para os organismos encontrados e o seu CT $[\mu \mathrm{m}]$. Os organismos estão divididos em seus respectivos morfotipos geométricos e correspondem ao banco de dados da Superfície (3-5m). Destaque para o CT (eixo $\mathrm{x}$ ) apresentado em escala logarítimica $\left(\log _{10}\right)$

Figura 18: Relação entre a razão S/V $\left[\mu^{-1}\right]$ para os organismos encontrados e o seu CT $[\mu \mathrm{m}]$. Os organismos estão divididos em seus respectivos morfotipos geométricos e correspondem ao banco de dados da PFMC (profundidade variável). Destaque para o CT (eixo $\mathrm{x}$ ) apresentado em escala logarítimica $\left(\log _{10}\right)$. 51

Figura 19: Distribuição da razão Superfície/Volume (S/V) entre os grupos fitoplanctônicos. $\quad \mathrm{FL}=$ Flagelados, DI=Diatomáceas Isoladas, $\mathrm{DC}=$ Diatomáceas em Cadeia, $\mathrm{CO}=$ Cocolitoforídeos, $\mathrm{Cl}=$ Cianobactérias, DA=Dinoflagelados Atecados, DT=Dinoflagelados Tecados, OT=Outras espécies. A razão S/V (eixo y) está representada em escala logarítmica. Os grupos taxonômicos estão alinhados de acordo com sua taxa de crescimento. 52

Figura 20: Distribuição da razão Superfície/Volume (S/V) entre os morfotipos geométricos. Os morfotipos estão representados pelos seus símbolos, veja Índice de Símbolos para detalhes. A razão S/V (eixo y) está representada em escala logarítmica. Os morfotipos estão alinhados de 
acordo com sua razão $S / V$, seguindo os valores de superfície, aumentando da esquerda para a direita do gráfico. 53

Figura 21: Relação entre a Biomassa e a razão Superfície/Volume ponderada pela biomassa $\left(S / V^{B}\right)$ para a superfície e PFMC............................................. 54

Figura 22: Relação entre $S_{f}$ e a [chl] (A) e a Biomassa (B)................................. 56

Figura 23: Relação entre $S_{f}$ e o Comprimento Total do organismos ponderado pela Biomassa $\left(\mathrm{CT}^{\mathrm{B}}\right)$. 57

Figura 24: Relação entre <aph> e a [chl] (A) e a Biomassa (B). 58

Figura 25: Relação entre <aph> e a razão Superfície/Volume ponderada pela biomassa $\left(\mathrm{S} / \mathrm{V}^{\mathrm{B}}\right)$

Figura 26: Distribuição dos resíduos de $S_{f}$ de acordo com o comprimento de onda. Em destaque os comprimentos de onda centrais de cada banda de resíduo analisada. 59

Figura 27: Distribuição espacial da temperatura da água na superfície (A) e na PFMC (B), da salinidade na superfície (C) e PFMC (D) e da concentração de clorofila-a superficial (E) e na PFMC (F) para o cruzeiro MCT-1. 95

Figura 28: Distribuição espacial da temperatura da água na superfície $(A)$ e na PFMC (B), da salinidade na superfície (C) e PFMC (D) e da concentração de clorofila-a superficial (E) e na PFMC (F) para o cruzeiro MCT-2. 


\section{Lista de Tabelas}

Tabela 1: Relação dos pigmentos identificados por HPLC, suas siglas e a quais grupos taxonômicos funcionam como pigmentos indicadores. Modificado de Wright (2005).

Tabela 2: Faixas de tamanho utilizadas durante a contagem do fitoplâncton em microscopia e critérios para aquisição de imagens.

Tabela 3: Relação das equações de conversão de volume celular para carbono celular utilizadas e suas referências principais. Adaptada de Menden-Deuer e Lessard (2000)..

Tabela 4: Parâmetros e ajuste das curvas Michaelis-Menten (MM) para cada cruzeiro oceanográfico e profundiadade (Superfície e PFMC). $\left(^{*}\right)$ representam significância estatística $(p<0.05)$ para a determinação dos parâmetros e $(\dagger)$ corresponde ao parâmetro que foi definido como limite superior para o ajuste de Bultra + pico do MCT-1 na PFMC 30

Tabela 5: Lista dos gêneros identificados em microscópio, seus respectivos morfotipos e o grupo taxonômico em que estão inseridos.

Tabela 6: Ocorrência dos morfotipos fitoplanctônicos de acordo com o grupo taxonômico. Os valores correspondem ao número total de observações entre as estações.

Tabela 7: Comparação das proporções das classes de tamanho do fitoplâncton entre as duas profundidades de coleta. Os valores nas células correspondem à média e desvio padrão e os valores de $p$ obtidos através de ANOVA. 55

Tabela 8: Sumário das comparações entre as proporções das classes de tamanho do fitoplâncton. Realizado ANOVA, com significância de 0.05.

Tabela 9: Relação das bandas de resíduo de $S_{f}$ e os principais pigmentos e formas geométricas que influenciam a magnitude do resíduo de $S_{f .} \ldots . . . .60$

Tabela 10: Lista das estações oceanográficas realizadas e suas respectivas profundidades e coordenadas geográficas.

Tabela 11: Descrição dos morfotipos fitoplanctônicos observados, seus códigos e sua representação geométrica. Adaptado de Sun e Liu (2003). 


\section{Índice de Símbolos}

\begin{tabular}{|c|c|c|}
\hline Símbolos & Unidades & Descrição \\
\hline $\bar{\lambda}$ & $\mathrm{nm}$ & Comprimento de onda \\
\hline$a_{\text {par }}$ & $m^{-1}$ & $\begin{array}{l}\text { Coeficiente de absorção de luz do material particulado em } \\
\text { suspensão }\end{array}$ \\
\hline$a_{\mathrm{ph}}$ & $m^{-1}$ & Coeficiente de absorção de luz pelo fitoplâncton \\
\hline$a_{\text {det }}$ & $m^{-1}$ & $\begin{array}{l}\text { Coeficiente de absorção de luz do material particulado em } \\
\text { suspensão não-vivo }\end{array}$ \\
\hline$a_{\mathrm{ph}}^{*}$ & $\mathrm{~m}^{2} \cdot \mathrm{mg}^{-1}$ & Coeficiente de absorção de luz específico da clorofila-a \\
\hline$<a_{\mathrm{ph}}>$ & $m^{-1}$ & Média de $\mathrm{a}_{\mathrm{ph}}$ dos comprimentos de onda de 400 a $700 \mathrm{~nm}$ \\
\hline$\overline{a_{\mathrm{ph}}}$ & Sem dimensão & $\begin{array}{l}a_{\mathrm{ph}} \text { em cada comprimento de onda normalizados por }< \\
a_{\mathrm{ph}}>\end{array}$ \\
\hline$a_{\text {pico }}$ & $m^{-1}$ & $\begin{array}{l}\text { Coeficiente de absorção de luz representando o } \\
\text { picoplâncton (Ciotti et al., 2002) }\end{array}$ \\
\hline$a_{\text {micro }}$ & $m^{-1}$ & $\begin{array}{l}\text { Coeficiente de absorção de luz representando o } \\
\text { microplâncton (Ciotti et al., 2002) }\end{array}$ \\
\hline$S_{f}$ & Sem dimensão & $\begin{array}{l}\text { Eficiência de absorção da luz pelo fitoplâncton (Ciotti et } \\
\text { al., 2002) }\end{array}$ \\
\hline $\mathrm{m}_{1} ; \mathrm{m}_{2}$ & Sem dimensão & $\begin{array}{l}\text { Parâmetros da curva MM para cálculo da biomassa do } \\
\text { ultra e picoplâncton; } B_{\text {ultra }+ \text { pico }}=\frac{m 1+[\text { chl }]}{m 2 \times[c h l]}\end{array}$ \\
\hline $\mathrm{p}_{1} ; \mathrm{p}_{2}$ & Sem dimensão & $\begin{array}{l}\text { Parâmetros da relação empírica entre } a_{\mathrm{ph}}(\lambda) \text { e [chl]; } \\
a_{p h}(\lambda)=p 1 \times[c h l]^{-p 2}\end{array}$ \\
\hline [chl] & $\mathrm{mg} \cdot \mathrm{m}^{-3}$ ou $\mu \mathrm{g} \cdot \mathrm{L}^{-1}$ & Concentração de Clorofila-a \\
\hline C:chl & $\begin{array}{l}g \cdot g^{-1} / \text { sem } \\
\text { dimensão }\end{array}$ & razão Carbono/Clorofila-a \\
\hline$f_{\text {micro }}$ & $\%$ & $\begin{array}{l}\text { Fração do microfitoplâncton (Vidussi et al., 2001; Uitz et } \\
\text { al., 2006) }\end{array}$ \\
\hline$f_{\text {nano }}$ & $\%$ & $\begin{array}{l}\text { Fração do nanofitoplâncton (Vidussi et al., 2001; Uitz et } \\
\text { al., 2006) }\end{array}$ \\
\hline$f_{\text {pico }}$ & $\%$ & $\begin{array}{l}\text { Fração do picofitoplâncton (Vidussi et al., 2001; Uitz et al., } \\
\text { 2006) }\end{array}$ \\
\hline$p_{\text {micro }}$ & $\%$ & Proporção da biomassa do microfitoplâncton \\
\hline$p_{\text {nano }}$ & $\%$ & Proporção da biomassa do nanofitoplâncton \\
\hline$B_{\text {ultra }}+$ pico & $\mathrm{mgC} \cdot \mathrm{m}^{-3}$ & Biomassa do Ultra + Picoplâncton \\
\hline$B_{\text {micro }}$ & $\mathrm{mgC} \cdot \mathrm{m}^{-3}$ & Biomassa do Microplâncton \\
\hline$B_{\text {nano }}$ & $\mathrm{mgC} \cdot \mathrm{m}^{-3}$ & Biomassa do Nanoplâncton \\
\hline
\end{tabular}




\begin{tabular}{|c|c|c|}
\hline Símbolos & Unidades & Descrição \\
\hline$B$ & $\mathrm{mgC} \cdot \mathrm{m}^{-3}$ & Biomassa Total da Comunidade Fitoplanctônica \\
\hline$B_{c e l}$ & pgC.cel ${ }^{-1}$ & Biomassa celular (um organismo/célula) \\
\hline$B_{s p}$ & $\mathrm{mgC} \cdot \mathrm{m}^{-3} \cdot \mathrm{sp}^{-1}$ & Biomassa dos organismos que compõem uma espécie \\
\hline V & $\mu \mathrm{m}^{3}$ & Biovolume Celular \\
\hline S & $\mu m^{2}$ & Superfície Celular \\
\hline $\mathrm{S} / \mathrm{V}$ & $\mu \mathrm{m}^{-1}$ & razão Superfície/Volume \\
\hline $\mathrm{S} / \mathrm{V}^{\mathrm{B}}$ & $\mu \mathrm{m}^{-1}$ & razão Superfície/Volume ponderado pela biomassa \\
\hline CT & $\mu \mathrm{m}$ & Comprimento Total da célula \\
\hline $\mathrm{CT}^{\mathrm{B}}$ & $\mu \mathrm{m}$ & Comprimento Total da célula ponderado pela biomassa \\
\hline $\mathrm{LT}$ & $\mu \mathrm{m}$ & Largura Total \\
\hline 3D & $\mu \mathrm{m}$ & Profundidade da célula \\
\hline MDL & $\mu \mathrm{m}$ & Máxima Dimensão Linear \\
\hline$\sum D P_{w}$ & $\mathrm{mg} \cdot \mathrm{m}^{-3}$ & $\begin{array}{l}\text { Somatória dos pigmentos marcadores normalizados pela } \\
\text { [chl] }\end{array}$ \\
\hline$A$ & sem dimensão & $\begin{array}{l}\text { Absorbância do filtro com material antes da remoção dos } \\
\text { pigmentos }\end{array}$ \\
\hline$A e$ & sem dimensão & $\begin{array}{l}\text { Absorbância do filtro com material após remoção dos } \\
\text { pigmentos }\end{array}$ \\
\hline$B r$ & sem dimensão & $\begin{array}{l}\text { Absorbância do filtro sem material e sem aplicação de } \\
\text { hipoclorito de sódio }\end{array}$ \\
\hline$B e$ & sem dimensão & $\begin{array}{l}\text { Absorbância do filtro sem material com aplicação de } \\
\text { hipoclorito de sódio }\end{array}$ \\
\hline$A^{\prime}$ & sem dimensão & $\begin{array}{l}\text { Absorbância do filtro com material antes da remoção dos } \\
\text { pigmentos corrigido em } 866 \mathrm{~nm}\end{array}$ \\
\hline$A e^{\prime}$ & sem dimensão & $\begin{array}{l}\text { Absorbância do filtro com material após remoção dos } \\
\text { pigmentos corrigido em } 866 \mathrm{~nm}\end{array}$ \\
\hline$B^{\prime}$ & sem dimensão & $\begin{array}{l}\text { Absorbância do filtro sem material e sem aplicação de } \\
\text { hipoclorito de sódio corrigido em } 866 \mathrm{~nm}\end{array}$ \\
\hline$B e^{\prime}$ & sem dimensão & $\begin{array}{l}\text { Absorbância do filtro sem material com aplicação de } \\
\text { hipoclorito de sódio corrigido em } 866 \mathrm{~nm}\end{array}$ \\
\hline$\overline{o f f}_{(866)}$ & sem dimensão & offset das absorbâncias em 866nm \\
\hline$A_{b}$ & sem dimensão & $\begin{array}{l}\text { Absorbância do filtro com material antes da remoção dos } \\
\text { pigmentos corrigido pelo branco }\end{array}$ \\
\hline \multirow[t]{2}{*}{$A_{b} e$} & sem dimensão & $\begin{array}{l}\text { Absorbância do filtro com material depois da remoção dos } \\
\text { pigmentos corrigido pelo branco }\end{array}$ \\
\hline & sem dimensão & Absorbância do filtro com material antes da remoção dos \\
\hline
\end{tabular}




\begin{tabular}{|c|c|c|}
\hline Símbolos & Unidades & Descrição \\
\hline$A_{b}{ }^{\prime}$ & & pigmentos com offset em 750nm \\
\hline$A_{b} e^{\prime}$ & sem dimensão & $\begin{array}{l}\text { Absorbância do filtro com material depois da remoção dos } \\
\text { pigmentos com offset em } 750 \mathrm{~nm}\end{array}$ \\
\hline$A_{\text {sus }}$ & sem dimensão & $\begin{array}{l}\text { Absorbância do material particulado em suspensão (vivo } \\
\text { e não-vivo) }\end{array}$ \\
\hline$A e_{\text {sus }}$ & sem dimensão & $\begin{array}{l}\text { Absorbância do material particulado em suspensão (não- } \\
\text { vivo) }\end{array}$ \\
\hline Vol & $\mathrm{m}^{3}$ & Volume de água filtrada \\
\hline$A_{o}$ & $\mathrm{~m}^{2}$ & Área do filtro utilizado \\
\hline$S$ & sem dimensão & $\begin{array}{l}\text { denotação de representa o cálculo para cada espécie } \\
\text { encontrada }\end{array}$ \\
\hline$A b$ & células. $L^{-1}$ & Abundância de organismos \\
\hline U.S. & células/cadeias & Unidades Sedimentadas \\
\hline$n_{c e l}$ & células & número de células \\
\hline$A_{t}$ & $\mu \mathrm{m}^{2}$ & Área total da câmara de sedimentação \\
\hline$A_{c}$ & $\mu \mathrm{m}^{2}$ & Área analisada da câmara de sedimentação \\
\hline$V_{a}$ & $\mathrm{ml}$ & Volume analisado \\
\hline$V_{i}$ & $\mathrm{ml}$ & Volume de amostra inicial \\
\hline$V_{c u b}$ & $\mathrm{ml}$ & Volume da cubeta de sedimentação \\
\hline$V_{\text {con }}$ & $\mathrm{ml}$ & Volume decantado \\
\hline $\bar{C}_{c a d}$ & $\mu \mathrm{m}$ & Comprimento mediano da cadeia de células \\
\hline$C_{c e l}$ & $\mu \mathrm{m}$ & Comprimento da célula no centro da cadeia \\
\hline$C_{\text {dist }}$ & $\mu \mathrm{m}$ & Distância entre as células da cadeia \\
\hline $\bar{C}_{\text {dist }}$ & $\mu \mathrm{m}$ & Distância mediana entre as células da cadeia \\
\hline$C_{1}$ & $\mu \mathrm{m}$ & Comprimento ponderado das células sem divisão \\
\hline$C_{2}$ & $\mu \mathrm{m}$ & Comprimento ponderado das células em divisão \\
\hline$n_{1}$ & $\mu \mathrm{m}$ & Número das células sem divisão \\
\hline$n_{2}$ & $\mu \mathrm{m}$ & Número das células em divisão \\
\hline $\bar{C}_{1}$ & $\mu \mathrm{m}$ & Comprimento mediano das células sem divisão \\
\hline $\bar{C}_{2}$ & $\mu \mathrm{m}$ & Comprimento mediano das células em divisão \\
\hline
\end{tabular}




\section{Lista de Abreviações}

\begin{tabular}{|c|c|}
\hline Abreviação & Descrição \\
\hline HPLC & Cromatografia Líquida de Alta Performance \\
\hline SUP & Profundidade de amostras da Superfície \\
\hline PFMC & Profundidade de Fluorescência Máxima da Clorofila-a \\
\hline$p$ & Probabilidade estatística \\
\hline$n$ & Número amostral \\
\hline$A T$ & Água Tropical \\
\hline ACAS & Águca Central do Atlântico Sul \\
\hline AIA & Água Intermediária Antártica \\
\hline APAN & Água Profunda do Atlântico Norte \\
\hline$C B$ & Corrente do Brasil \\
\hline$A S P$ & Água Subtropical de Plataforma \\
\hline$P R P$ & Pluma do Rio da Prata \\
\hline MPS & Material Particulado em Suspensão \\
\hline CM & Corrente das Malvinas \\
\hline ZCBM & Zona de Confluência Brasil-Malvinas \\
\hline IOPs & Propriedades Óticas Inerentes \\
\hline AOPS & Propriedades Óticas Aparentes \\
\hline Fuco & Fucoxantina \\
\hline Perid & Peridinina \\
\hline Hex-Fuco & 19'-Hexanoiloxifucoxantina \\
\hline But-Fuco & 19'-Butanoiloxifucoxantina \\
\hline Allo & Aloxantina \\
\hline$T C h l-b$ & Clorofila-b + Divinil Clorofila-b \\
\hline Zea & Zeaxantina \\
\hline$F L$ & Flagelado (grupo taxonômico) \\
\hline DI & Diatomáceas Isoladas (grupo taxonômico) \\
\hline$D C$ & Diatomáceas em Cadeia (grupo taxonômico) \\
\hline CO & Cocolitoforídeos (grupo taxonômico) \\
\hline$P I$ & Picoplâncton (grupo taxonômico/tamanho) \\
\hline $\mathrm{Cl}$ & Cianobactérias (grupo taxonômico) \\
\hline$D A$ & Dinoflagelados Atecados (grupo taxonômico) \\
\hline$D T$ & Dinoflagelados Tecados (grupo taxonômico) \\
\hline OT & Outros (grupo taxonômico) \\
\hline $1-H$ & Esférico (morfotipo) \\
\hline $2-H$ & Prolado (morfotipo) \\
\hline $3-H$ & Elipsóide (morfotipo) \\
\hline $4-H$ & Cilindro (morfotipo) \\
\hline $5-H$ & Cilindro + 2 Esferas (morfotipo) \\
\hline $7-H$ & Cone (morfotipo) \\
\hline $8-H$ & Duplo Cone (morfotipo) \\
\hline $9-H$ & Cone + Meia Esfera (morfotipo) \\
\hline $10-H$ & Caixa Retangular (morfotipo) \\
\hline $11-H$ & Prisma Elíptico (morfotipo) \\
\hline $12-H$ & Prisma Elíptico com constrição transapical (morfotipo) \\
\hline $13-H$ & Prisma Paralelogramo (morfotipo) \\
\hline 23-SL & Prisma Elíptico + 4 Cones (morfotipo) \\
\hline $25-S L$ & Elipsóide + 2 Cones + Cilindro (morfotipo) \\
\hline $28-H$ & Cilindro - alongado valvar (morfotipo) \\
\hline $29-H$ & Prisma Elíptico - alongado valvar (morfotipo) \\
\hline
\end{tabular}




\section{Agradecimentos}

Inicialmente agradeço aos meus grandes mentores, meus melhores amigos de amor incondicional. Àqueles que sabem exatamente quando um telefonema com um simples "bom dia meu filho" fará toda a diferença no seu dia. Agradeço aos meus pais embora "agradecer" nunca será o suficiente.

Agradeço à Áurea Maria Ciotti pelo ensino, paciência (e foi muita) e todo o esforço desprendido para que eu chegasse até aqui. Por mostrar que não devemos nos contentar com nada menos que o ótimo. Por ser minha segunda mãe e meu guida em diversos momentos.

Aos meus grandes amigos (and I mean it!) do laboratório. Mesmo sabendo que posso contar com vocês a qualquer momento, só quando eu realmente preciso, nos momentos mais difícies, você percebe as maravilhosas pessoas que estão ao seu redor. Por ordem dos casórios:

- à Bianca Tocci, pelos bons momentos de discussão, que para os outros sempre irá parecer "mano, vocês vão se matar!" e pelos ainda melhores momentos de rir da cara dessas pessoas. E como um bom cavalheiro: "Bia, você está linda hoje".

- à Ana Luiza Peres, que mesmo podendo resumir em "o que seria de mim sem você?", vale a pena dizer que adoro os seus momentos geeks, sua indecisão ao atravesar a rua e acima de tudo, seu café.

- à Maria Fernanda Giannini, pelos bons momentos de risada, por ouvir (e gostar!) de todas as besteiras que eu falo. E sempre me atentando pro mal caminho.

- à Ana Carolina Mazzuco pela ajuda sempre e pelo bom humor, além dos ótimos momentos passados juntos no laboratório. Foco no projeto Madame!

- à Amábile Ferreira, que finalmente voltou à família, enorme disposição e sempre me fazendo dar boas risadas com seu jeitinho

- à Amália Detoni, por ser muito engraçada!

- ao Daniel Schaeffer pelas palavras de apoio ("aham") nos melhores momentos.

Aos amigos espalhados pelo mundo e gostaria de destacar alguns nomes. Janaína Barata pois com você tudo é muito mais simples e por 
sempre se lembrar desse amigo aqui. Ao Tiago Ferreira por ter se tornado um grande amigo, ter me dado suporte nos momentos de angústia no meio da madrugada, enfim, te amo menino. E a todos os amigos do Cebimar, pelas good vibes nos momentos finais desse trabalho.

Agradeço também às correções e sugestões despendidas pela banca avaliadora, Profa. Dra. Clarisse Odebrecht (FURG) e Profa. Dra. Sônia Gianesella (IO-USP).

Agradeço à Fundação de Amparo à Pesquisa do Estado de São Paulo (FAPESP) pelo auxílio deste projeto e à bolsa desprendida ao aluno (Proc. 2011/04783-4).

Ao $\mathrm{CNPq}$ pelo fomento do projeto que permitiu os cruzeiros oceanográficos (MCT-1 e MCT-2) (CNPq Edital 558217/2009-5).

À Marinha do Brasil e nominalmente à tripulação do navio NHo Cruzeiro do Sul por toda ajuda e estrutura desprendida para a realização do projeto.

Agradeço à Profa. Dra. Virgínia Tavano (FURG) e ao Dr. Rafael Mendes (FURG), pelos dados de concentração de pigmentos gentilmente cedidos.

Agradeço também à Profa Dra. Gleyci Moser (UERJ) pelos dados de citometria de fluxo cedidos que auxiliaram no desenvolvimento do modelo de biomassa do picofitoplâncton.

À Profa. Dra. Denise Tenenbaum (UFRJ) pelos valiosos conselhos sobre identificação e enumeração do fitoplâncton. 


\section{Resumo}

O estabelecimento da função das assembléias fitoplanctônicas nos oceanos depende de estimativas robustas de sua biomassa e taxas fotossintéticas. Assim, é essencial descrever a relação entre grupos taxonômicos e seus morfotipos geométricos e como afetam as taxas de absorção de luz. Este trabalho investigou a influência da forma do fitoplâncton, através de sua razão Superfície/Volume (S/V) no coeficiente de absorção de luz. Comunidades fitoplanctônicas de plataforma continental foram detalhadas taxonomicamente, categorizadas em morfotipos para o cálculo da biomassa fitoplanctônica (teor carbono), razão $S / V$ e tamanho médio das células, e suas relações com o coeficiente de absorção. Diatomáceas e dinoflagelados foram os principais grupos formadores de biomassa. A razão Carbono:Clorofila-a foi diferente entre a superfície e a profundidade de máximo de fluorescência, enquanto que a biomassa permaneceu constante. Observamos morfotipos exclusivos a determinados grupos taxonômicos, contudo, os intervalos de $S / V$ são compartilhados entre grupos taxonômicos e entre morfotipos. As equações utilizadas na conversão entre volume celular e biomassa devem incorporar informações taxonômicas. Os resultados comprovam a boa performance de modelos para a determinação de tamanho do fitoplâncton por pigmentos. A $S / V$ e a dominância de formas planas ou "robustas" na comunidade influenciam a absorção de luz pelo fitoplâncton espectralmente.

Palavras-chave: biomassa celular; grupos taxonômicos; morfotipo geométricos; coeficiente de absorção de luz; razão Carbono:Clorofila; Razão Superfície/Volume; tamanho celular 


\section{Abstract}

Acurate descriptions of phytoplankton community structure depend on reliable estimation of biomass and on the understanding of light absorption. It is crucial to trace relationships between taxonomic groups and geometrical morphotypes. We investigated the influence of phytoplankton shapes in the light absorption coefficient by investigating surface/volume (S/V) ratios. Phytoplankton communities from the continental shelf were detailed taxonomical and categorized in geometrical morphotypes in order to calculate phytoplankton biomass, S/V ratios and size to explore relationships with spectral light absorption coefficients. Diatoms and dinoflagellates were the main groups present in high biomass. The Carbon-to-Chlorophyll ratio varied between water surface and the chlorophyll maximum depth while biomass remained fairly constant. Exclusive morphotypes were observed for some taxonomic groups; however, distinct taxonomic groups and morphotypes shared $S / V$ ratios ranges. The conversion between cell volume and biomass must take taxonomic composition into account. The results show a good performance of pigment-based models for description of phytoplankton size classes. The S/V ratio and the dominance of stout and attenuate shapes within the community affects the phytoplankton light absorption in specific wavelegnths.

Key-words: cellular biomass; taxonomic groups; geometric morphotypes; light absorption coefficient; Carbon-to-Chlorophyll ratio; Surface:Volume ratio; cell size 


\section{Introdução}

\subsection{Determinação da Biomassa do Fitoplâncton Marinho}

A quantificação da biomassa dos produtores primários é importante para prever o fluxo de energia entre diferentes níveis tróficos (Anderson, 2005; Mitra et al., 2007). Nos oceanos, a biomassa alcançada por determinados grupos fitoplanctônicos é resultado das suas maiores taxas de crescimento em comparação aos demais grupos (Margalef, 1978; Smayda e Reynolds, 2001), e sua sobrevivência a estresses ambientais e pastagem (Vollenweider, 1969). Taxas de produção primária do fitoplâncton marinho tem sido estudadas por muitas décadas (e.g. Steeman-Nielsen, 1952; Pomeroy, 1974; Maclntyre et al., 2002; Williams et al., 2002; Falkwoski et al., 2003), onde a biomassa do fitoplâncton é estimada pela concentração da clorofila-a [chl]. Todavia, as estimativas de taxas de produção primária do fitoplâncton deveriam ser baseadas em seu conteúdo de carbono celular, uma vez que relações tróficas são analisadas de acordo com trocas de energia e carbono.

A clorofila-a, comum a todos os organismos fitoplanctônicos, é o pigmento de maior concentração intracelular, exceto no gênero Prochlorococcus, onde a Divinil Clorofila-a (DVchl) é seu equivalente fotossintético (Waterbury, 1986). Medidas de [chl] são simples e possuem metodologias robustas e bem estabelecidas (Holm-Hansen, 1965) e a conversão para o conteúdo de carbono fitoplanctônico depende da atribuição de um valor para a razão de Carbono:Clorofila-a (C:chl) em uma dada comunidade (Eppley, 1968). Contudo, tanto a [chl] quando o carbono intracelular variam amplamente (Cullen, 1982). Estimativas de C:chl a partir de experimentos laboratoriais com cultivos monoespecíficos demonstram valores entre 19 e 714.3 (Jonge, 1980 e referências; Kruskopf e Flynn, 2006). As variações na razão $C$ :chl são atribuídas às mudanças na disponibilidade de luz (Falkwoski e LaRoche, 1991), na concentração de nutrientes disponíveis (Goericke e Montoya, 1998) e por mudanças na temperatura ideal de crescimento dos organismos (Geider et al., 1997). Já em comunidades naturais, a razão $\mathrm{C}$ :chl parece variar menos, com valores 
reportados entre 10 e 90 (Parsons e Strickland, 1959; Eppley, 1968; Eppley et al., 1971; Eppley et al., 1977).

As estimativas do carbono orgânico planctônico, auto ou heterotrófico, em comunidades naturais são dificultadas pela co-ocorrência de porções variáveis, e muitas vezes significativas, de partículas não-vivas (detritos) nas amostras (Smetacek e Hendrikson, 1979; Caron et al., 1995). A porção viva do carbono orgânico em suspensão é potencialmente determinada por indicadores bioquímicos como ATP (Sinclair et al., 1979), porém esses não são capazes de isolar o carbono fitoplanctônico daquele do zooplâncton (Mei et al., 2003), principalmente em regiões oligotróficas (Banse, 1977).

O carbono exclusivo ao fitoplâncton pode ser obtido por microscopia, por meio do cálculo do biovolume das células. Entretanto, essas medidas demandam tempo e um grau razoável de conhecimento de taxonomia do fitoplâncton pelo observador. Basicamente, os organismos fitoplanctônicos enumerados são associados a uma forma geométrica (Hillebrand et al., 1999; Sun e Liu, 2003) e através de medidas lineares, seu biovolume celular é calculado e convertido em carbono através de relações empíricas (Verity et al., 1992; Montagnes et al., 1994; Menden-Deuer e Lessard, 2000 e referências). As equações de conversão de biovolume para carbono celular dependem do grupo taxonômico (e.g. tabela 4 em Menden-Deuer e Lessard, 2000).

Fotografias de amostras naturais vivas (e.g. Sieracki et al., 1998; Olson e Sosik, 2007) são ferramentas alternativas e potencialmente aplicáveis em tempo real para se identificar as espécies que ocorrem em comunidades fitoplanctônicas naturais. Porém, a quantidade de informação gerada é elevada e sua interpretação exige que algorítmos sejam desenvolvidos para serem computacionalmente eficientes (Congestri, et al., 2000; Moberg e Sosik, 2012) sem que sejam perdidas informações taxonômicas relevantes (Carpentier et al., 1999; Sieracki et al., 1998; Sosik e Olson, 2007). A maior dificuldade encontrada na interpretação de fotografias de fitoplâncton é associar a forma do organismo observado à sua real estrutura tridimensional e portanto às estimativas mais precisas de volume celular. Assim, é ,necessário identificar se padrões de exclusividade e dominância de morfotipos existem entre os diferentes grupos taxonômicos. 
É razoável se esperar que a dominância dos organismos fitoplanctônicos em comunidades naturais esteja relacionada a sua eficiência em absorver luz e nutrientes, que por sua vez são função de seu tamanho e de sua razão superfície/volume (S/V) (Sournia, 1982; Kirk, 1994; Smith e Kalff, 1982) e das condições ambientais. Em ambientes naturais, as classes de tamanho dominantes do fitoplâncton tendem a ser maiores quando a disponibilidade de nutrientes é maior (Cullen et al., 2002). Porém, são poucos os estudos que quantificam o papel dos morfotipos, do tamanho celular e da razão $S / V$ nas relações com o carbono fitoplanctônico em uma determinada região. Trabalhos pioneiros (Lewis, 1976; Smith e Kalff, 1982) de fato mostram que a razão superfície/volume (S/V) dos organismos dominantes em uma comunidade fitoplanctônica está associada às variáveis ambientais. Todavia, apesar da enorme diversidade de formas e tamanhos do fitoplâncton (Margalef, 1978), Lewis (1976) sugere que o intervalo da razão $\mathrm{S} / \mathrm{V}$ é menor do que o esperado pelos morfotipos e diferentes classes de tamanho.

\subsection{Absorção de luz pelo Fitoplâncton}

A luz absorvida pelo fitoplâncton nos diferentes comprimentos de onda $\left(a_{\mathrm{ph}}(\lambda), \mathrm{m}^{-1}\right)$ pode ser medida in situ por instrumentos (e.g., Morrison e Sosik, 2002) ou em amostras discretas com o auxílio de um espectrofotômetro (e.g., Tassan Ferrari 1995). A magnitude de $a_{\mathrm{ph}}(\lambda)$ é uma função da concentração dos pigmentos e do tamanho celular (Bricaud et al., 2004 e referências). Por essa razão, a variabilidade observada em $a_{\mathrm{ph}}(\lambda)$ tem sido utilizada como ferramenta para discriminar grupos de fitoplâncton (Brewin et al., 2011 e referências). A [chl], sendo o pigmento intracelular dominante e presente em todos os grupos taxonômicos, prescreve relações robustas entre com $a_{\mathrm{ph}}(\lambda)$. Dessa forma, a influência taxonômica em $a_{\mathrm{ph}}(\lambda)$, exceto durante florações, é de segunda ordem (Ciotti et al., 1999).

As primeiras relações empíricas entre $a_{\mathrm{ph}}(\lambda)$ e a [chl] surgiram de estudos em cultivos monoespecificos de Chlorella, reportando que a absorção espectral da luz pelas células íntegras era menor do que aquela 
dos pigmentos dissolvidos (Duysens, 1956), fato denominado de "packaging effect" (efeito de empacotamento). Além disso, as magnitudes de $a_{\mathrm{ph}}(\lambda)$ são influenciadas pelos processos fotoquímicos intracelulares (Prézelin, 1981).

Funções analíticas entre $a_{\mathrm{ph}}(\lambda)$, o tamanho celular e a composição intracelular de pigmentos foram apresentadas por Morel e Bricaud (1981), seguindo as premissas de van de Hulst (1957). Assim, o efeito de empacotamento em células de fitoplâncton seguiam as funções teóricas para esferas homogêneas, guiado pelo tamanho da esfera e pelo coeficiente de absorção do seu material constituinte..

Em amostras naturais, ,Prieur e Sathyendranath (1981) demonstraram que a relação entre o coeficiente de absorção da luz pelo material particulado em suspensão em $440 \mathrm{~nm}\left(a_{p}, \mathrm{~m}^{-1}\right)$ e a [chl] não seguia uma função linear mas seguindo

$$
a_{p}(440)=[c h l]^{0.6}
$$

sugerindo a diminuição da eficiência da absorção de luz com o aumento da [chl], que foi posteriormente relacionada às mudanças no tamanho do organismo dominante (Yentsch e Phinney, 1989).

A não linearidade entre $a_{\mathrm{ph}}(\lambda)$ e [chl] foi observada em vários estudos (Bricaud e Stramski, 1990; Woszniak e Ostrowska, 1990; Bricaud et al., 1995), seguindo a forma

$$
a_{p h}(\lambda)=p 1(\lambda) \times[c h l]^{-p 2(\lambda)}
$$

onde $p 1$ e $p 2$ representam parâmetros empíricos dependentes do comprimento de onda (valores presentes na tabela 2 de Bricaud et al., $1995 \mathrm{e}$ revisados parcialmente em Bricaud et al., 2004) que se relacionam à tendência de maior empacotamento de pigmentos nas células com 0 aumento da [chl]. Após a consolidação desses modelos empíricos, a extração de informações sobre as comunidades do fitoplâncton através da variabilidade em $a_{\mathrm{ph}}(\lambda)$ seguiu duas tendências principais: i) a função do tamanho dominante ou fração dominante no grau de empacotamento celular; 
e ii) a função da presença de pigmentos acessórios marcadores de determinados grupos taxonômicos.

As tentativas de quantificação do tamanho celular pelo grau de empacotamento iniciaram com o "modelo de mistura" proposto por Ciotti, et al., (2002). Nesse, a absorção espectral de comunidades é decomposta em uma proporção linear entre dois extremos que representam o menor e o maior tamanho celular e grau de empacotamento possível em águas superficiais. Esse modelo gera um coeficiente adimensional, $S_{f}$, que varia entre um contínuo de valores entre 1 e 0 que representam o mínimo e máximo grau de empacotamento, e não exatamente o tamanho. Uma abordagem similar foi proposta por Sathyendranath et al., (2001), em que ao invés de $a_{\mathrm{ph}}(\lambda)$ variar entre dois extremos a composição das comunidades (em escala regional) foi atribuída a dois componentes, picoplâncton e diatomáceas, sendo a última adicionada a partir de um valor mínimo de [chl]. Essas duas abordagens foram revisitadas e refinadas em uma série de publicações (ver revisão em Brewin et al., 2011).

A absorção de luz espectral pelo fitoplâncton tem sido igualmente caracterizada em função da composição dos diferentes pigmentos acessórios (Hoepffner e Sathyendranath, 1991, Bidigare et al., 1990) que complementam a [chl] intracelular e são identificados por Cromatografia Liquida de Alta Performance (HPLC). A composição de pigmentos acessórios, por sua vez, pode ser utilizada para discriminar grupos taxonômicos do fitoplâncton (Claustre, 1994), apesar de sua grande co-variação com a [chl] (Trees et al., 2000). Porém, alguns estudos utilizam razões entre pigmentos acessórios e a [chl] como índices para discriminar grandes grupos taxonômicos (Prézelin et al., 2000; Sathyendranath et al., 2001), ou ainda bibliotecas de espectros de cor do oceano medidas por satélite associadas a esses perfis de pigmentos acessórios (Alvain et al., 2005). Apesar de existirem poucos pigmentos acessórios exclusivos a um determinado grupo taxonômico, existem modelos amplamente utilizados que computam a predominância de classes de tamanho na comunidade fitoplanctônica a partir de alguns pigmentos marcadores (Vidussi et al., 2001; Uitz et al., 2006).

A validação dos modelos e procedimentos descritos acima é, até o momento, insipiente pela carência de bases de dados contendo medidas 
reais de tamanho e de biomassa nas comunidades naturais. Ressalta-se que o grau de empacotamento e a concentração de pigmentos acessórios são função de outros fatores que não a composição taxonômica, como a fotoaclimatação (e.g., Kitchen e Zaneveld, 1990). 


\section{Objetivos}

Avaliar a influência dos diferentes morfotipos do fitoplâncton no coeficiente de absorção de luz pelo fitoplâncton em comunidades naturais. Para tanto, pretende-se:

1. Caracterizar diferentes comunidades em função de seus grupos taxonômicos e morfotipos celulares

2. Analisar como o tamanho dominante da comunidade ponderado por cabono se relaciona com outros descritores de comunidade

3. Estabelecer relações entre os morfotipos e grupos taxonômicos com a razão superfície/volume

4. Avaliar as respostas de modelos bio-óticos com dados de carbono para comunidades naturais

5. Avaliar como os descritores de comunidade atualmente utilizados explicam as variações no coeficiente de absorção de luz pelo fitoplâncton

6. Quantificar as relações entre a eficiência de absorções de luz $\left(\mathrm{S}_{\mathrm{f}}\right)$ pelo fitoplâncton e o tamanho celular 


\section{3. Área de Estudo}

\subsection{Aspectos Geográficos}

A plataforma continental sul e sudeste brasileira estende-se de aproximadamente $21^{\circ} \mathrm{S}$ à $34^{\circ} \mathrm{S}$, correspondendo às plataformas dos estados do Espírito Santo (ES) ao Rio Grande do Sul (RS). A porção setentrional da plataforma sudeste caracteriza-se por ser mais estreita em relação à parte austral, onde apresenta sua maior extensão na altura do estado de São Paulo (SP), atingindo $200 \mathrm{Km}$ da linha de costa até a quebra de plataforma. A plataforma continental sul apresenta pouca variação em sua extensão, tendo em média $140 \mathrm{Km}$ de distância entre continente e talude oceânico. A quebra de plataforma ocorre aproximadamente aos $200 \mathrm{~m}$ de profundidade (Castro et al. 2006).

\subsection{Massas de Água e Hidrodinâmica}

A Água Tropical (AT), a Água Central do Atlântico Sul (ACAS), a Água Intermediária Antártica (AIA) e a Água Profunda do Atlântico Norte (APAN) estão distribuídas verticalmente até os $3000 \mathrm{~m}$ de profundidade ao longo de todo o talude continental (Castro, 1996; Silveira et al., 2000). A Corrente do Brasil (CB), que flui em direção sul ao largo da costa leste da América do Sul, é a corrente de contorno oeste que participa do Giro Subtropical do Atlântico Sul. Esta corrente está centrada entre as isóbatas de 200 e 1000 m, ocupando a parte mais externa da plataforma continental e talude da região sudeste-sul brasileira, sendo responsável por transportar a AT e a ACAS nos níveis de 0-200 e 200-500 m aproximadamente (Castro, 1996). Devido às mudanças em largura da plataforma continental e às abruptas mudanças na orientação de costa, muitas vezes a CB produz feições de mesoescala capazes de transportar essas massas de água por sobre a plataforma continental (Silveira et al., 2000). Desta forma, as massas de água superficiais presentes nesta área são: AT, transportada para sul pela CB. $\mathrm{Na}$ porção sul da plataforma continental encontra-se a, Água Subtropical de 
Plataforma (ASP) que flui para norte por uma corrente costeira, com temperaturas e salinidades mais baixas (Möller et al., 2008).

\subsection{Feições oceanográficas de meso-escala}

$\mathrm{Na}$ plataforma continental sul, a principal feição de meso-escala compreende o aporte continental proveniente principalmente do Rio da Prata (Pluma do Rio da Prata, PRP, Möller et al., 2008) e, localmente nas adjacências da Lagoa dos Patos. A variação latitudinal da PRP é um processo bem documentado (e.g., Souza e Robinson 2004) onde, durante o inverno e o verão a extensão da pluma de águas de baixa salinidade varia entre $27^{\circ} \mathrm{S}$ e $32^{\circ} \mathrm{S}$ aproximadamente, em função da descarga de águas continentais e do regime de ventos (Möller et al., 2008). Os poucos estudos disponíveis sobre a concentração de nutrientes (Fillmann, 1990), mostram a importância das águas do Rio da Prata (silicato e fosfato), da ASP (nitrato e fosfato) e da ACAS (nitrato) (Braga et al. 2008). Águas do Rio da Prata são uma fonte de silicato, e quando se propagam para o norte fertilizam as águas da plataforma sul brasileira (Piola et al., 2000; Braga et al., 2008).

$\mathrm{Na}$ plataforma sudeste, a intrusão da ACAS sobre a plataforma continental ocorre durante processos de ressurgência costeira e de quebra de plataforma, alcançando regiões rasas e próximas da costa, com maior frequência nos meses de primavera e verão. Este processo fertiliza a base da zona eufótica com nutrientes inorgânicos, modificando temporariamente a típica condição meso-oligotrófica da plataforma sudeste, que carece de grandes volumes de aporte continental. O aporte de nutrientes proporciona condições favoráveis para o desenvolvimento do plâncton e aumento da produtividade primária em regiões como Cabo Frio localizado na latitude de $23^{\circ} \mathrm{S}$ (e.g., Castro, 1996; Gaeta e Brandini, 2006).

A região de Cabo de São Tomé $\left(22^{\circ} S\right)$ apresenta uma plataforma continental estreita e é, portanto, mais suscetível à influência de vórtices e meandros que se formam na CB (Castro, 1996). Diversos estudos apontam a frequente ocorrência de vórtices ciclônicos e anti-ciclônicos de meso-escala nesta região (Silveira et al. 2000; Castelão et al. 2004; Calado, 2006). Estas feições, muitas vezes, contribuem para a penetração da ACAS na base da 
zona eufótica, influenciando a distribuição de nutrientes, o Material Particulado em Suspensão (MPS), e a comunidade fitoplantônica local.

\subsection{Climatologia das correntes oceânicas e Condições meteorológicas}

No verão, devido à maior vorticidade potencial e meandramento da $\mathrm{CB}$, a AT encontra-se em menores latitudes no talude e quebra de plataforma continental. Essa massa de água é caracterizada por baixos níveis de nutrientes (Braga e Niencheski, 2006), e localizada acima de uma forte termoclina permanente, impedindo a fertilização da zona eufótica.

$\mathrm{Na}$ região de encontro da CB com a Corrente das Malvinas (CM),

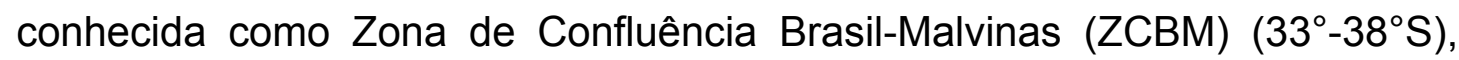
ocorrem importantes variações físico-químicas sazonais e meridionais (Lima et al., 1996), com a CB carregando água quente e salina dos trópicos em direção aos polos, enquanto que a CM leva água fria, menos salina e rica em nutrientes dos polos em direção a regiões tropicais. A CM apresenta uma oscilação semi-anual (Garcia e Garcia, 2008), porém diversos trabalhos mostram que a frente da ZCBM encontra-se mais ao norte de aproximadamente $36^{\circ} \mathrm{S}$, durante o inverno, e mais ao sul desta latitude durante o verão (Barre et al., 2006).

$\mathrm{Na}$ plataforma continental sudeste brasileira o padrão de circulação atmosférica é regido pelos constantes ventos de nordeste oriundos do Anticiclone Semi-Permanente do Atlântico Sul, dominantes e frequentes durante todo o ano (Dourado \& Oliveira 2001). Segundo Valentin (2001) o clima da região de Cabo Frio depende do deslocamento deste anticiclone e do anticiclone polar juntamente com massas de ar frias que se originam ao sul da Argentina. A zona de baixa pressão formada entre os dois anticiclones corresponde a uma frente fria cuja posição e velocidade determinam a meteorologia da área de estudo. Durante a passagem de frentes, mais intensas e frequentes durante o inverno, há a predominância de ventos de sudoeste e aumento da pluviosidade, enquanto que os ventos de nordeste são menos intensos $\left(<6 \mathrm{~ms}^{-1}\right)$ e associados a uma menor precipitação $(<800$ 
$\mathrm{mm}$ ano-1) (Valentin, 2001). O regime de chuvas é mais intenso na primavera (32\% do total anual) e menor no inverno (18\% do total anual).

\subsection{Aspectos biológicos das comunidades fitoplanctônicas}

Ao largo da plataforma e talude continental sudeste-sul do Brasil, altas concentrações de clorofila-a estão principalmente relacionadas com frentes termohalinas e processos de ressurgência costeira e de quebra de plataforma (Ciotti et al., 1995; Odebrecht e Garcia, 1998). Nas regiões costeiras próximas a sistemas estuarinos, lagunares ou ressurgências costeiras, ocorrem fertilizações de nutrientes para a zona eufótica por processos de aporte de água continental (Braga e Niencheski 2006), ascensão de água de subsuperfície (Valentin et al., 1987) e por transporte de água subterrânea em regiões rasas próximas à costa (Niencheski et al. 2007). Essas fertilizações aumentam e sustentam a produção primária de regiões costeira e plataforma interna. Em ambiente oceânico, o estoque de nutriente mais próximo da zona eufótica encontra-se nas camadas subsuperficiais. Portanto, a fertilização da zona eufótica ocorre somente quando houver qualquer processo oceanográfico que rompa a estrutura fisicamente estável da termoclina, resultando em ressurgência de águas profundas, facilitando o fluxo de nutrientes para a zona eufótica (Mann \& Lazier 1991). Na ausência desta ruptura da termoclina, prevalece o sistema de produção regenerada (e.g., Metzler et al., 1997) no qual o nitrogênio inorgânico, normalmente limitante em ecossistemas marinhos, está disponível sob a forma de compostos reduzidos (amônio, ureia, etc.), oriundos da excreção da comunidade planctônica e da regeneração bacteriana na coluna de água. Eventualmente, este tipo de produção altera-se com a produção nova, baseada em fontes externas de nitrogênio introduzido no sistema por ressurgências de água subsuperficiais, aportes atmosféricos, difusão molecular na base da zona eufótica e pela fixação do $\mathrm{N}_{2}$ por Trichodesmium spp.

\subsection{Características bio-óticas e cor do oceano}

As propriedades óticas dos oceanos podem ser divididas em Propriedades Óticas Inerentes (IOPs), que dependem dos componentes 
presentes na água e em Propriedades Óticas Aparentes (AOPs), função da distribuição geométrica do campo luminoso e sua interação com as IOPs (Preisendorfer, 1961). As principais IOPs são a absorção e o espalhamento da luz, enquanto que as principais AOPs consistem da reflectância da superfície dos oceanos e a os coeficientes de atenuação vertical difusa da luz. A partir das contribuições dos constituintes da água, é possível classificar as águas nos oceanos (Morel e Prieur, 1977). Águas Caso 1 são aquelas onde o fitoplâncton é o principal constituinte ótico atenuando a luz. Em Águas Caso 2 a atenuação da luz é influenciada por outros constituintes óticos, como partículas e matéria orgânica dissolvida, além do fitoplâncton.

$\mathrm{Na}$ plataforma continental sul do Brasil, a pluma do Rio da Prata possui grande influência nas propriedades óticas das águas costeiras e na cor do oceano (e.g. Huret et al., 2005). Nesse caso, a maior contribuição na absorção da luz pela matéria orgânica dissolvida de origem continental é atribuída à pluma do Rio da Prata (Martinez et al., 2005; Giannini et al., 2013).

No Oceano Atlântico Sul, estudos com concentração de clorofila-a derivada de sensoriamento remoto e consequentemente a cor do oceano possuem ciclos anuais de variação. Garcia e Garcia, 2008 e Piola et al., 2008 demonstraram que essas variações estão diretamente relacionados ao regime de descárga do Rio da Prata e da extensão de sua pluma. Variações anuais da cor do oceano também foram observadas para as águas de plataforma continental sul do Brasil (Ciotti et al., 2010). 


\section{Materiais e Métodos}

\subsection{Obtenção das Amostras}

Duas campanhas oceanográficas foram realizadas na plataforma continental sul e sudeste brasileira e talude continental adjacente entre os anos de 2010 e 2011 a bordo do Navio Hidroceanográfico Cruzeiro do Sul da Marinha do Brasil (FIGURA 1A). A primeira campanha (MCT-1) foi realizada em Julho de 2010 na costa dos estados do Rio de Janeiro e São Paulo (FIGURA 1B). A segunda campanha (MCT-2) ocorreu entre dezembro de 2010 e janeiro de 2011, compreendendo toda a extensão de plataforma continental do Rio Grande do Sul ao Rio de Janeiro (FIGURA 1C e 1D).

Em cada estação oceanográfica foram realizados perfis verticais de salinidade, temperatura e fluorescência da clorofila-a (CTD Sea-Bird mod. 911 com fluorímetro ECO Chlorophyll Fluorometer - Wetlabs ${ }^{\circledR}$ acoplado). As profundidades de coleta de água foram selecionadas a medida que os perfis verticais eram realizados. Selecionamos espacialmente as estações de forma que representassem diferentes estados tróficos e condições oceanográficas que pudessem resultar em diferentes composições de comunidades fitoplanctônicas. Para estas estações selecionadas (estações em destaque $(\Theta)$ nas Figuras 1B, 1C e 1D) foram analisadas amostras de superfície (3-5m) e da profundidade de fluorescência máxima da clorofila-a (PFMC) (profundidade variável). 


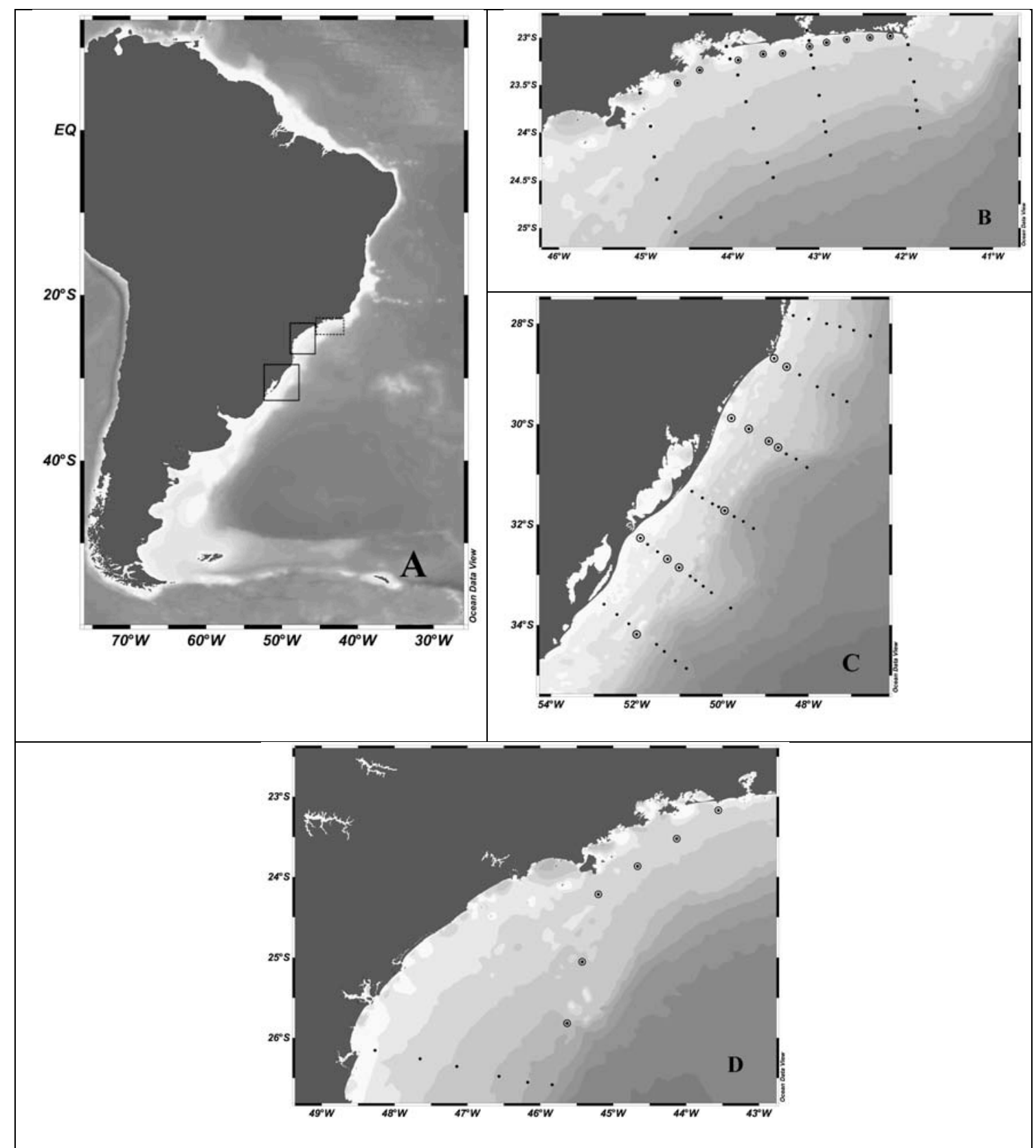

Figura 1: Localização da área de estudo e estações de coleta de amostras de água com as estações utilizadas neste trabalho em destaque $(\Theta)$. A) Distribuição espacial da malha amostral dos dois cruzeiros oceanográficos MCT-1 e MCT-2, destacados, respectivamente, em linha pontilhada e linha contínua. B) Estações oceanográficas realizadas pelo cruzeiro MCT-1 em julho de 2010. C) Distribuição das estações oceanográficas do cruzeiro MCT-2 de dezembro de 2010 para a plataforma continental sul. D) Estações oceanográficas do MCT-2 na plataforma continental sudeste brasileira.

\subsection{Processamento das Amostras}

Para cada amostra de água coletada, as seguintes variáveis foram analisadas: 


\subsubsection{Coeficiente de Absorção de Luz pelo Fitoplâncton $\left(\boldsymbol{a}_{p h}(\lambda)\right.$, $\left.m^{-1}\right)$}

Para o cálculo de $a_{\mathrm{ph}}(\lambda)$, foram filtrados de 1 a $2 \mathrm{~L}$ de água para cada profundidade em filtro de fibra de vidro (GF/F Whatman ${ }^{\circledR}$ capacidade de retenção de $0.7 \mu \mathrm{m})$. Os filtros foram imediatamente congelados em nitrogênio líquido e posteriormente armazenados em ultrafreezer $\left(-80^{\circ} \mathrm{C}\right)$, sempre mantidos ao abrigo da luz para evitar degradação dos pigmentos fotossintéticos. Os filtros foram descongelados, hidratados com água do mar filtrada e lidos em espectroradiômetro (USB4000 - Ocean Optics $®$ ) com esfera integradora acoplada (Tassan e Ferrari, 1995). Os filtros eram dispostos com a face com o material retido voltada para o feixe de luz e a luz transmitida era lida na esfera integradora. As leituras dos filtros foram realizadas antes e depois da remoção dos pigmentos com Hipoclorito de Sódio 0.5\% (Tassan e Ferrari, 1995), resultando em seus respectivos espectros de absorbância $A(\lambda)$ e $A e(\lambda)$.

Filtros GF/F hidratados com água do mar filtrada em $0.2 \mathrm{~m}$ (Acrodisk, Whatman $®$ ) foram utilizados como referência de brancos (isto é, filtros sem material) e lidos no espectroradiômetro a cada grupo de 10 amostras. Os filtros para referência de branco foram submetidos ao mesmo tratamento com Hipoclorito de Sódio $0.5 \%$ que os filtros com material particulado. Dessa forma, obtivemos espectros de absorbância $B r(\lambda)$ e $B e(\lambda)$ para antes e depois do tratamento, respectivamente. A utilização destes filtros como branco permite quantificar e remover os efeitos da alta difração do próprio filtro no sinal de $a_{\mathrm{ph}}(\lambda)$.

Todos os espectros de absorbância $(A(\lambda), A e(\lambda), B r(\lambda)$ e $B e(\lambda))$ foram ajustados para possuir o mesmo valor em 866nm (Equações 3 e 4), onde não ocorre absorção da luz pelas partículas (vivas e não-vivas) presentes na água.

$$
\begin{aligned}
& A^{\prime}(\lambda), A e^{\prime}(\lambda), B^{\prime}(\lambda), B e^{\prime}(\lambda)=-\left(A_{(866)}, A e_{(866)}, B r_{(866)}, B e_{(866)}\right)+\overline{o f f}_{(866)}( \\
& \overline{o f f}_{(866)}=\frac{A_{(866)}+A e_{(866)}+B r_{(866)}+B e_{(866)}}{4}
\end{aligned}
$$


Sendo $\overline{o f f}_{(866)}$ a média dos valores de absorbância para todos os espectros em 866nm $\left(A_{(866)}, A e_{(866)}, B r_{(866)}, B e_{(866)}\right)$. Os espectros dos filtros de referência de branco $\left(B^{\prime}(\lambda)\right.$ e $\left.B e^{\prime}(\lambda)\right)$ foram subtraídos dos espectros de absorbância dos filtros com material $\left(A^{\prime}(\lambda), A e^{\prime}(\lambda)\right)$ correspondentes (Equações 5 e 6).

$$
\begin{aligned}
& A_{b}(\lambda)=A^{\prime}(\lambda)-B^{\prime}(\lambda) \\
& A_{b} e(\lambda)=A e^{\prime}(\lambda)-B e^{\prime}(\lambda)
\end{aligned}
$$

Os cálculos para obtenção de $a_{\mathrm{ph}}(\lambda)$ a partir das leituras de absorbância seguindo Mitchell (1990) assumem que a absorção em 750nm é 0 , portanto, todo o espectro é ajustado de forma que $A_{b}(\lambda)$ e $A_{b} e(\lambda)$ sejam 0 em 750nm (Equação 7 e 8).

$$
\begin{aligned}
& A_{b}{ }^{\prime}(\lambda)=A_{b}(\lambda)-A_{b(\lambda=750)} \\
& A_{b} e^{\prime}(\lambda)=A_{b} e(\lambda)-A_{b} e_{(\lambda=750)}
\end{aligned}
$$

A absorbância, entretanto, é dada para o material concentrado no filtro, isto é, as partículas estão muito próximas umas das outras e não correspondem com a disposição das mesmas encontradas em suspensão na água. Assim, os valores de absorbância $\left(A_{b}{ }^{\prime}(\lambda)\right.$ e $\left.A_{b} e^{\prime}(\lambda)\right)$ foram corrigidos para corresponder aos valores de absorção do material em suspensão $\left(A_{\text {sus }}(\lambda)\right.$ e $\left.A e_{\text {sus }}(\lambda)\right)$. Essa correção é corresponde à amplificação do caminho ótico, seguindo as Equações 9 e 10. Os parâmetros $a$ e $b$ são dependentes do equipamento ótico e foram utilizados, respectivamente, os valores de 0.49 e 0.54 (Ciotti et al., 1999) (Eq. 3).

$$
\begin{gathered}
A_{\text {sus }}(\lambda)=a \times A_{b}{ }^{\prime}(\lambda)+b \times A_{b}^{\prime 2}(\lambda) \\
A e_{\text {sus }}(\lambda)=a \times A_{b} e^{\prime}(\lambda)+b \times A_{b} e^{\prime 2}(\lambda)
\end{gathered}
$$


A absorção do material particulado $\left(a_{\text {par }}(\lambda)\right)$ e do material não vivo e não colorido (detritos) $\left(a_{\text {det }}(\lambda)\right)$ são obtidas através das Equações 11 e 12:

$$
\begin{aligned}
& a_{\text {par }}(\lambda)=\frac{23 \times A_{\text {sus }}(\lambda) \times A_{o}}{\operatorname{Vol}} \\
& a_{\text {det }}(\lambda)=\frac{23 \times A e_{\text {sus }}(\lambda) \times A_{o}}{V o l}
\end{aligned}
$$

onde $A_{o}$ corresponde à área do filtro $\left(\mathrm{m}^{2}\right)$ e $\mathrm{Vol}$ corresponde ao volume de amostra que foi filtrada $\left(\mathrm{m}^{3}\right)$. Por fim, a absorção de luz pelo fitoplâncton é obtida pela subtração de $a_{\text {det }}(\lambda)$ de $a_{\text {par }}(\lambda)$, seguindo a Equação 13:

$$
a_{p h}(\lambda)=a_{p a r}(\lambda)-a_{d e t}(\lambda)
$$

As variações de $a_{\mathrm{ph}}(\lambda)$ encontradas neste trabalho foram calculadas a partir de formulações matemáticas seguindo as Equações 14 a 16.

$$
\begin{aligned}
& a_{\mathrm{ph}}^{*}(\lambda)=\frac{a_{\mathrm{ph}}(\lambda)}{[c h l]} \\
& <a_{\mathrm{ph}}>=\frac{\sum_{700}^{400} a_{\mathrm{ph}}(\lambda)}{\sum_{700}^{400} \lambda} \\
& \overline{a_{\mathrm{ph}}}(\lambda)=\frac{a_{\mathrm{ph}}(\lambda)}{<a_{\mathrm{ph}}>}
\end{aligned}
$$

Onde $a_{\mathrm{ph}}^{*}(\lambda)\left[\mathrm{m}^{2} \cdot \mathrm{mg}^{-1}\right]$ representa o coeficiente de absorção de luz específico da clorofila-a, ou seja, normalizado por unidade de clorofila-a. Valores de $a_{\mathrm{ph}}^{*}(\lambda)$ serão comparados com a razão S/V da comunidade fitoplanctônica. $\left\langle a_{\mathrm{ph}}>\left[\mathrm{m}^{-1}\right]\right.$ corresponde à média dos valores de $a_{\mathrm{ph}}(\lambda)$ dos comprimentos de onda de 400 a 700nm que assumimos como o valor da magnitude do coeficiente de absorção de luz pelo fitoplâncton. Valores de $<a_{\text {ph }}>$ serão utilizados nas relações com a biomassa, [chl] e com a razão S/N da comunidade fitoplanctônica. Já $\overline{a_{\mathrm{ph}}}(\lambda)$ (sem dimensão) representa os valores de $a_{\mathrm{ph}}(\lambda)$ em cada comprimento de onda normalizados por $\left.<a_{\mathrm{ph}}\right\rangle$. A 
normalização de $a_{\mathrm{ph}}(\lambda)$ pela média entre os comprimento de onda de $400 \mathrm{e}$ 700 remove os efeitos da magnitude da absorção de luz e assim obtemos informações apenas da forma do espectro de $a_{\mathrm{ph}}(\lambda)$. Muitos dos modelos criados para identificar grupos taxonômicos e informações sobre o tamanho dos organismos através de $a_{\mathrm{ph}}(\lambda)$ utilizam $\overline{a_{\mathrm{ph}}}(\lambda)$ pois identificam variações no comportamento espectral de $a_{\mathrm{ph}}(\lambda)$ e não em sua magnitude.

\subsubsection{Modelos Bio-óticos}

\subsubsection{Vidussi et al., 2001 e Uitz et al., 2006}

O modelo desenvolvido por Vidussi et al. (2001) baseia-se na estimativa da proporção de classes de tamanho dentro de uma comunidade fitoplanctônica de acordo com os pigmentos marcadores. Este modelo foi utilizado para validar seu desempenho com dados de biomassa (teor de carbono) de comunidades naturais fitoplanctônicas. As Equações 17 a 19 representam as proporções das classes do micro $\left(f_{\text {micro }}\right)$, nano $\left(f_{\text {nano }}\right)$ e picofitoplâncton $\left(f_{\text {pico }}\right)$, respectivamente.

$$
\begin{gathered}
f_{\text {micro }}=\frac{1.41 \times[\text { Fuco }]+1.41 \times[\text { Perid }]}{\sum D P_{w}} \\
f_{\text {nano }}=\frac{1.27 \times[\text { Hex }- \text { Fuco }]+0.35 \times[\text { But-Fuco }]+0.60 \times[\text { Allo }]}{\sum D P_{w}} \\
f_{\text {pico }}=\frac{1.01 \times[\text { TChlb }]+0.86 \times[\text { Zea }]}{\sum D P_{w}} \\
\left.\sum \text { But-Fuco }\right]+0.60 \times[\text { Allo }]+1.01 \times[\text { TChlb }]+0.86 \times[\text { Zea }]
\end{gathered}
$$

onde [Fuco], [Perid], [Hex-Fuco], [But-Fuco], [Allo], [TChlb] , e $[Z e a]$ representam, respectivamente, as concentrações $\left[\mathrm{mg} \cdot \mathrm{m}^{-3}\right.$ ] dos pigmentos Fucoxantina, Peridinina, 19'-Hexanoiloxifucoxantina, 19'Butanoiloxifucoxantina, Aloxantina, Clorofila-b + Divinil Clorofila-b e 
Zeaxantina; e $\sum D P_{w}\left[\mathrm{mg} \cdot \mathrm{m}^{-3}\right]$ corresponde à soma ponderada de todos os pigmentos diagnósticos.

Para a comparação de $f_{\text {micro }}$ e $f_{\text {nano }}$ com os dados de carbono da comunidade fitoplanctônica, foram obtidas as proporções das classes de tamanho do microplâncton $\left(p_{\text {micro }}\right)$ e do nanoplâncton $\left(p_{\text {nano }}\right)$ de acordo com seu o teor de carbono. Em suma, $p_{\text {micro }}$ corresponde à somatória de todo 0 carbono dos organismos ( $B_{\text {micro }}$ ) maiores que $20 \mu \mathrm{m}$ em relação ao carbono total da comunidade $(B)$ (Equação 21). Da mesma forma, $p_{\text {nano }}$ corresponde à somatória do carbono dos organismos $\left(B_{\text {nano }}\right)$ com comprimento total entre 5 e $20 \mu \mathrm{m}$ (Equação 22).

$$
\begin{aligned}
& p_{\text {micro }}=\frac{\sum_{20 \mu m}^{\infty} B_{\text {micro }}}{B} \\
& p_{\text {nano }}=\frac{\sum_{5 \mu \mathrm{m}}^{20 \mu \mathrm{m}} B_{\text {nano }}}{B}
\end{aligned}
$$

\subsubsection{Ciotti et al., 2002}

A partir de curvas normalizadas de $\overline{a_{\mathrm{ph}}}(\lambda)$ entre 400 e $700 \mathrm{~nm}$, foi calculado o parâmetro de tamanho dominante da comunidade $\left(\mathrm{S}_{\mathrm{f}}\right)$ proposto por Ciotti et al. (2002). O parâmetro Sf é estimado de forma que a soma dos quadrados entre a curva de absorção de luz $\left(\overline{a_{\mathrm{ph}}}(\lambda)\right)$ e a construída pelo modelo $\left(\hat{a}_{p h}(\lambda)\right)$ sejam o menor possível. A curva $\hat{a}_{p h}(\lambda)$ é obtida através da Equação 23, baseada no parâmetro da eficiência de absorção de luz $\left(\mathrm{S}_{\mathrm{f}}\right)$ e de duas curvas absorção de luz $\left(a_{\text {pico }}(\lambda)\right.$ e $\left.a_{\text {micro }}(\lambda)\right)$ que representam os extremos de grau de empacotamento esperado para comunidades fitoplanctônicas (Ciotti et al., 2002). $a_{\text {pico }}(\lambda)$ é representado por uma curva de absorção de luz média de comunidades dominadas por Prochlorococcus sp. e $a_{\text {micro }}(\lambda)$ é representado por uma curva de absorção de luz de uma floração de Gonyaulax sp (veja detalhes em Ciotti et al., 2002).

$$
\hat{a}_{p h}(\lambda)=\left[S_{f} \times a_{\text {pico }}(\lambda)\right]+\left[\left(1-S_{f}\right) \times a_{\text {micro }}(\lambda)\right]
$$


Os resíduos do ajuste de $S_{f}$ nas curvas de $\overline{a_{\mathrm{ph}}}(\lambda)$ foram obtidos para cada comprimento de onda, e sua análise resultou em picos nítidos centrados em algumas bandas. A fim de associar estes resíduos às variáveis obtidas da comunidade fitoplanctônica, foram selecionadas 5 bandas espectrais que apresentaram as maiores variações no ajuste de $S_{f}$ em relação à $\overline{a_{\mathrm{ph}}}(\lambda)$. As bandas correpondem a intervalos de $5 \mathrm{~nm}$ centradas em 475, 490, 543, 650 e $665 \mathrm{~nm}$ e para cada banda espectral foram feitas médias dos valores do resíduo de $\mathrm{S}_{\mathrm{f}}$ encontrados.

\subsubsection{Concentração de pigmentos intracelulares $\left[\mathrm{mg} \cdot \mathrm{m}^{-3}\right]$}

A concentração específica dos principais pigmentos celulares e da clorofila-a foi obtida através de Cromatografia Líquida de Alta Performance (HPLC, High Performance Liquid Chromatography) em parceria com a Profa. Dra. Virgínia M. Tavano e o Dr. Rafael Mendes do Laboratório de Fitoplâncton e Microorganismos Marinhos da Universidade Federal de Rio Grande (FURG). Para cada amostra, foi filtrado um volume conhecido de água (1-2L) em filtros GF/F e os filtros foram imediatamente congelados e armazenados em nitrogênio líquido ao abrigo da luz. A extração dos pigmentos foi realizada utilizando-se metanol a 95\% tamponado com $2 \%$ de acetato de amônio. Para auxiliar no processo de extração os filtros foram macerados e colocados a $-20^{\circ} \mathrm{C}$ durante 60 minutos e posteriormente os extratos foram sonicados por 5 minutos. Em seguida, as amostras foram centrifugadas durante 5 minutos a $3^{\circ} \mathrm{C}$ e o sobrenadante filtrado através de um filtro de membrana de $0,2 \mu \mathrm{m}$ de porosidade (Millipore Fluoropore Membrane filters, $13 \mathrm{~mm}$ de diâmetro). O filtrado foi então imediatamente colocado no auto-injetor do HPLC, refrigerado a $4^{\circ} \mathrm{C}$. Os extratos foram analisados utilizando um HPLC Shimadzu composto por um módulo distribuidor de solventes (LC-20AD) com um sistema de controle (CBM-20A), um detector de fotodiodos (SPD-M20A) e um detector de fluorescência (RF10AXL). A separação cromatográfica dos diversos pigmentos, incluindo a clorofila-a, foi efetuada usando uma coluna C8 monomérica (SunFire; $15 \mathrm{~cm}$ de comprimento; 4,6 mm de diâmetro e 3,5 $\mu \mathrm{m}$ de tamanho das partículas) a uma temperatura constante de $25^{\circ} \mathrm{C}$. A fase móvel (solventes) e o seu 
respectivo gradiente seguiram o método desenvolvido por Zapata et al. (2000) e otimizado por Mendes et al. (2007), com um fluxo de $1 \mathrm{ml} / \mathrm{min}$ e um volume de injeção de $100 \mu \mathrm{l}$. A identificação e quantificação dos picos referentes aos diferentes pigmentos foram realizadas usando como referência padrões comerciais da DHI (Institute for Water and Environment, Denmark). A concentração foi calculada a partir do sinal obtido pelo detector de fotodiodos e/ou pelo detector de fluorescência. A Tabela 1 representa a lista dos pigmentos identificados pela técnica de HPLC empregada nas amostras desse projeto.

Tabela 1: Relação dos pigmentos identificados por HPLC, suas siglas e a quais grupos taxonômicos funcionam como pigmentos indicadores. Modificado de Wright (2005).

\begin{tabular}{|c|c|c|}
\hline Pigmento & Símbolo & Indicador \\
\hline Clorofila-a & $\mathrm{Chla}$ & \\
\hline $\begin{array}{l}\text { Divinil Clorofila-a } \\
\text { Clorofila-a + Divinil Clorofila-a } \\
\text { (incluindo alômeros e epímeros) }\end{array}$ & $\begin{array}{l}\text { DV Chl a } \\
\text { [chl] }\end{array}$ & Prochlorococcus sp. \\
\hline 19'-Butanoiloxifucoxantina & But-fuco & $\begin{array}{l}\text { Crisofíceas (principal); } \\
\text { Primnesiofíceas } \\
\text { (secundário) }\end{array}$ \\
\hline Fucoxantina & Fuco & $\begin{array}{l}\text { Diatomáceas (principal); } \\
\text { Crisofíceas (secundário); } \\
\text { Primnesiofíceas } \\
\text { (secundário) }\end{array}$ \\
\hline 19'-Hexanoiloxifucoxantina & Hex-fuco & Primnesiofíceas \\
\hline Aloxantina & Allo & Criptofíceas \\
\hline Zeaxantina & Zea & Cianobactéria \\
\hline Peridinina & Perid & Dinoflagelados \\
\hline Clorofila $b+$ Divinil Clorofila $b$ & TChl-b & Clorófitas \\
\hline
\end{tabular}

\subsubsection{Abundância de Organismos Fitoplanctônicos [células. $L^{-1}$ ]}

\subsubsection{Organismos maiores que $5 \mu \mathrm{m}$}

\subsection{Contagem em microscópio invertido}

Para cada amostra selecionada, 2L de água foram conservados com formaldeído (solução final $0.4 \%$ ) tamponado com tetraborato de sódio $(\mathrm{pH}=$ 8.0). Em função das condições oligotróficas e da heterogeneidade espacial, decidimos concentrar as amostras previamente à contagem dos organismos. Para a concentração das amostras, as mesmas foram deixadas em repouso 
por sete dias (Sournia, 1978) para a total sedimentação das partículas presentes na água. Após este período, o sobrenadante foi cuidadosamente removido e seu volume medido. Da mesma forma, foi medido o volume de amostra restante (decantado). Alíquotas de $100 \mathrm{ml}$ deste volume decantado foram homogeneizadas e posteriormente deixadas em repouso por 72 horas em câmara de sedimentação (Utermöhl, 1958), onde os organismos fitoplanctônicos foram contabilizados em microscópio invertido equipado com contraste de fase (Olympus ${ }^{\circledR}$ - CKX041). Para fins de normalização da ocorrência de espécies raras e da correta estimativa da densidade celular, foram contadas no mínimo 400 unidades sedimentadas (u.s.) em cada amostra (Tenenbaum, D., comunicação pessoal). Cada unidade sedimentada correspondente a um organismo isolado ou a uma cadeia/colônia/filamento de organismos. Caso esse número não fosse atingido em até metade da câmara, contava-se a câmara de sedimentação inteira.

O microplâncton $(>20 \mu \mathrm{m})$ foi contado no aumento de $200 x$ e a identificação ocorreu geralmente no aumento de 400x. A contagem e identificação do nanoplâncton $(5-20 \mu \mathrm{m})$ foram realizadas no aumento de 400x. Daqui em diante, os termos microplâncton, nanoplâncton e picoplâncton referem-se apenas aos organismos fitoplanctônicos. Dessa forma, cada amostra teve uma sequência de duas contagens no microscópio, sendo uma para o microplâncton e outra para o nanoplâncton.

Para efeitos de normalização, uma vez que a abundância celular é dada em células. $\mathrm{L}^{-1}$, as u.s. que correspondiam a cadeias/colônias/filamentos tiveram suas células enumeradas. Quando essa enumeração não era possível devido à difícil visualização das unidades celulares, o número de células era estimado, basicamente, de acordo com o tamanho da cadeia e o tamanho médio de suas células (veja tópico "Cálculo do número de células por cadeia" abaixo). A abundância dos organismos foi obtida de acordo com as equações 24 e 25 :

$$
\begin{gathered}
A b^{S}=1000 \times \frac{n_{c e l}^{s} \times A_{t}}{A_{c} \times V_{a}} \\
V_{a}=\frac{V_{i} \times V_{c u b}}{V_{c o n}}
\end{gathered}
$$


onde $A b$ representa a abundância de organismos em [cel/L] de uma determinada espécie representada pelo superescrito "s"; $n_{c e l}^{s}$ corresponde ao número de células da espécie; $A_{t}$ e $A_{c}$ representam a área total da câmara e a área contada $\left[\mu^{2}\right]$, respectivamente; $V_{a}$ corresponde ao volume total analizado [ml], obtido através do volume inicial da amostra antes de decantar $\left(V_{i}[\mathrm{ml}]\right)$, do volume da cubeta de sedimentação $\left(V_{c u b}[\mathrm{ml}]\right)$ e do volume de amostra restante (decantada) após a decantação $\left(V_{\text {con }}[\mathrm{ml}]\right)$.

\subsection{Cálculo do número de células por cadeia}

Um dos grandes problemas que taxonomistas encontram durante a enumeração de organismos fitoplanctônicos é a presença de organismos em cadeia ou em aglomerados (Vraducci et al., 2007). Na maioria dos casos, é possível contar as células de uma cadeia individualmente, permitindo que a abundância daquela espécie seja devidamente calculada. Contudo, em alguns casos, devido ao tamanho das células e por estarem muito próximas umas das outras na cadeia, a contagem individual acaba sendo prejudicada. Exemplos claros são cadeias de cianobactérias filamentosas (Oscilatorialles, Nostocales), onde, nos piores casos, é impossível distinguir os limites celulares sem utilizar técnicas de microscopia, como contraste de interferência (DIC). Além disso, a própria organização das células na colônia ou na cadeia, ou mesmo a disposição espacial da cadeia no campo visual impede a contagem das células. Para todos os casos em que o número de células não pode ser visualizado, estimativas foram utilizadas baseadas em critérios como i) tamanho da célula, ii) tamanho da cadeia, iii) distância entre células, iv) presença de células em divisão. A seguir encontram-se as equações para todos os casos de estruturação de cadeia que foram encontrados:

1. Cadeias de células contíguas:

$$
n_{c e l}^{s}=\frac{u . s .^{s} \times \bar{C}_{c a d}^{s}}{C_{c e l}^{s}}
$$


2. Cadeias de células igualmente espaçadas:

$$
n_{c e l}^{s}=\frac{u . s . s \times \bar{C}_{c a d}^{s}}{C_{c e l}^{s}+C_{d i s t}}
$$

3. Cadeias de células com espaços irregulares entre células:

$$
n_{\text {cel }}^{s}=\frac{u . s^{s} \times \bar{C}_{c a d}^{s}}{C_{c e l}^{s}+\bar{C}_{\text {dist }}}
$$

4. Cadeias com células em divisão:

$$
n_{\text {cel }}^{s}=\frac{u . s^{s} \times \bar{C}_{c a d}^{s}}{C_{1}^{s}+C_{2}^{s}}
$$

sendo

$$
C_{1}^{s}=\frac{n_{1} \times \bar{C}_{1}}{n_{1}+n_{2}} \quad \text { e } \quad C_{2}^{s}=\frac{n_{2} \times \bar{C}_{2}}{n_{1}+n_{2}}
$$

onde $\bar{C}_{c a d}^{s}$ representa o comprimento mediano das cadeias encontradas para a espécie "s" e $C_{c e l}^{S}$ o comprimento da células presentes no centro da cadeia, $C_{\text {dist }}$ representa o espaço entre células e $\bar{C}_{\text {dist }}$ representa o espaço mediano entre as células. Foi escolhido a medida ao centro da cadeia de forma a minimizar os efeitos de diferenciação e frequente divisão celular presente nas extremidades das cadeias. Para cadeias com células em divisão (Eq. 29), utilizamos o tamanho ponderado das células divididas $C_{1}^{s}$ e das células em divisão $C_{2}^{s}$, de acordo com o tamanho mediano das respectivas células $\left(\bar{C}_{1}\right.$ e $\left.\bar{C}_{2}\right)$ e seu número dentro da cadeia $\left(n_{1}\right.$ e $\left.n_{2}\right)$ (eq. 30 e 31 ).

\subsection{Registro dos organismos por faixa de tamanho}

Durante as contagens, os organismos observados eram categorizados em faixas de tamanho de acordo com a máxima dimensão linear medida (MDL [ $[\mu \mathrm{m}]$ ) (Tabela 2). Em média, cinco organismos de cada espécie ou 
grupo em cada faixa de tamanho eram fotografados (câmera Mshot®-90 acoplada ao microscópio, resolução de 3.0 megapixels) ou, em alguns casos, todos os organismos de uma faixa de tamanho específica (Tabela 2). A seleção das faixas de tamanho baseou-se em variações de tamanho entre os indivíduos da mesma espécie ou em variações de acordo com o ciclo de vida do organismo e foram sugeridas pela Dra. Denise Rivera Tenenbaum (Universidade Federal do Rio de Janeiro) e modificadas após discussão com outros pesquisadores da área.

Tabela 2: Faixas de tamanho utilizadas durante a contagem do fitoplâncton em microscopia e critérios para aquisição de imagens.

\begin{tabular}{cl}
\hline Faixa de Tamanho & Fotografias \\
\hline $5-10 \mu \mathrm{m}$ & ao menos 5 organismos de cada espécie \\
$10-20 \mu \mathrm{m}$ & ao menos 5 organismos de cada espécie \\
$20-30 \mu \mathrm{m}$ & ao menos 5 organismos de cada espécie \\
$30-50 \mu \mathrm{m}$ & ao menos 5 organismos de cada espécie \\
$50-80 \mu \mathrm{m}$ & ao menos 5 organismos de cada espécie \\
$80-100 \mu \mathrm{m}$ & ao menos 5 organismos de cada espécie \\
$100-200 \mu \mathrm{m}$ & todos os organismos \\
acima de $200 \mu \mathrm{m}$ & todos os organismos \\
cadeias/colônias/filamentos & todos os organismos \\
\hline
\end{tabular}

\subsection{Identificação}

Todos os organismos contabilizados foram identificados preferencialmente ao nível de espécie ou gênero, baseados em bibliografia especializada destacando-se para diatomáceas: Hustedt (1930), Cupp (1943), Ricard (1987), Hasle e Syvertsen (in Tomas, 1997); para dinoflagelados: Wood (1968), Balech (1988), Taylor (1976), Steidinger e Tangen (in Tomas, 1997), Graham e Bronikowsky (1944); para cocolitoforídeos: Heimdal (in Tomas, 1997); para cianobactérias: Komárek e Anagnostidis $(1989,2005)$ e Anagnostidis e Komárek (1988). Toda a taxonomia foi atualizada através do banco de dados online (www.algaebase.org). Em alguns casos, a identificação a nível de espécie não era possível, de forma a classificarmos os organismos em categorias 
supra-genéricas ou mesmo de acordo com o seu morfotipo geométrico (Sun e Liu 2003; Hillebrand et al. 1999; Verity et al., 1992).

\subsubsection{Cálculo do Biovolume celular, Superfície Celular e Razão Superfície/Volume}

\subsubsection{1 - Definição de morfotipos geométricos e Medidas Lineares}

Todos os organismos foram classificados em morfotipos geométricos seguindo Sun e Liu (2003) e Hillebrand et al. (1999), ou por observação do organismos em diferentes ângulos e associando-o a um morfotipo específico. Afim de descrever a comunidade fitoplanctônica de acordo com seus morfotipos geométricos, utilizamos o limite mínimo de ocorrência de $10 \%$. Assim, foram contabilizados todos os morfotipos em todas as amostras e aqueles morfotipos cuja ocorrência foi menor que $10 \%$ do total de organismos observados e medidos $(n=9840)$ não foram utilizados nas análises e correspondem aos morfotipos 1) Cilindro +2 cones; 2) Cone + meia esfera + cilindro e 3) Meia esfera.

Medidas lineares foram realizadas nas fotografias obtidas durante a enumeração e identificação dos organismos. As medidas foram realizadas no programa Image $®$ com as escalas das imagens ajustadas através de régua milimétrica (Olympus $®$ ). As principais medidas obtidas para cada organismo foram i) comprimento, ii) largura, iii) profundidade/3D, iv) Máxima Dimensão Linear, v) comprimento e largura das projeções e vi) tamanho da cadeia/colônia/filamentos. A partir das medidas lineares realizadas nas imagens, foram calculados o biovolume celular $(V)\left[\mu \mathrm{m}^{3}\right]$ e a superfície celular (S) $\left[\mu \mathrm{m}^{2}\right]$ associando cada morfotipo ao organismo encontrado. Todas as equações para determinação de $V$ e $S$ seguiram o proposto por Sun e Liu (2003) e esses valores foram utilizados para o calculo da razão Superfície/Volume (S/V) $\left[\mu \mathrm{m}^{-1}\right]$ de cada organismo.

Um dos maiores obstáculos no cálculo do biovolume celular é a medida da profundidade ou "dimensão oculta" (3D) em microscopia de luz (Verity et al., 1992). Nos casos de espécies abundantes, a chance dos organismos sedimentarem em diferentes ângulos de visão para análise em 
microscópio é alta e permite a medida da terceira dimensão. Espécies menos abundantes ou das quais somente foi possível obter um único ângulo de visão, utilizamos as proporções sugeridas por Olenina et al. (2006). Para espécies diferentes das apresentadas por Olenina et al. (2006), a terceira dimensão foi considerada como sendo igual à largura ou sendo $1 / 3$ do comprimento total quando a largura não era facilmente obervada.

\subsubsection{Cálculo de Biomassa em unidades de Carbono [mgC.m $\left.\mathrm{m}^{-3}\right]$}

\subsubsection{Organismos menores que $5 \mu \mathrm{m}$}

Apesar de havermos coletado amostras para identificação de organismos por citometria de fluxo, os resultados estão duvidosos e optamos por não utilizar esses dados. A determinação de biomassa dos organismos do picoplâncton e ultraplâncton (organismos menores que $5 \mu \mathrm{m}$ ) foi, portanto, estimada a partir do modelo proposto por Vidussi et al. (2001), que resulta na proporção da clorofila-a dos organismos do picoplâncton (menores que $2 \mu \mathrm{m}$ $f_{\text {pico }}$ ), com os parâmetros adaptados de Uitz et al. (2006).

Para determinar a porção de carbono pertencente a $f_{\text {pico }}$, utilizamos uma taxa de conversão C:chl igual a 8, seguindo observações de Grob et al. (2007) da abundância e biomassa dos organismos picoplanctônicos de acordo com a concentração de clorofila-a. O carbono do ultra e picoplâncton $\left(B_{\text {ultra }+ \text { pico }}, \mathrm{mgC} \cdot \mathrm{m}^{-3}\right)$ foi então estimado empiricamente como uma função da [chl] seguindo uma equação Michaelis-Menten (Equação 32). Este ajuste baseia-se em dois parâmetros $m 1$ e $m 2$ que definem, respectivamente, 0 limite superior da contribuição da biomassa do ultra e picoplâncton, e a concentração de clorofila-a em que a curva atinge metade do valor máximo de carbono correspondente ao ultra e picoplanctônico. Os parâmetros $m 1$ e $m 2$ foram calculadas independentemente para cada cruzeiro e profundidade. A equação 32 foi ajustada para um máximo de [chl] de $2 \mathrm{mg} \cdot \mathrm{m}^{-3}$, escolhido com base nos valores de [chl] observados.

$$
B_{\text {ultra }+ \text { pico }}=\frac{m 1+[\mathrm{chl}]}{m 2 \times[c h l]}
$$




\subsubsection{Organismos maiores que $5 \mu \mathrm{m}$}

As diferenças de concentração intracelular de carbono entre os grupos de organismos (i.e. diatomáceas, dinoflagelados, cocolitoforídeos entre outros) resultam na utilização de parâmetros diferentes na conversão de volume para biomassa (e.g. Verity et al., 1992; Montagnes et al., 1994; Menden-Deuer e Lessard, 2000). Dessa froma, o valor de volume de cada organismo foi convertido em biomassa em carbono $\left(B_{c e l}, \mathrm{pgC}_{\text {célula }}{ }^{-1}\right)$ de acordo com o grupo taxonômico e o tamanho do organismo (Tabela 3, segundo Menden-Deuer e Lessard, 2000). Após a determinação do carbono por unidade celular, o carbono orgânico fitoplanctônico de cada espécie $\left(B_{s p}\right.$, $\mathrm{mgC} \cdot \mathrm{m}^{-3}$ ) foi obtido multiplicando-se $B_{c e l}$ pelo número de organismos contados de cada espécie. Por fim, a biomassa fitoplanctônica total ( $B$, $\mathrm{mgC} \cdot \mathrm{m}^{-3}$ ) para cada amostra analisada foi determinada através da soma de $B_{s p}$ que ocorreram na mesma e de $B_{\text {ultra+pico. }}$

Tabela 3: Relação das equações de conversão de volume celular para carbono celular utilizadas e suas referências principais. Adaptada de Menden-Deuer e Lessard (2000).

\begin{tabular}{|c|c|c|}
\hline Grupo Taxonômico & $\begin{array}{l}\text { Volume -> } \\
\text { Biomassa }\end{array}$ & Literatura \\
\hline $\begin{array}{l}\text { Protistas (exc. } \\
\text { Diatomáceas) }\end{array}$ & $0.216 * V^{0.939}$ & $\begin{array}{l}\text { Parsons et al., (1961); Mullin et al. (1966); } \\
\text { Verity e Langdon (1984); Moal et al. (1987); } \\
\text { Verity et al., (1992); Montagnes et al. (1994); } \\
\text { Menden-Deuer e Lessard, } 2000\end{array}$ \\
\hline Protistas $<3000 \mu \mathrm{m}^{3}$ & $0.261^{*} V^{0.860}$ & $\begin{array}{c}\text { Parsons et al., (1961); Mullin et al. (1966); } \\
\text { Strathmann (1966); Moal et al. (1987); Verity et } \\
\text { al., (1992); Montagnes et al. (1994); Menden- } \\
\text { Deuer e Lessard, } 2000\end{array}$ \\
\hline Diatomáceas & $0.288 * V^{0.811}$ & $\begin{array}{c}\text { Parsons et al., (1961); Mullin et al. (1966); } \\
\text { Strathmann (1966); Moal et al. (1987); } \\
\text { Montagnes et al. (1994) }\end{array}$ \\
\hline Diatomáceas $>3000 \mu \mathrm{m}^{3}$ & $0.117 * V^{0.881}$ & $\begin{array}{c}\text { Parsons et al., (1961); Mullin et al. (1966); } \\
\text { Strathmann (1966); Moal et al. (1987); } \\
\text { Montagnes et al. (1994) }\end{array}$ \\
\hline Dinoflagelados & $0.444 * V^{0.864}$ & $\begin{array}{l}\text { Parsons et al., (1961); Mullin et al. (1966); Moal } \\
\text { et al. (1987); Verity et al., (1992); Montagnes et } \\
\text { al. (1994); Menden-Deuer e Lessard, } 2000\end{array}$ \\
\hline Cocolitoforídeos & $0.228 * V^{0.899}$ & $\begin{array}{c}\text { Mullin et al. (1966); Moal et al. (1987); Verity et } \\
\text { al. (1992); Montagnes et al. (1994) }\end{array}$ \\
\hline $\begin{array}{l}\text { Nanofitoplâncton } \\
\text { (quando não } \\
\text { identificado) }\end{array}$ & $0.433 * V^{0.863}$ & Verity et al, 1992 \\
\hline
\end{tabular}




\subsubsection{Análise de Dados}

As comparações das variáveis de acordo com a profundidade (superfície e PFMC) foram realizadas através de Análise de Variância (ANOVA). Para testar se a biomassa e razão S/N foi diferente entre os grupos taxonômicos e entre os morfotipos foi utilizada ANOVA. Nos casos em que a ANOVA era utilizada não balanceada, foram realizados Testes $t$-student para comprovar o resultado.

As comparações na determinação da biomassa fitoplanctônica com a utilização de diferentes equações de conversão de biovolume celular para Biomassa foram realizadas através de Teste $t$-student pareado. A utilização de Teste $t$-student pareado proporciona uma comparação par a par entre o valor de biomassa obtidos através de equações dependentes do grupos taxonômico e o valor obtido através de uma única equação geral.

Regressões lineares simples foram utilizadas para estimar as relações entre variáveis independentes.

A análise de Aikaken Information Criteriation (AIC) foi utilizada para comparar a magnitude dos resíduos de $S_{f}$ (veja seção 4.2.2.2) com a concentração de pigmentos acessórios, com a razão S/V e com a contribuição de biomassa de cada morfotipo geométrico. 


\section{Resultados}

\subsection{Biomassa e Razão C:chl}

A biomassa em unidades de carbono do ultra e picoplâncton foi calculada através da concentração de pigmentos marcadores e de ajustes empíricos à [chl] (veja seção 4.2.6.1). As curvas apresentaram ajuste significativo para todos os parâmetros, exceto para um deles durante as amostras do cruzeiro MCT-1 na profundidade do máximo de fluorescência (Tabela 4). O parâmetro $m 1$ variou entre 3.14 e 4.01 , enquanto que $\circ$ parâmetro $m 2$ variou entre 0.48 e 0.87 (Tabela 3). Para o MCT-1 na PFMC, o parâmetro $m 1$ foi assumido como 4.0 , pois foi o valor mais baixo testado a permitir uma quantificação estatisticamente significativa de $m 2$.

Tabela 4: Parâmetros e ajuste das curvas Michaelis-Menten (MM) para cada cruzeiro oceanográfico e profundiadade (Superfície e PFMC). ${ }^{*}$ ) representam significância estatística $(p<0.05)$ para a determinação dos parâmetros e $(\dagger)$ corresponde ao parâmetro que foi definido como limite superior para o ajuste de $\boldsymbol{B}_{\text {ultra+pico }}$ do MCT-1 na PFMC.

\begin{tabular}{|c|c|c|}
\hline & \multicolumn{2}{|c|}{ Parâmetros da Curva MM } \\
\hline & $m 1$ & $m 2$ \\
\hline MCT-1 Superfície & $3.65 \overline{53^{*}}$ & $0.675 \overline{6^{*}}$ \\
\hline MCT-1 PFMC & $4.0 \dagger$ & $0.8789 *$ \\
\hline MCT-2 Superfície & $4.0178^{*}$ & $0.8026^{*}$ \\
\hline MCT-2 PFMC & $3.1490^{*}$ & $0.4836^{*}$ \\
\hline
\end{tabular}

A comparação entre a utilização de uma única equação para a determinação da biomassa através do volume (Equação 33, para protistas) e ao cálculo com equações diferenciadas (Menden-Deuer e Lessard, 2000), resultou em diferenças de biomassa. Para a $B_{s p}$, o uso de uma única equação resultou em valores, em média, $0.062 \mathrm{mgC} \cdot \mathrm{m}^{-3}$ maiores que os resultados de múltiplas equações (Teste $t$-student pareado, $\mathrm{p}<0.001, \mathrm{n}=2011$; Figura 2A). Quando todos os organismos em uma dada estação foram somados $(B)$, a diferença foi, em média, de $4.02 \mathrm{mgCm}^{-3}$, sendo maior com o uso de uma única equação (Teste $t$-student pareado, $p<0.001$, $n=49$; Figura 2B).

$$
B_{c e l}=0.216 \times V^{0.939}
$$



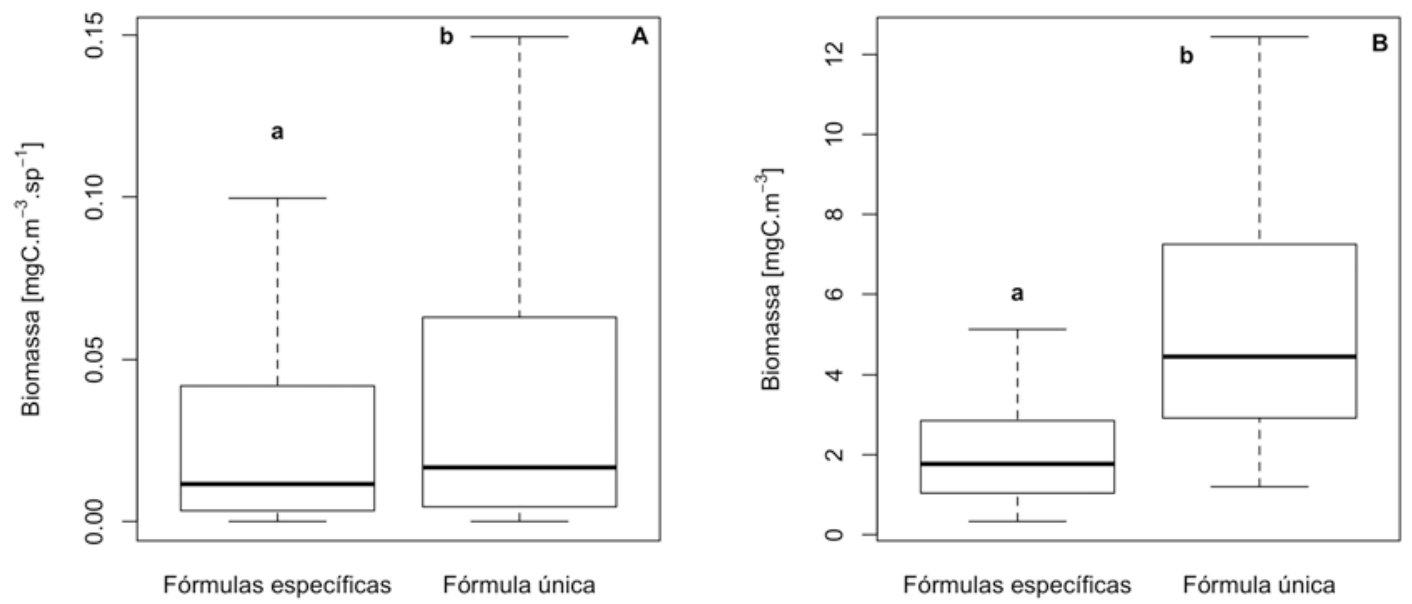

Figura 2: Comparação entre o uso de fórmulas de conversão de volume para biomassa. A) Biomassa representada por espécie dentro de cada amostra e B) Biomassa total da comunidade fitoplanctônica. Superescritos "a" e "b" representam diferença estatística (Teste $t$-student pareado, $\mathrm{p}<0.001, \mathrm{n}=2011$ ). Não estão representados os outliers em ambos os gráficos.

A Figura 3 demonstra a relação entre a biomassa da comunidade fitoplanctônica de todas as classes de tamanho $(B)$ com a [chl]. Para ambas as profundidades (superfície e PFMC) a relação entre a $B$ e a [chl] foi significativa $(p<0.01)$ e apresentou $R^{2}$ de 0.52 e 0.41 na superfície e PFMC, respectivamente.

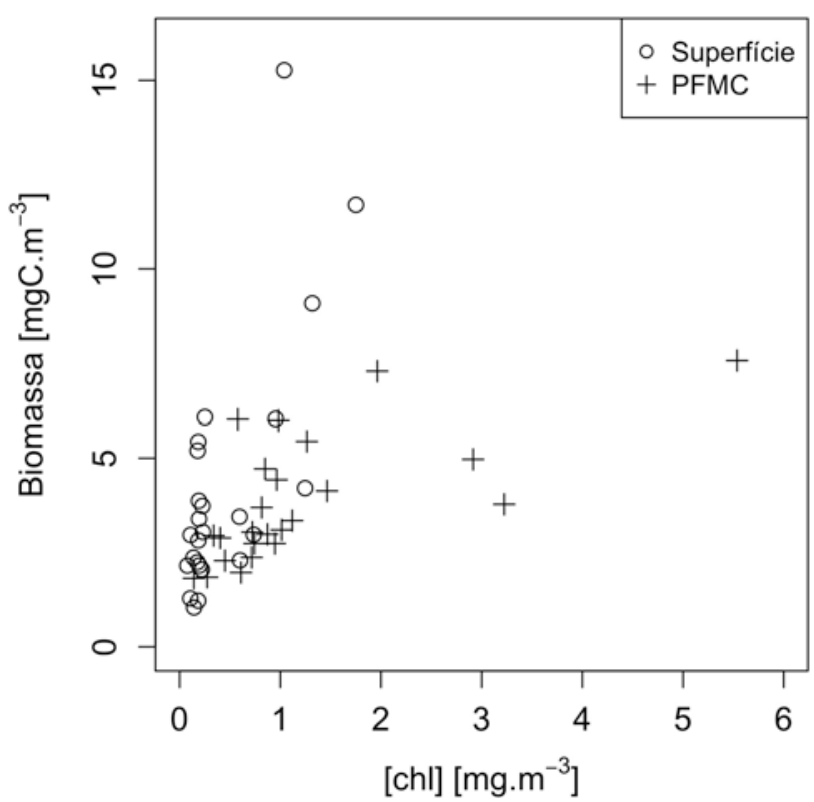

Figura 3: Relação entre a biomassa do fitoplâncton $(B)$ e a concentração de clorofila-a ([chl]). 
A biomassa fitoplanctônica média calculada para a superfície foi de 3.0 $\pm 3.4 \mathrm{mgC} \cdot \mathrm{m}^{-3}$, enquanto que para a PFMC foi de $3.2 \pm 1.7 \mathrm{mgC} . \mathrm{m}^{-3}$ (Figura 4A), não havendo diferença entre os valores observados nas duas profundidades (ANOVA, $\mathrm{p}=0.59, \mathrm{n}=49$ ). Contudo, os valores máximos atingidos na superfície foram o dobro daqueles da PFMC (15.3 mgC.m ${ }^{-3}$ e 7.6 $\mathrm{mgC} . \mathrm{m}^{-3}$, respectivamente). A [chl] foi maior na PFMC (ANOVA, $p=0.0049$, $\mathrm{n}=49$ ), onde apresentou valor médio de $1.2 \pm 1.19 \mathrm{mg} \cdot \mathrm{m}^{-3}$, enquanto que na superfície a média foi de $0.45 \pm 0.46 \mathrm{mg} \cdot \mathrm{m}^{-3}$. A razão C:chl, foi diferente entre as duas profundidades (Figura 4B) (ANOVA, p<0.01, n=49). A razão C:chl média para as amostras de superfície e PFMC juntas foi de $6.7 \pm 7.8$, com máximo de 29.4. Para a superfície, o valor médio de C:chl foi de $12.8 \pm 8.4$ (Figura 4B), enquanto que para a PFMC foi de $3.9 \pm 2.8$ ), sendo as duas profundidades diferentes estatisticamente(ANOVA, $p<0.001, n=49$ ).

Devido à necessidade das estimativas de biomassa baseadas em pigmentos na determinação do carbono dos organismos menores que $5 \mu \mathrm{m}$, analisamos a biomassa e a razão C:chl apenas com o micro e nanoplâncton (Figura 4C e Figura 4D). Note que a [chl] estimada para as classes de tamanho pico e ultraplâncton foram removidas do valor total de [chl] para essa análise. A biomassa do micro e nanoplâncton somadas é igual entre a superfície e a PFMC (ANOVA, $\mathrm{p}=0.056, \mathrm{n}=49$ ) (Figura 4C), mantendo o mesmo padrão observado quando a biomassa de toda a comunidade fitoplanctônica é analisada. A razão C:chl exclusiva ao nano e microfitoplâncton foi diferente entre a superfície e a PFMC (ANOVA, $p<0.001$, $\mathrm{n}=49$ ), novamente mantendo-se o padrão observado quanto todas as classes de tamanho são observadas juntas (Figura 4D). 

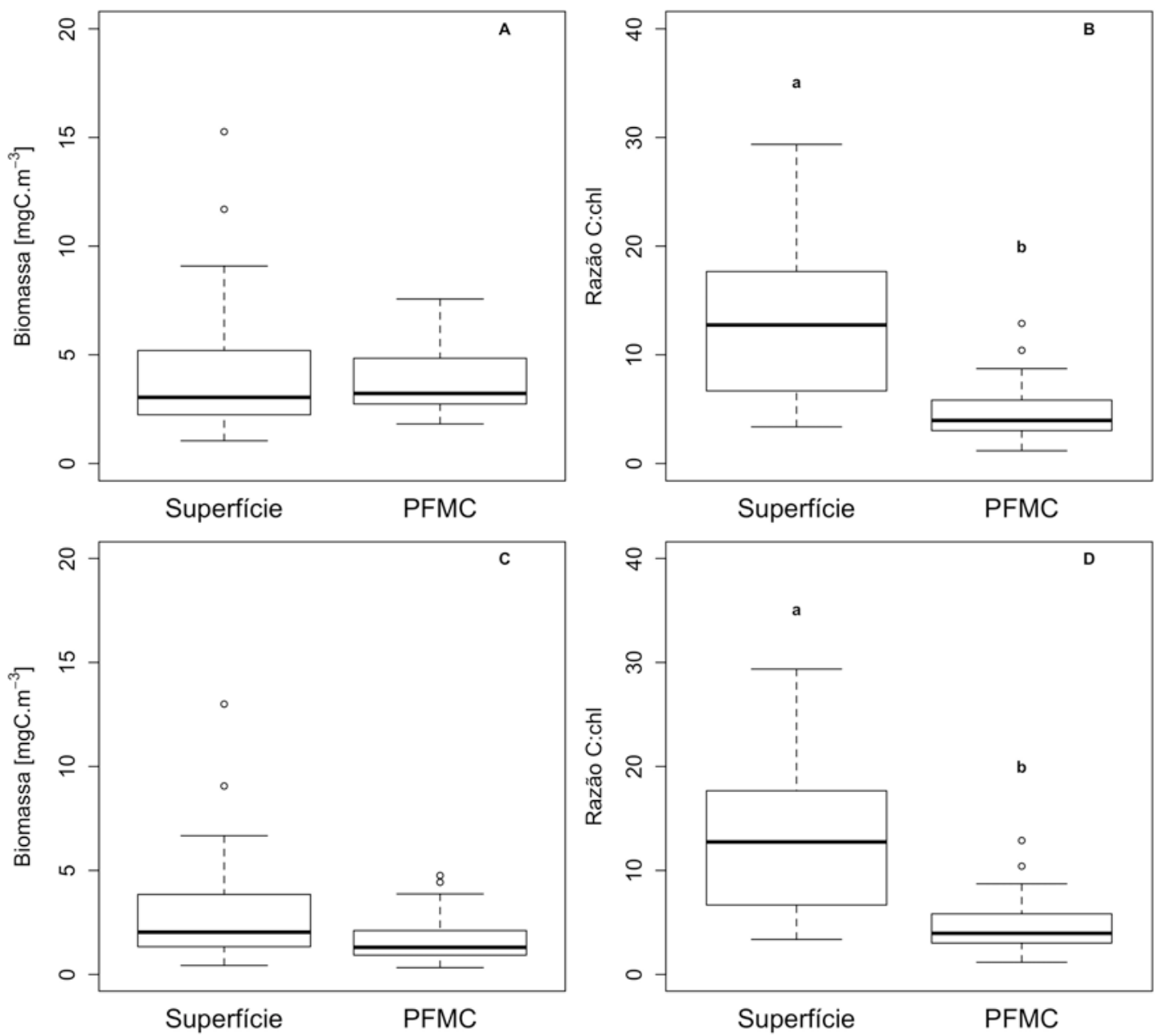

Figura 4: Distribuição da biomassa e da razão C:chl entre Superfície e PFMC de toda a comunidade fitoplanctônica (A e B) e excluindo o ultra e picoplâncton (C e D). As denotações "a" e "b" representam diferença estatística entre os grupos de dados em cada gráfico (ANOVA, $p<0.05, n=49$ ).

\subsection{Classificação da Comunidade Fitoplanctônica}

A comunidade fitoplanctônica de plataforma continental apresentou 8 grupos taxonômicos sendo eles: i) Diatomáceas Isoladas, ii) Diatomáceas em Cadeia, iii) Dinoflagelados Atecados, iv) Dinoflagelados Tecados, v) Cianobactérias, vi) Cocolitoforídeos, vii) Flagelados e viii) Ultra + Picoplâncton (Tabela 5). Essa classificação baseia-se na contribuição de biomassa em carbono de cada grupo taxonômico para a comunidade fitoplanctônica. Apenas os grupos taxonômicos que contabilizaram mais de $10 \%$ da biomassa total da comunidade foram selecionados. No caso do grupo "Flagelados", estão agrupados não apenas flagelados marinhos, como também os Silicoflagelados (Tabela 5). O gênero Protoperidinium e algumas 
espécies de Gymnodinium, Gyrodinium e Dinophysis foram removidas das análises por se tratarem de organismos heterotróficos.

Dos 31 morfotipos propostos por Hillebrand et al. (1999) e Sun e Liu (2003), apenas 19 morfotipos foram observados, sendo que destes, apenas 16 ocorreram em mais de $10 \%$ do total de organismos observados. Os morfotipos encontrados em baixa abundância e que não serão utilizados nas análises são i) Cilindro + 2 cones; ii) Cone + meia esfera + cilindro e iii) Meia esfera. Dessa forma, os organismos fitoplanctônicos de plataforma continental podem ser descritos por apenas 16 formas geométricas principais (Tabela 5), sendo: i) Esfera; ii) Prolado; iii) Elipsóide; iv) Cilindro; v) Cilindro + 2 meia esferas; vi) Cone; vii) Duplo cone; viii) Cone + meia esfera; ix) Caixa Retangular; x) Prisma Elíptico; xi) Prisma Elíptico com constrição transapical; xii) Prisma Paralelogramo; xiii) Prisma Elíptico + 4 cones; xiv) Elipsóide + 2 cones + cilindro; xv) Cilindro (alongado valvar); xvi) Prisma Elíptico (alongado valvar).

Tabela 5: Lista dos gêneros identificados em microscópio, seus respectivos morfotipos e o grupo taxonômico em que estão inseridos.

\begin{tabular}{|c|c|c|}
\hline Gêneros & Morfotipo & Grupo Taxonômico \\
\hline \multicolumn{3}{|l|}{ Bacillariophyta } \\
\hline Asteromphalus & Cilindro & Diatomácea Isolada \\
\hline Bacteriastrum & Cilindro (alongado valvar) & $\begin{array}{l}\text { Diatomácea Isolada, } \\
\text { Diatomácea em Cadeia }\end{array}$ \\
\hline Chaetoceros & Prisma Elíptico (alongado valvar) & $\begin{array}{l}\text { Diatomácea Isolada, } \\
\text { Diatomácea em Cadeia }\end{array}$ \\
\hline Climacodium & Prisma Elíptico + 4 cones & $\begin{array}{l}\text { Diatomácea Isolada, } \\
\text { Diatomácea em Cadeia }\end{array}$ \\
\hline Corethron & Cilindro +2 meia esferas & Diatomácea Isolada \\
\hline Coscinodiscus & Cilindro & Diatomácea Isolada \\
\hline Cyclotella & Cilindro & Diatomácea Isolada \\
\hline Cylindrotheca & Prisma paralelogramo & Diatomácea Isolada \\
\hline Diploneis & $\begin{array}{c}\text { Prisma Elíptico com constrição } \\
\text { transapical }\end{array}$ & Diatomácea Isolada \\
\hline Fragilaria & Prisma Elíptico (alongado valvar) & $\begin{array}{l}\text { Diatomácea Isolada, } \\
\text { Diatomácea em Cadeia }\end{array}$ \\
\hline Grammatophora & Caixa Retangular & Diatomácea Isolada \\
\hline Haslea & Prisma paralelogramo & Diatomácea Isolada \\
\hline Helicotheca & Prisma Elíptico (alongado valvar) & $\begin{array}{l}\text { Diatomácea Isolada, } \\
\text { Diatomácea em Cadeia }\end{array}$ \\
\hline Hemiaulus & Prisma Elíptico (alongado valvar) & $\begin{array}{l}\text { Diatomácea Isolada, } \\
\text { Diatomácea em Cadeia }\end{array}$ \\
\hline Leptocylindrus & Cilindro (alongado valvar) & Diatomácea Isolada, \\
\hline
\end{tabular}




\begin{tabular}{|c|c|c|}
\hline Gêneros & Morfotipo & Grupo Taxonômico \\
\hline Liloma & Caixa Retangular & $\begin{array}{l}\text { Diatomácea em Cadeia } \\
\text { Diatomácea Isolada, } \\
\text { Diatomácea em Cadeia }\end{array}$ \\
\hline Meuniera & Prisma Elíptico (alongado valvar) & $\begin{array}{l}\text { Diatomácea Isolada, } \\
\text { Diatomácea em Cadeia }\end{array}$ \\
\hline Navicula & Prisma Elíptico & $\begin{array}{l}\text { Diatomácea Isolada, } \\
\text { Diatomácea em Cadeia }\end{array}$ \\
\hline Nitzschia & Prisma paralelogramo & Diatomácea Isolada \\
\hline Odontella & Prisma Elíptico (alongado valvar) & $\begin{array}{l}\text { Diatomácea Isolada, } \\
\text { Diatomácea em Cadeia }\end{array}$ \\
\hline Paralia & Cilindro & Diatomácea em Cadeia \\
\hline Pleurosigma & Prisma paralelogramo & Diatomácea Isolada \\
\hline Pseudo-nitzschia & Prisma paralelogramo & $\begin{array}{l}\text { Diatomácea Isolada, } \\
\text { Diatomácea em Cadeia }\end{array}$ \\
\hline Rhizosolenia & Cilindro (alongado valvar) & $\begin{array}{l}\text { Diatomácea Isolada, } \\
\text { Diatomácea em Cadeia }\end{array}$ \\
\hline Striatellaceae & Prisma Elíptico (alongado valvar) & Diatomácea Isolada \\
\hline Thalassionema & Caixa Retangular & $\begin{array}{l}\text { Diatomácea Isolada, } \\
\text { Diatomácea em Cadeia }\end{array}$ \\
\hline Thalassiosira & Cilindro & $\begin{array}{l}\text { Diatomácea Isolada, } \\
\text { Diatomácea em Cadeia }\end{array}$ \\
\hline Thalassiothrix & Caixa Retangular & Diatomácea Isolada \\
\hline \multicolumn{3}{|l|}{ Dynophyta } \\
\hline Alexandrium & Elipsóide & Dinoflagelado Tecado \\
\hline Amphidinium & Elipsóide & Dinoflagelado Atecado \\
\hline Corythodinium & Prolado & Dinoflagelado Tecado \\
\hline Dinophysis & Elipsóide & Dinoflagelado Tecado \\
\hline Gonyaulax & Duplo cone & Dinoflagelado Tecado \\
\hline Gymnodinium & Elipsóide; Esfera & Dinoflagelado Atecado \\
\hline Gyrodinium & Elipsóide & Dinoflagelado Atecado \\
\hline Heterocapsa & Cone + meia esfera & Dinoflagelado Tecado \\
\hline Neoceratium & Elipsóide +2 cones + cilindro & Dinoflagelado Tecado \\
\hline Oxytoxum & Prolado & Dinoflagelado Tecado \\
\hline Peridinium & Elipsóide; Esfera & Dinoflagelado Tecado \\
\hline Phalacroma & Elipsóide & Dinoflagelado Tecado \\
\hline Podolampas & Cone & Dinoflagelado Tecado \\
\hline Prorocentrum & Elipsóide & Dinoflagelado Tecado \\
\hline Pyrocystis & Elipsóide & Dinoflagelado Tecado \\
\hline Pyrophacus & Elipsóide & Dinoflagelado Tecado \\
\hline Scrippsiella & Cone + meia esfera & Dinoflagelado Tecado \\
\hline
\end{tabular}

\section{Cyanobacteria}

Anabaena

Richelia

Trichodesmium

Esfera

Cilindro (alongado valvar)
Cianobactéria

Cianobactéria

Cianobactéria

\section{Haptophyta}

Calciosolenia

Coronosphaera

Gephyrocapsa
Prolado
Elipsóide
Esfera

Cocolitoforídeo

Cocolitoforídeo

Cocolitoforídeo 


\begin{tabular}{ccc}
\hline Gêneros & Morfotipo & Grupo Taxonômico \\
\hline Helicosphaera & Prolado & Cocolitoforídeo \\
Ophiaster & Esfera & Cocolitoforídeo \\
Rhabdosphaera & Esfera & Cocolitoforídeo \\
Umbilicosphaera & Prolado & Cocolitoforídeo \\
Phaeocystis & Esfera & Flagelado \\
Euglenophyta & & \\
Euglena & Elipsóide, Prolado & Flagelado \\
Eutreptiella & Elipsóide & Flagelado \\
Chlorophyta & & Flagelado \\
Pyramimonas & Cone & Flagelado \\
Tetraselmis & Elipsóide & \\
Ochrophyta & & Flagelado \\
Dictyocha & Esfera & \\
\hline
\end{tabular}

Dentre os grupos taxonômicos encontrados, podemos estabelecer relações de dominância e exclusividade de morfotipos celulares dentro de cada grupo (Tabela 6). As diatomáceas (isoladas e em cadeia) apresentam os seguintes morfotipos exclusivos: Cilindro, Caixa retangular, Prisma Elíptico, Prisma Elíptico com constrição, Prisma Paralelogramo, Prisma Elíptico +4 cones e Prisma Elíptico (valvar). O morfotipo Elipsóide +2 cones + cilindro e o Duplo Cone são específicos de Dinoflagelados Tecados. Morfotipos estruturalmente mais simples (Esfera, Prolado, Elipsóide) ocorrem na maioria dos grupos, sendo impossível delimitar relações com os grupos taxonômicos. As cianobactérias encontradas são representadas pelos morfotipos Esféricos e Cilindro (valvar), porém não exclusivos. A classe ultra+picoplâncton foi assumida como sendo composta por organismos esféricos, por isso sua aparente exclusividade, e espera-se que outras morfotipos estejam presentes neste grupo (Tabela 6). 
Tabela 6: Ocorrência dos morfotipos fitoplanctônicos de acordo com o grupo taxonômico. Os valores correspondem ao número total de observações entre as estações.

\begin{tabular}{|c|c|c|c|c|c|c|c|c|c|}
\hline \multirow[t]{2}{*}{ Morfotipos } & \multicolumn{9}{|c|}{ Grupos Taxonômicos } \\
\hline & 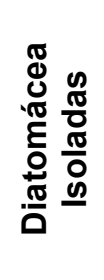 & 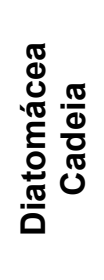 & 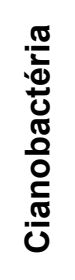 & 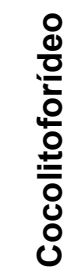 & 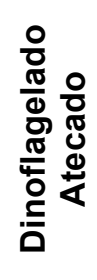 & 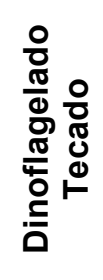 & $\begin{array}{l}\frac{0}{0} \\
\frac{\pi}{0} \\
\frac{\pi}{\pi} \\
\frac{\pi}{4}\end{array}$ & 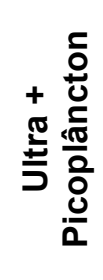 & 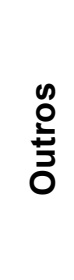 \\
\hline Esférico & & & 47 & 126 & 71 & 5 & 76 & 49 & 161 \\
\hline Prolado & & & & 56 & 4 & 46 & 31 & & 141 \\
\hline Elipsóide & & & & 15 & 37 & 144 & 79 & & 24 \\
\hline Cilindro & 166 & 17 & & & & & & & \\
\hline Cilindro + 2 meia esferas & 1 & & & & & & & & 26 \\
\hline Cone & & & & & & 5 & 1 & & \\
\hline Duplo cone & & & & & & 24 & & & \\
\hline Cone + meia esfera & & & & & & 83 & 8 & & 50 \\
\hline Caixa Retangular & 151 & 55 & & & & & & & \\
\hline Prisma Elíptico & 13 & & & & & & & & \\
\hline $\begin{array}{l}\text { Prisma Elíptico com constrição } \\
\text { transapical }\end{array}$ & 23 & 1 & & & & & & & \\
\hline Prisma Paralelogramo & 25 & 2 & & & & & & & \\
\hline Prisma Elíptico + 4 cones & & 16 & & & & & & & \\
\hline Elipsóide +2 cones + cilindro & & & & & & 57 & & & \\
\hline Cilindro (alongado valvar) & 6 & 23 & 39 & & & & & & \\
\hline $\begin{array}{l}\text { Prisma Elíptico (alongado } \\
\text { valvar) }\end{array}$ & 8 & 23 & & & & & & & \\
\hline
\end{tabular}

\subsection{Descritores de Comunidade e Tamanho ponderado}

Quando as observações feitas em todas as estações oceanográficas são organizadas em um gradiente de biomassa total (Figura 5 e Figura 6) é possível comparar como a [chl] e o tamanho médio dos organismos ponderado por carbono $\left(\mathrm{CT}^{\mathrm{B}}\right)$ variam. Na superfície, a [chl] (Figura 5B) aumenta conforme progride-se para estações com maior biomassa (Figura $5 A)$. Contudo, $\circ C^{B}$ apresenta maiores valores em estações com biomassa medianas (Figura 5C). Na PFMC, o padrão é o oposto, os maiores valores de [chl] (Figura 6B) são observados em estações que apresentam biomassa mediana, e o $\mathrm{CT}^{\mathrm{B}}$ aumenta nas estações com maior biomassa (Figura $6 \mathrm{C}$ ). É 
importante ressaltar que as medidas são independentes e que o contraste observado é resultado, dentre outras coisas, do desenho amostral.

$\mathrm{O} \mathrm{CT}^{\mathrm{B}}$ foi maior na superfície (ANOVA, $\mathrm{p}=0.026, \mathrm{n}=49$ ), com uma média de $42.95 \pm 36.51 \mu \mathrm{m}$ e atingindo o máximo de $\mathrm{CT}^{\mathrm{B}}$ observado para as amostras $(149 \mu \mathrm{m})$. Na PFMC, o valor médio de $\mathrm{CT}^{\mathrm{B}}$ foi $23.18 \pm 21.58 \mu \mathrm{m}$, enquanto que o valor máximo observado para esta profundidade foi de $82.31 \mu \mathrm{m}$.
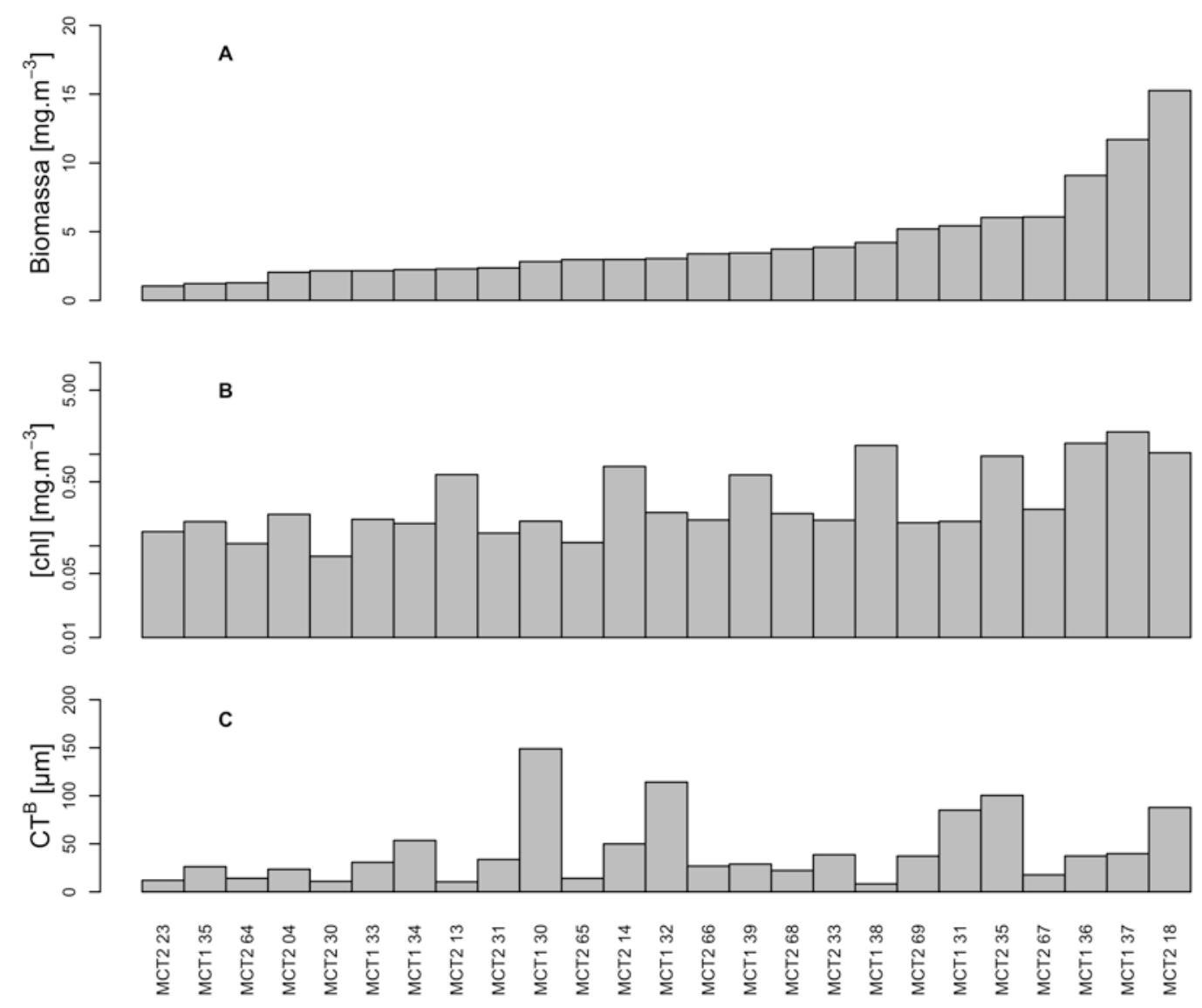

Figura 5: Distribuição das estações oceanográficas alinhadas de acordo com a biomassa total da comunidade fitoplanctônica para a Superfície. A) Biomassa [mgC. $\mathrm{m}^{-3}$ ]; B) [chl] $\left[\mathrm{mg} \cdot \mathrm{m}^{-3}\right.$ ] em escala logarítmica; C) Comprimento Total ponderado pela Biomassa $\left(\mathrm{CT}^{\mathrm{B}}\right)$. 

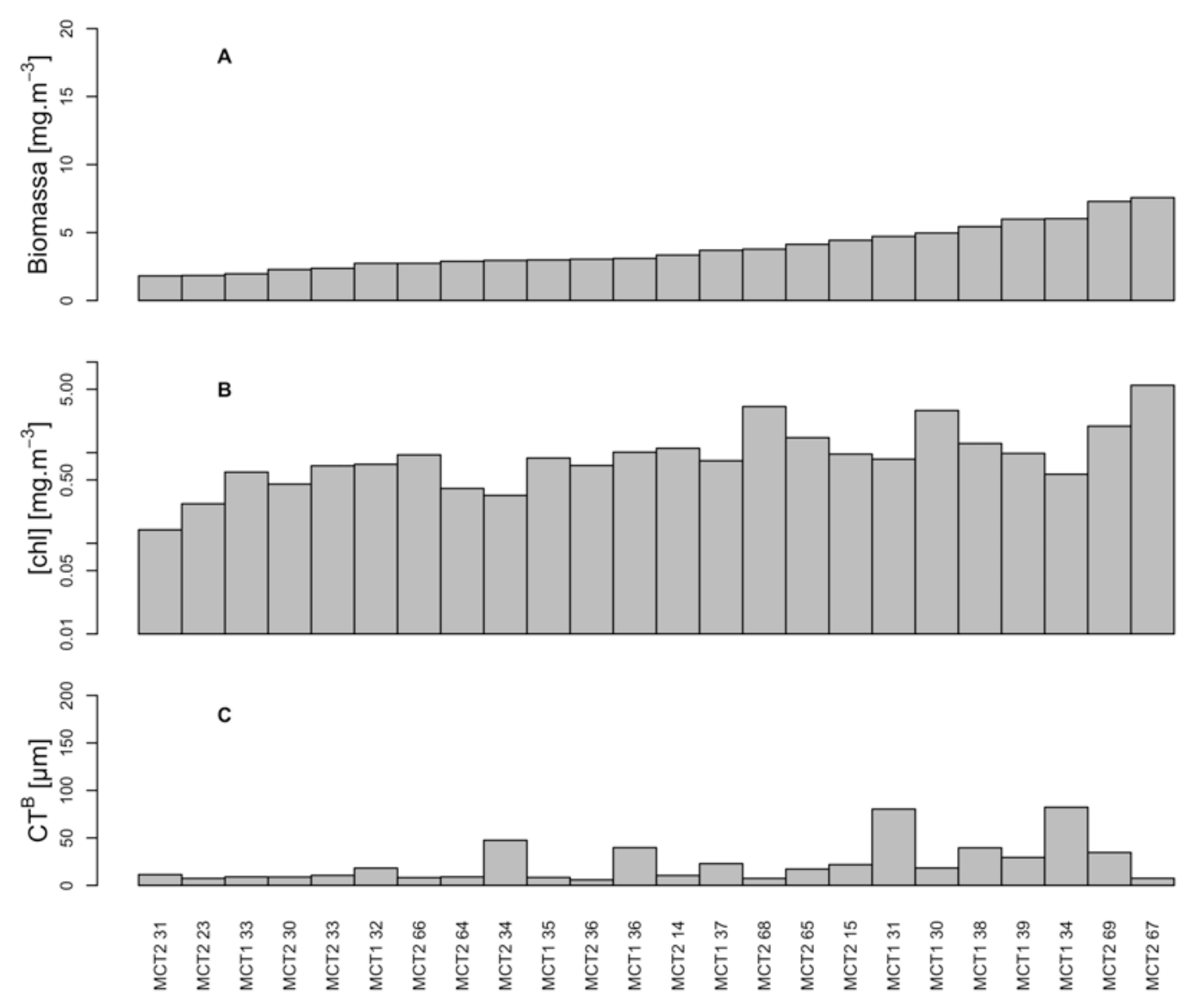

Figura 6: Distribuição das estações oceanográficas alinhadas de acordo com a biomassa total da comunidade fitoplanctônica para a PFMC. A) Biomassa [mgC. ${ }^{-3}$ ]; B) [chl] [mg. $\mathrm{m}^{-3}$ ] em escala logarítmica; C) Comprimento Total ponderado pela Biomassa $\left(\mathrm{CT}^{\mathrm{B}}\right)$.

De maneira mais quantitativa, $0 \mathrm{CT}^{\mathrm{B}}$ apresentou relação positiva com a biomassa (Figura 7A) na PFMC $\left(R^{2}=0.26, p=0.011\right)$, enquanto que na superfície, foi obtido um $\mathrm{R}^{2}=0.17$, porém essa relação foi marginalmente significativa $(p=0.043)$. O aumento no $n$ amostral ou o melhor detalhamento em tamanho dos organismos menores que $5 \mu \mathrm{m}$ pode melhorar essa relação. Quando comparado com a [chl], o CTB não apresentou relação significativa ( $p>0.05)$ em ambas as profundidades. 

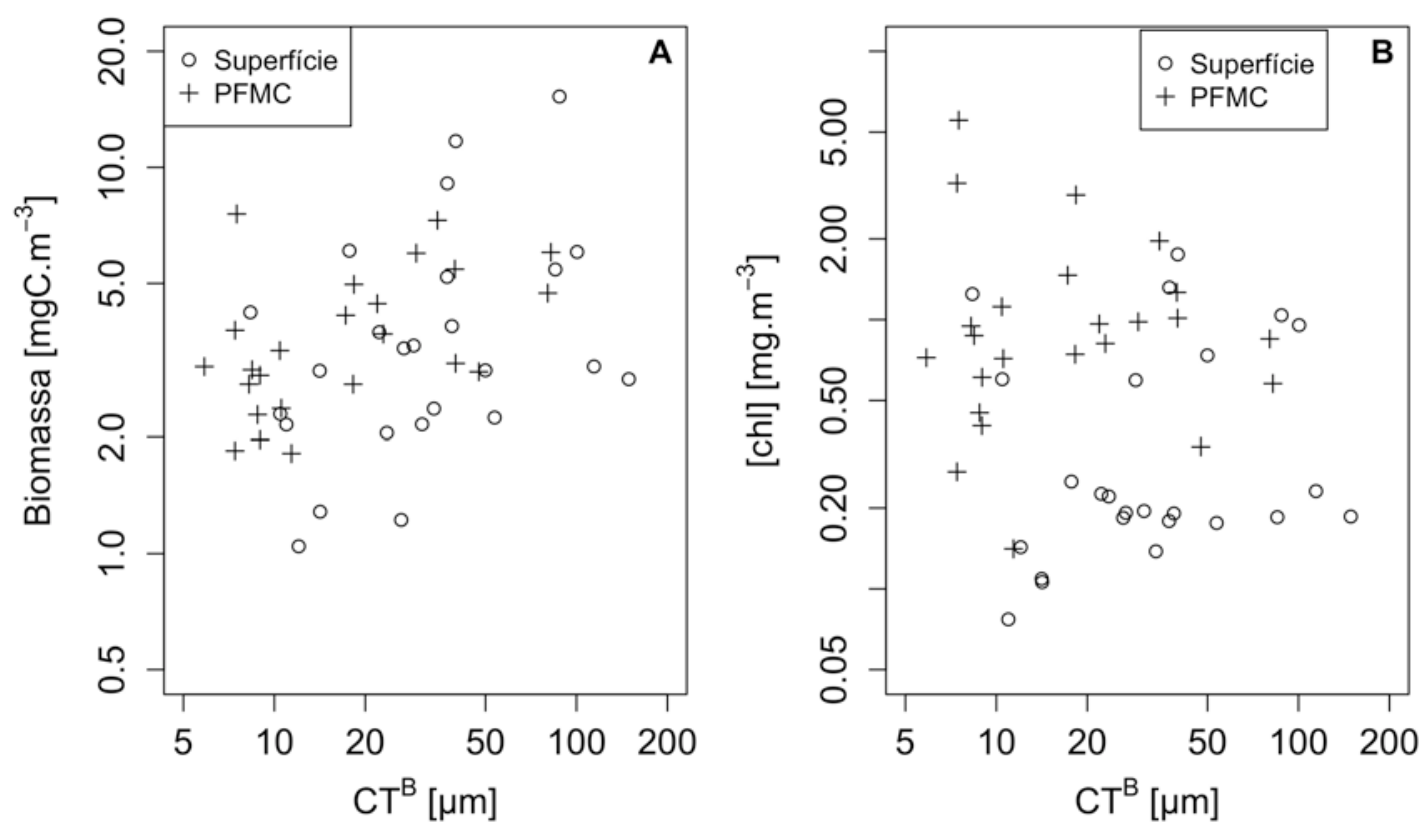

Figura 7: Relação entre $O C T^{B}$ e a Biomassa (A) e a [chl] (B). Todos os eixos estão em escala logarítmica.

A biomassa fitoplanctônica não apresentou diferença significativa entre os diferentes grupos taxonômicos na superfície e na PFMC (ANOVA, p>0.05). Para essa análise, a biomassa do ultra+picoplâncton foi removida, uma vez que a mesma foi estimada através da concentração de pigmentos. Embora não tenha apresentado diferença estatística, os maiores valores de biomassa (acima de 2 mgC.m-3) ocorreram apenas entre os Flagelados (FL), Diatomáceas Isoladas (DI) e os Dinoflagelados Tecados (DT), na superfície (Figura 8A). Na PFMC, os maiores valores de biomassa foram observados apenas nos grupos das Diatomáceas em Cadeia (DC) (Figura 8B). 

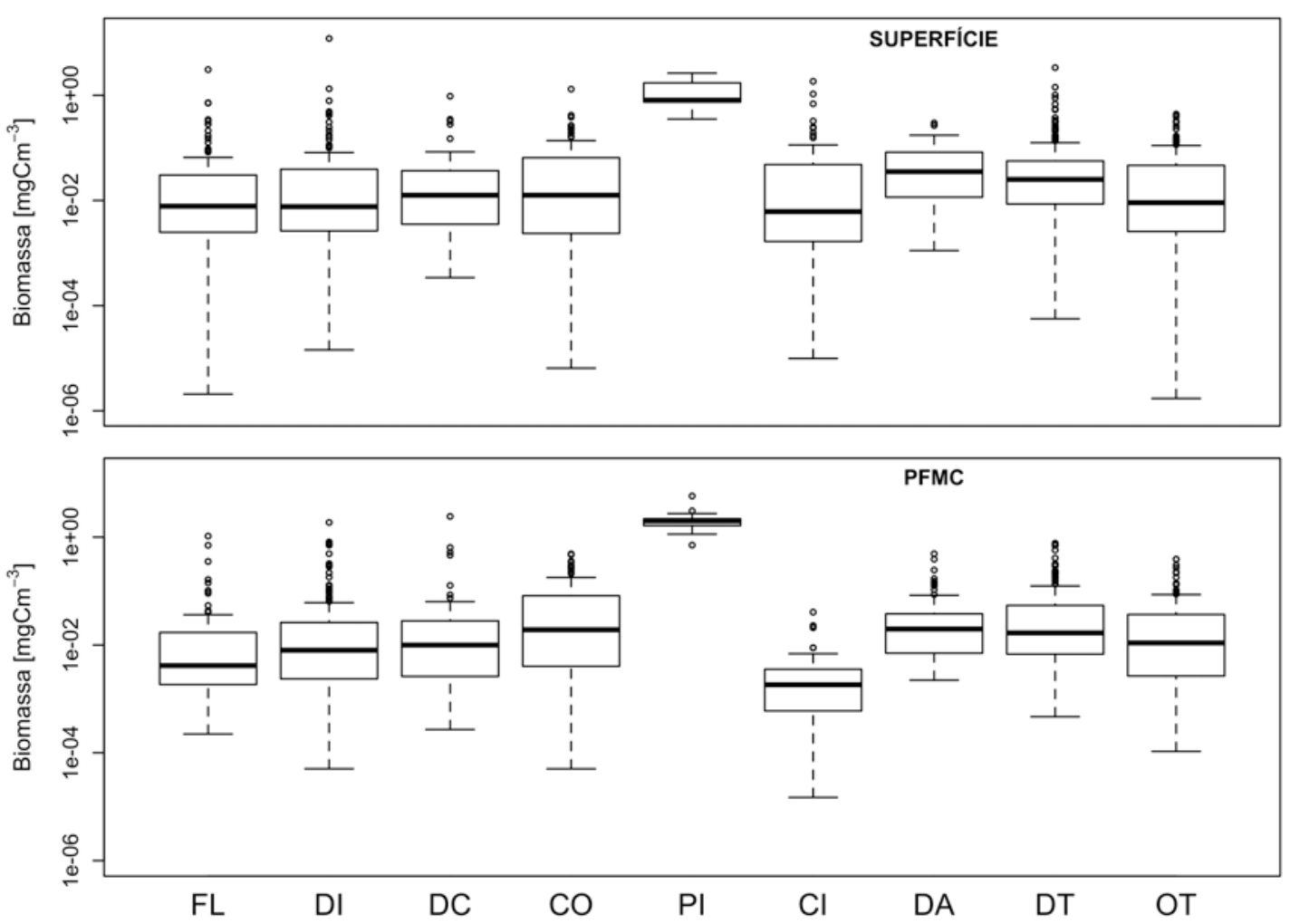

Figura 8: Distribuição da Biomassa celular entre os diferentes grupos taxonômicos na superfície (A) e na PFMC (B). Valores de biomassa em escala logarítmica.

Analisando-se a biomassa entre os morfotipos geométricos, não foi possível estabelecer diferença estatística de um morfotipo em relação a todos os outros (ANOVA). Contudo, em alguns casos, a biomassa foi diferente da maioria dos outros morfotipos. Na superfície, os morfotipos Prisma Elíptico com constrição transapical $(12-\mathrm{H})$ e Prisma Paralelogramo (13-H) valores de biomassa significativamente diferente de outros 9 e 12 morfotipos, respectivamente (Figura 9A). Ainda em superfície, os maiores valores de biomassa ocorreram nos morfotipos Esfera (1-H), Elipsóide (3-H) e Cilindro (4-H). Na PFMC, o morfotipo Cone (7-H) foi o menos abundante, por isso sua menor variação. $\mathrm{Na}$ PFMC, a variação dos valores de biomassa entre todos os morfotipos foi muito semelhante, impossibilitando estabelecer diferenças da biomassa entre os morfotipos (Figura 9B). 

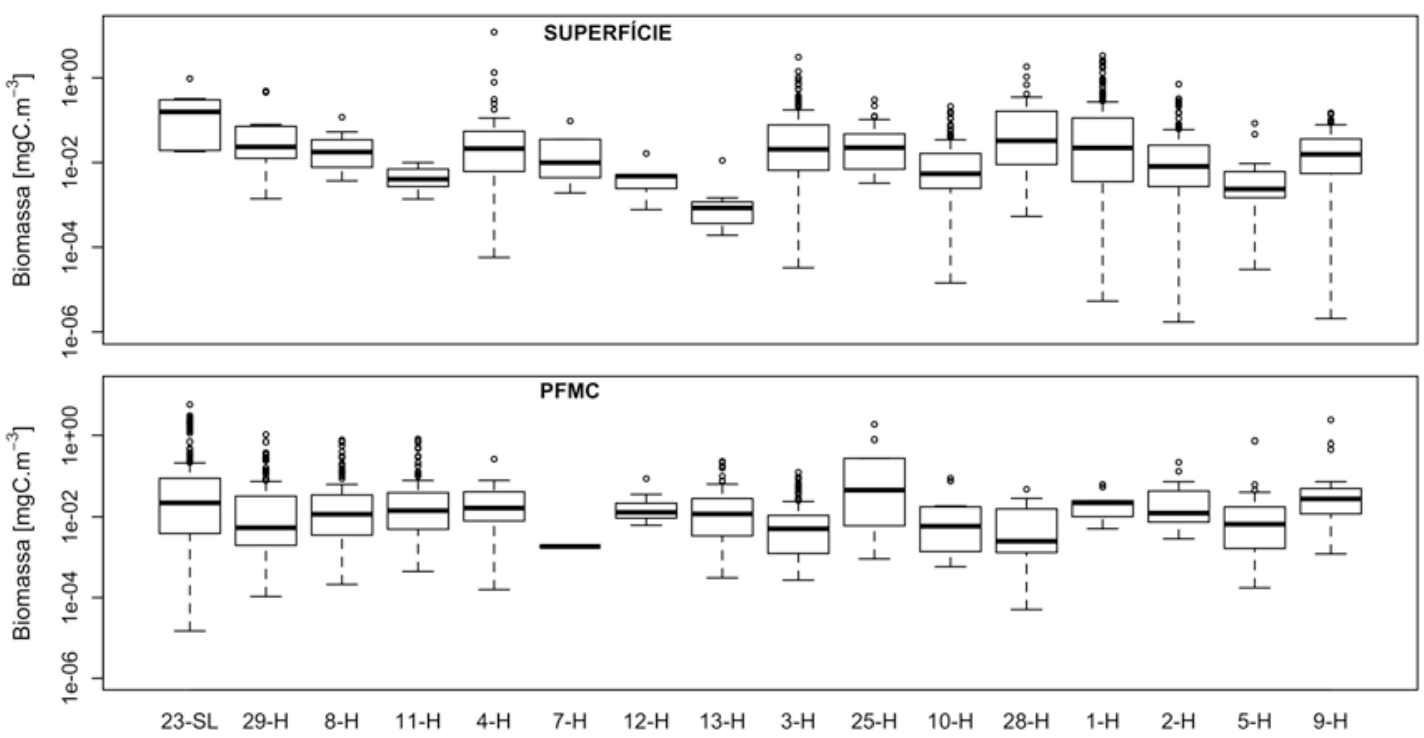

Figura 9: Distribuição da Biomassa celular entre os diferentes morfotipos celulares na superfície (A) e na PFMC (B). A organização dos morfotipos está de acordo com sua razão $S / V$, seguindo os valores de superfície, aumentando da esquerda para a direita do gráfico. Valores de biomassa em escala logarítmica.

Para identificar a contribuição de cada grupo taxonômico no acúmulo de biomassa (carbono), as estações oceanográficas foram apresentadas em ordem crescente de biomassa na superfície e PFMC (Figura 10 e Figura 11, respectivamente). $\mathrm{Na}$ superfície, as estações com maior biomassa apresentaram dominância de Diatomáceas Isoladas (DI) (Figura 10B) e de Dinoflagelados Tecados (DT) (Figura 10H) e Flagelados (FL) (Figura 10A). Nota-se, também, que a contribuição de Diatomáceas e Dinoflagelados nas estações é alternada. Contudo, para os outros grupos, as contribuições foram pontuais ao longo do gradiente de biomassa das estações.

A contribuição estimada do pico+ultraplâncton motrou-se semelhante em todas as estações da superfície, mantendo valores próximos a $2 \mathrm{mgC} \cdot \mathrm{m}^{-3}$ (Figura 10E). Na PFMC (Figura 11) as Diatomáceas em Cadeia (DC) e os Dinoflagelados Tecados (DT) contribuem significativamente para a biomassa da estação com maior biomassa (Figura 11C e Figura 11H, respectivamente). Assim como na superfície, a biomassa estimada para o pico+ultraplâncton foi semelhante em todas as estações (Figura 11E) mas enfatiza-se que esses resultados devem ser analisados com cautela uma vez que foram empiricamente determinadas pela [chl]. A biomassa dos outros grupos taxonômicos foi menor que $1 \mathrm{mgC} \cdot \mathrm{m}^{-3}$, apresentando variações entre as estações independente do gradiente de biomassa. 

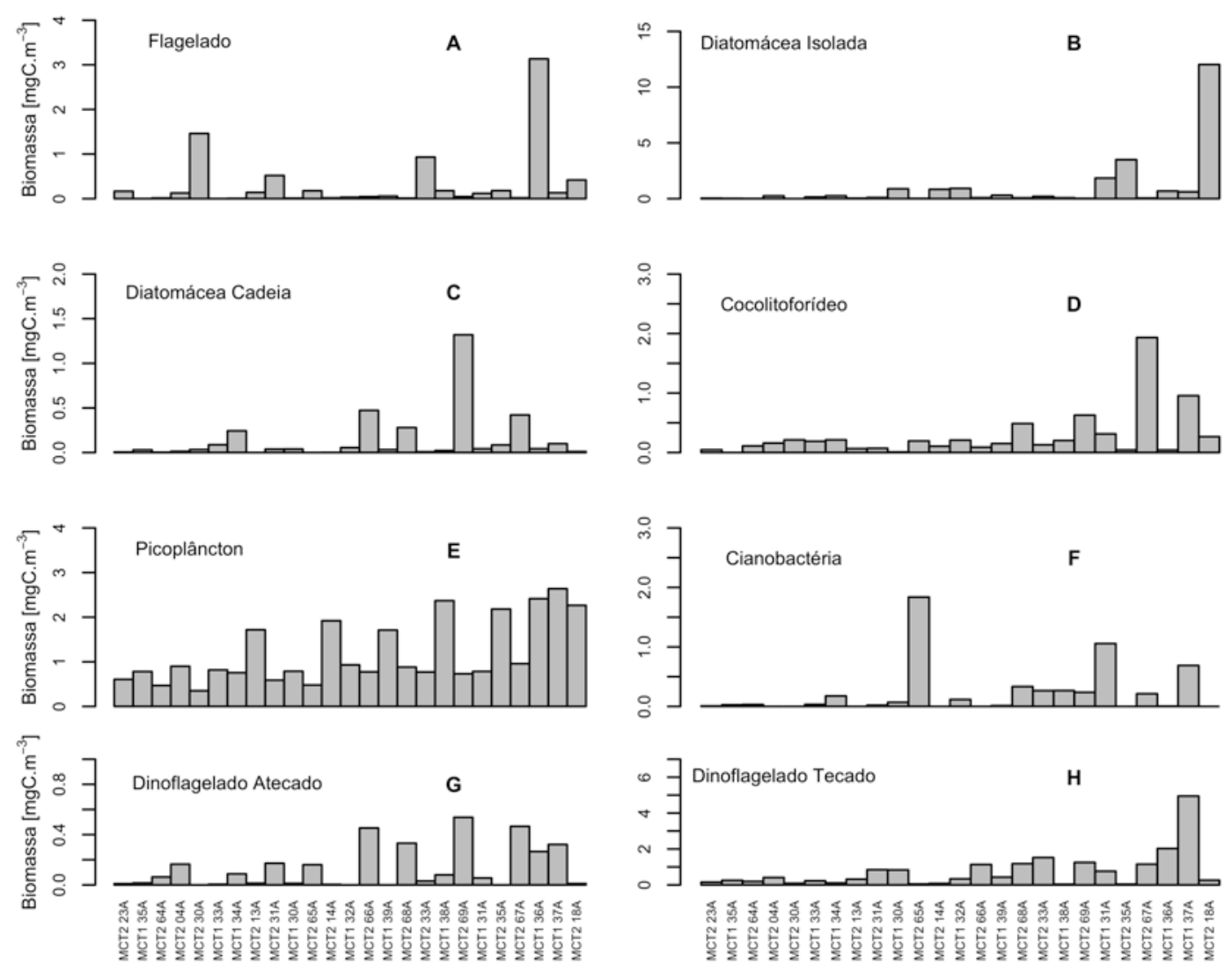

Figura 10: Distribuição da biomassa fitoplanctônica $\left[\mathrm{mg} \cdot \mathrm{m}^{-3}\right.$ ] dividida entre os grupos taxonômicos encontrados em cada estação oceanográfica na superfície - notar diferença de escalas. As estações (eixo x) estão alinhadas de acordo com a biomassa total da estação, ou seja, da estação com menor biomassa (esquerda) para a estação com maior biomassa (direita). 

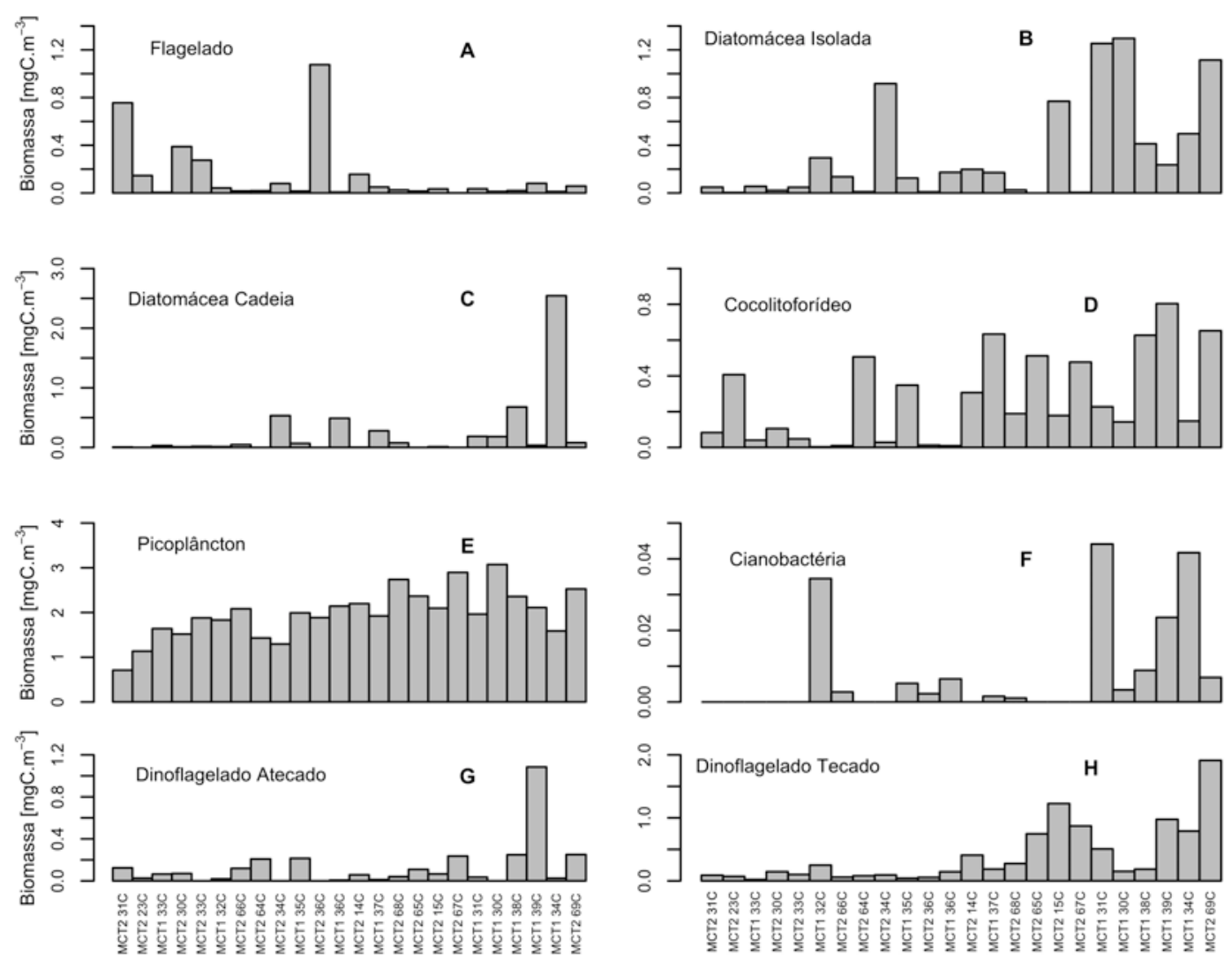

Figura 11: Distribuição da biomassa fitoplanctônica $\left[\mathrm{mg} \cdot \mathrm{m}^{-3}\right.$ ] dividida entre os grupos taxonômicos encontrados em cada estação oceanográfica na PFMC - notar diferença de escalas. As estações (eixo x) estão alinhadas de acordo com a biomassa total da estação, ou seja, da estação com menor biomassa (esquerda) para a estação com maior biomassa (direita).

A contribuição dos morfotipos fitoplanctônicos para a biomassa total (Figuras 12 a 15) mostra que as maiores contribuições no acúmulo de biomassa foram dos morfotipos Esfera (1-H) (Figuras 12A e 12C) e Elipsóide (3-H) (Figuras 14A e 14C), sendo que os morfotipos Cilindro (4-H) (Figuras 12D e 14D), Cilindro valvar (28-H) (Figuras 13G e 15G) e Prisma Elíptico (11H) (Figuras 13B e 15B) apresentam altos valores de biomassa apenas em algumas estações. A maioria dos morfotipos manteve biomassa abaixo de 1 $\mathrm{mgC} \cdot \mathrm{m}^{-3}$ em todas as estações oceanográficas de superfície (Figuras $12 \mathrm{e}$ 13). Na PFMC, a maior contribuição para a biomassa foi semelhante à superfície, sendo as contribuições dos morfotipos Esfera (1-H) e Elipsóide (3$\mathrm{H}$ ) as mais substanciais (Figuras 14A e 14C). Contribuições pontuais de alta biomassa são observadas para o morfotipo Cilindro (4-H) (Figura 14D) e Prisma alongado valvar $(29-\mathrm{H})$ (Figura $15 \mathrm{H})$. Todos os demais morfotipos 
apresentaram valores de carbono orgânico menores que 1 mg.m ${ }^{-3}$ (Figuras 14 e 15).
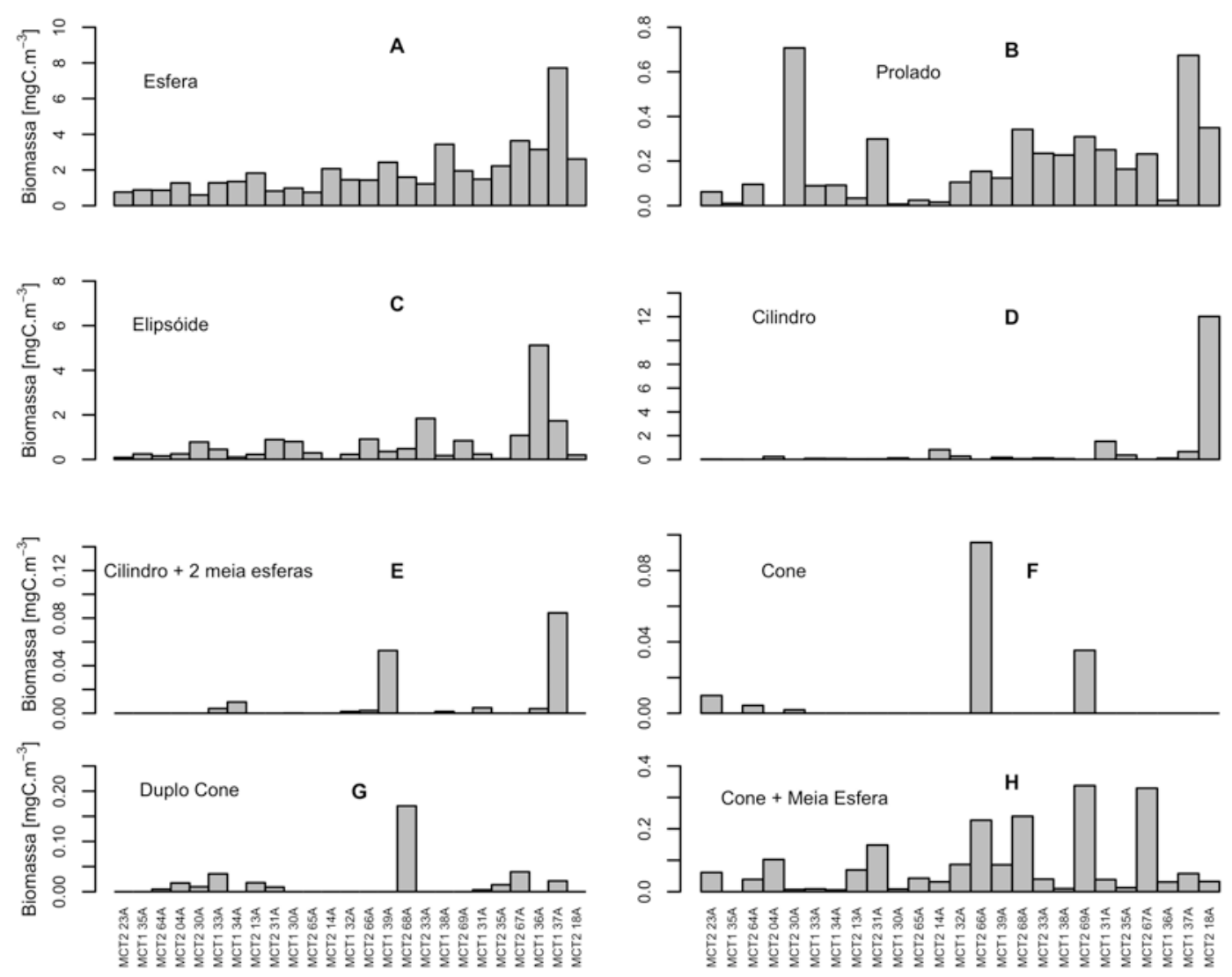

Figura 12: Distribuição da biomassa fitoplanctônica [mg. $\mathrm{m}^{-3}$ ] dividida entre os morfotipos encontrados em cada estação oceanográfica na superfície. As estações (eixo x) estão alinhadas de acordo com a biomassa total da estação, ou seja, da estação com menor biomassa (esquerda) para a estação com maior biomassa (direita) - notar diferença de escalas. 

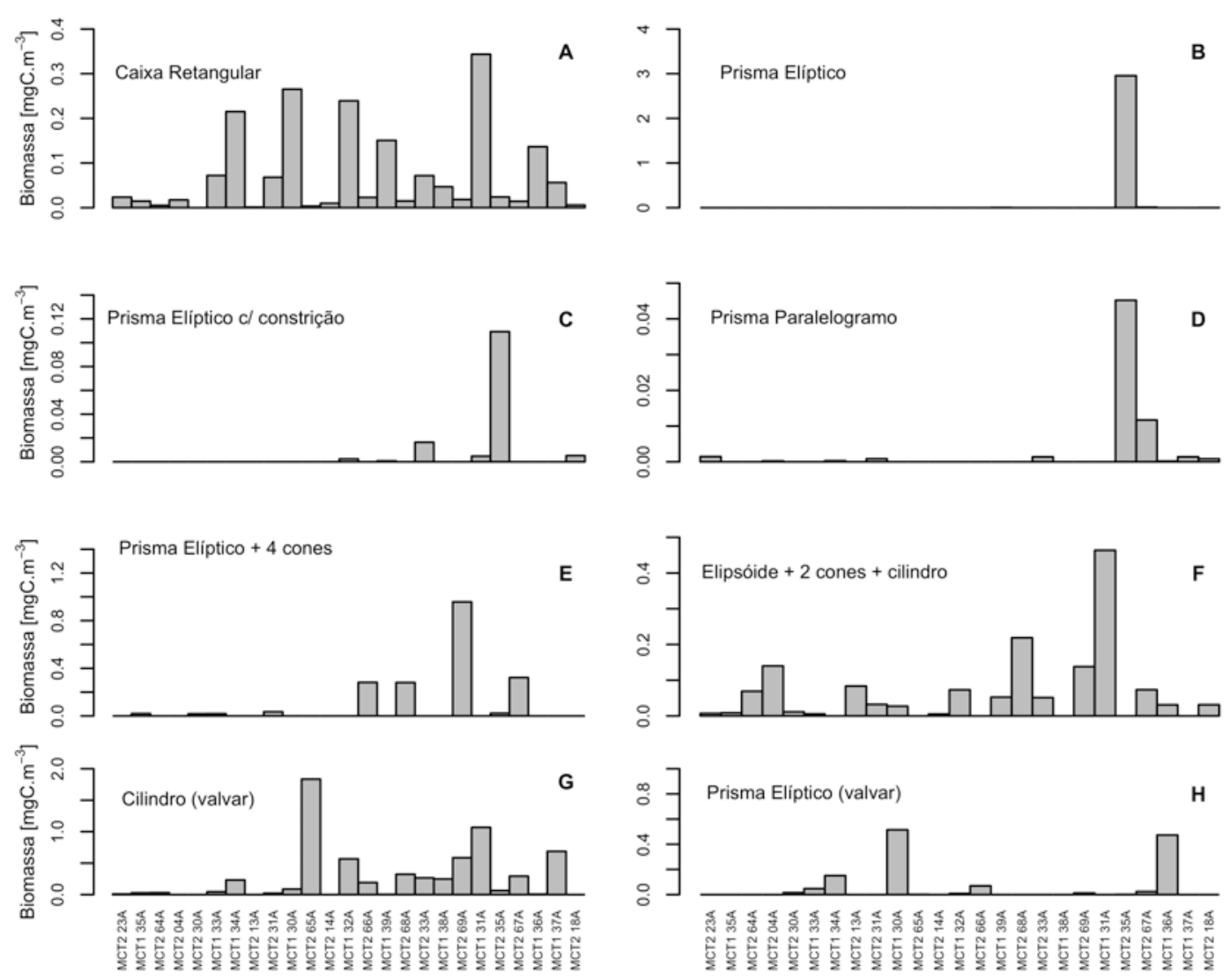

Figura 13: Continuação da Figura 12. Mantido o mesmo enunciado. - notar diferença de escalas. 

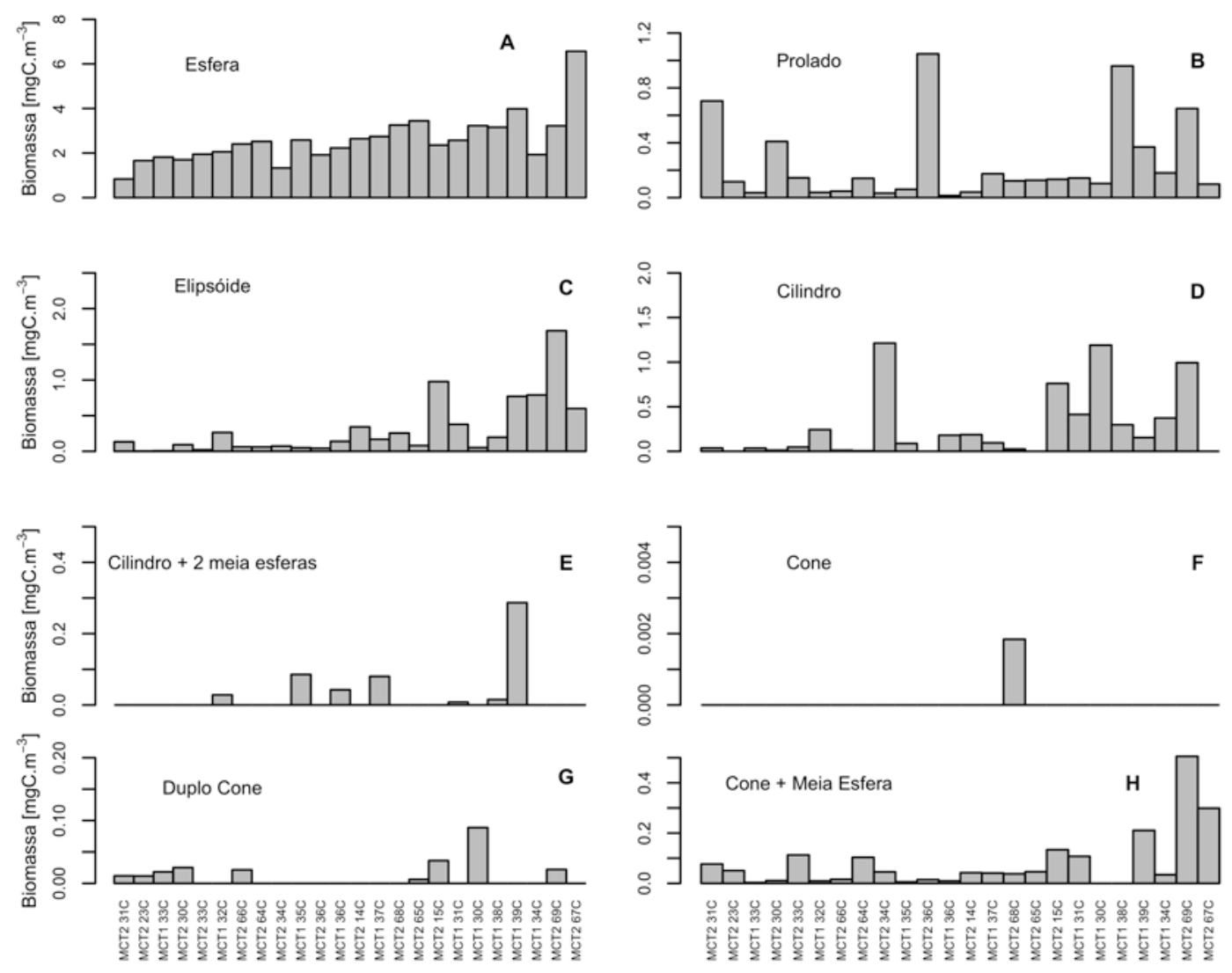

Figura 14: Distribuição da biomassa fitoplanctônica $\left[\mathrm{mg} \cdot \mathrm{m}^{-3}\right.$ ] dividida entre os morfotipos encontrados em cada estação oceanográfica na PFMC. As estações (eixo $\mathrm{x}$ ) estão alinhadas de acordo com a biomassa total da estação, ou seja, da estação com menor biomassa (esquerda) para a estação com maior biomassa (direita). - notar diferença de escalas. 

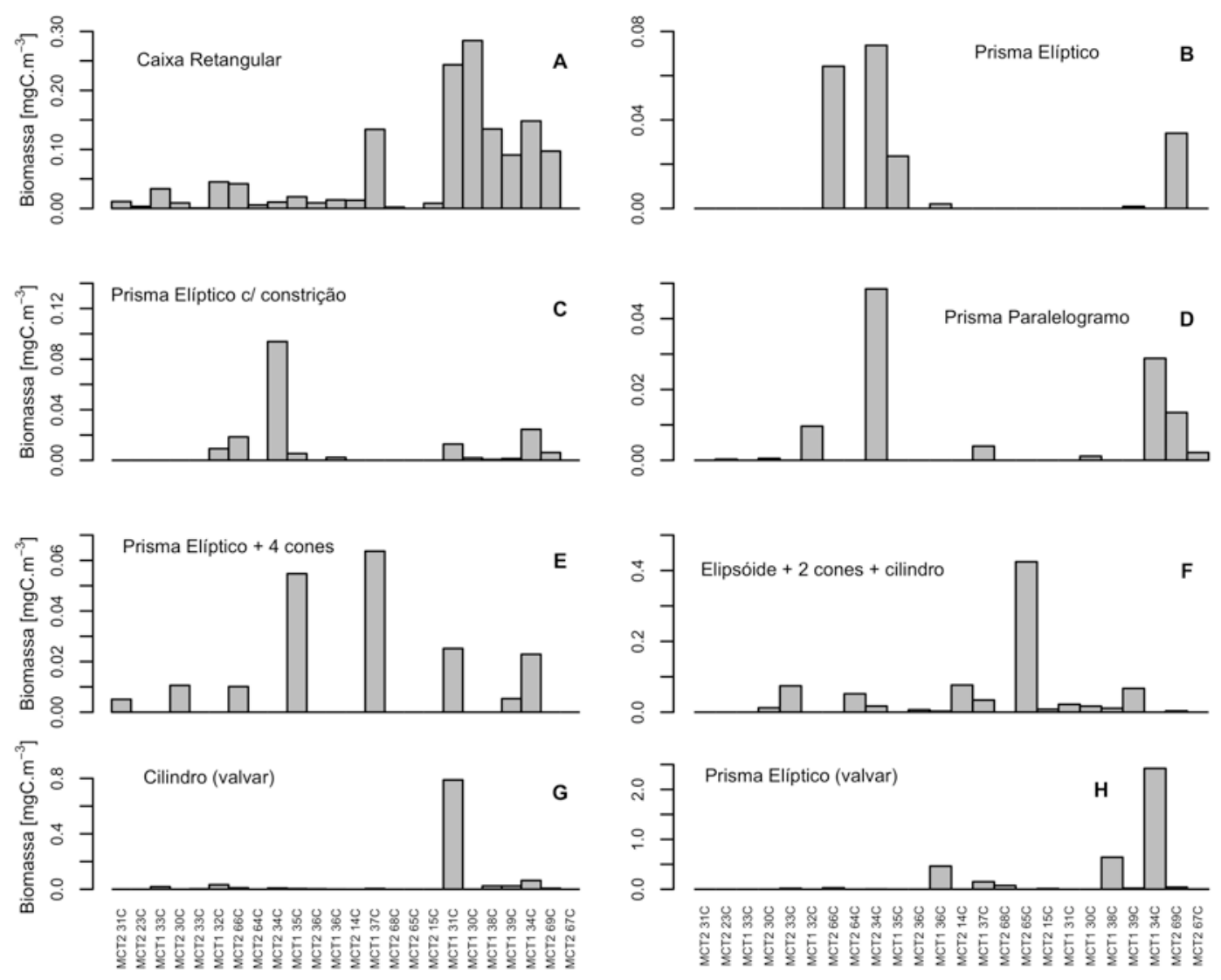

Figura 15: Continuação da Figura 14. O mesmo enunciado mantido. - notar diferença de escalas.

\subsection{Razão S/V}

A razão Superfície/Volume (S/V) dos morfotipos fitoplanctônicos analisados é esperada decrescer com o tamanho do organismo. Curvas teóricas podem ser construídas entre $S / N$ e o comprimento total do organismos (CT, $\mu \mathrm{m})$. Essas curvas ilustram funções exponenciais, desde que as proporções de medidas de cada morfotipo se mantenham constantes no gradiente de tamanho (Figura 16). No morfotipo Cone + meia esfera, o incremento em volume resultado do aumento do CT é proporcional ao incremento em superfície, resultando em uma razão S/V constante e destacadamente alta em relação aos demais morfotipos. Outros morfotipos como o Elipsóide + 2 cones + cilindro e o Cone apresentam alta S/N, enquanto que a Esfera apresenta a menor razão S/V dentre os 16 morfotipos analisados. 


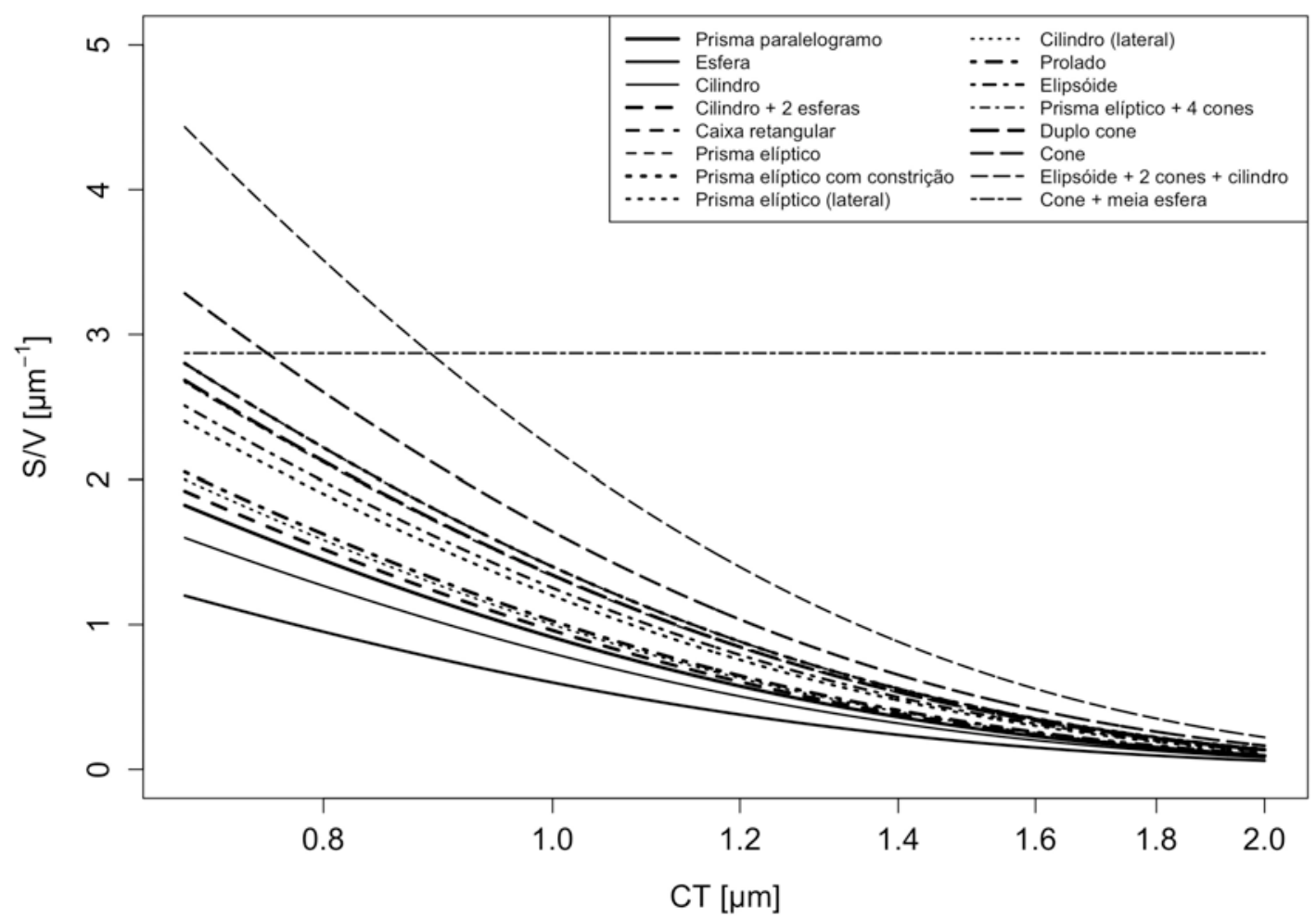

Figura 16: Relação $S / V$ hipotética entre os morfotipos fitoplanctônicos encontrados. As equações de cada morfotipo seguiram o apresentado por Sun e Liu (2003) e foram calculadas em um gradiente de CT de 5 a $100 \mu \mathrm{m}$ em intervalos de $0.1 \mu \mathrm{m}$. A largura e profundidade de cada forma foram estipulados como sendo metade do comprimento total e $1 / 3$ do comprimento total, respectivamente. Morfotipos com múltiplas formas geométricas mantiveram a mesma proporção entre dimensões. O CT (eixo x) está demonstrado em escala logarítmica $\left(\log _{10}\right)$.

Nas amostras de superfície (Figura 17), abaixo dos $20 \mu \mathrm{m}$ de CT, as maiores razões $S / V$ são observadas entre as formas mais "robustas", isto é, Esferas, Prolados, Elipsóides, Cone + meia esfera (Figuras 17A e 17B). Com o aumento de CT, formas "planas" (Caixa Retangular, Prisma Elíptico, Prisma Elíptico com constrição transapical, Prisma Paralelogramo) e as formas compostas passam a apresentar as maiores razões S/N (Figuras 17C e 17D).

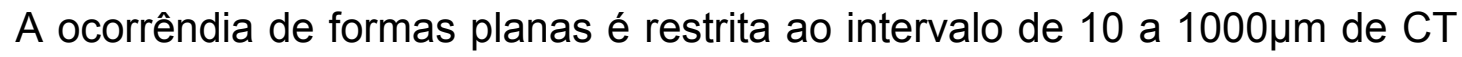
(Figura 17C). Os mesmos padrões de S/V em função do CT são observados para a PFMC (Figura 18). Ressalta-se que o morfotipo Cone + meia esfera apresentou os maiores valores de $S / V$ (aproximadamente $3.5 \mu \mathrm{m}^{-1}$ ) para o

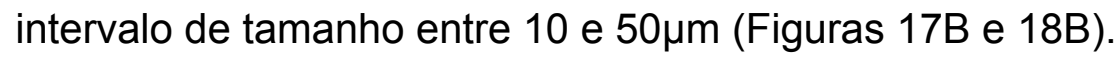



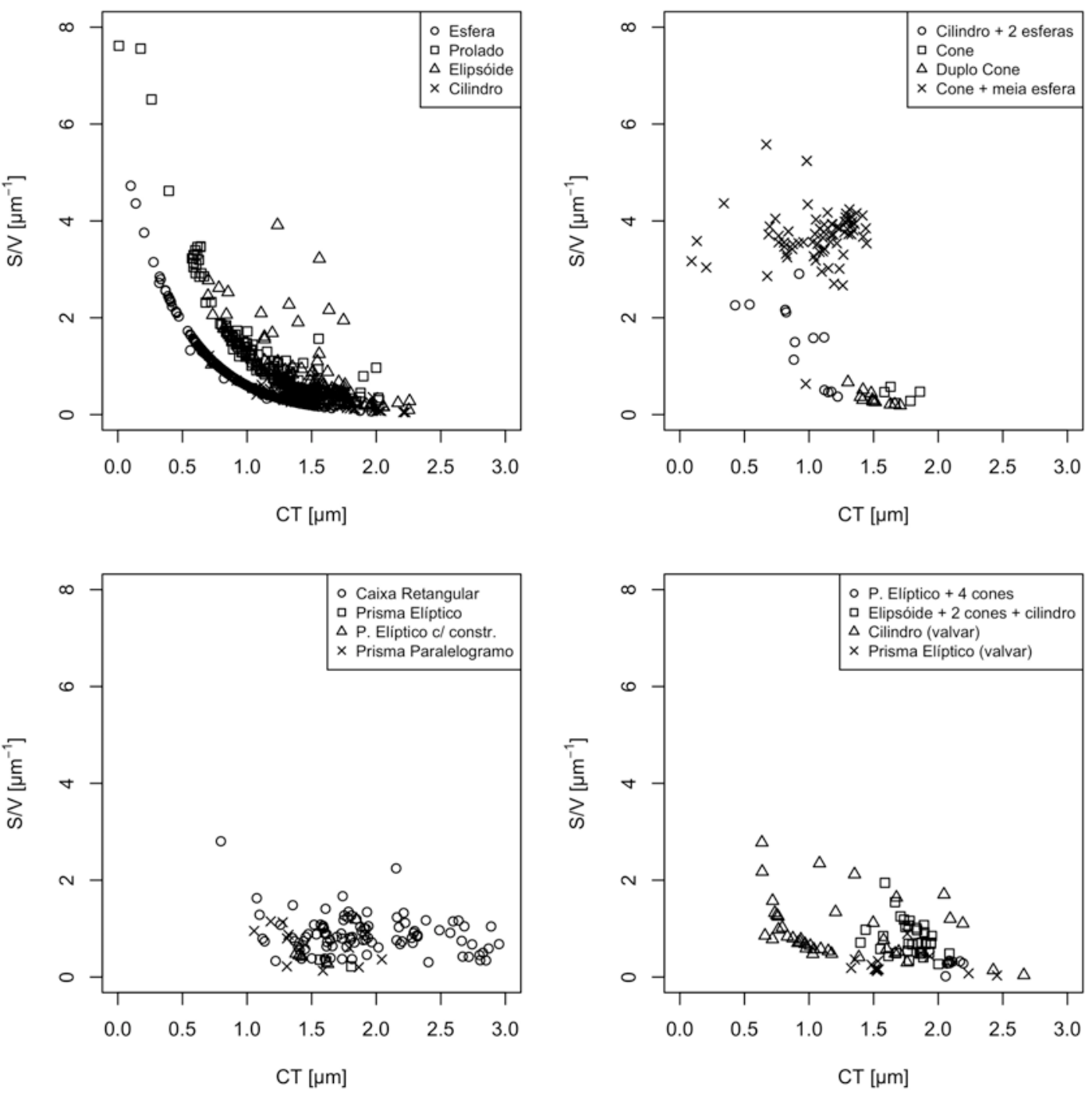

Figura 17: Relação entre a razão $S / V\left[u m^{-1}\right]$ para os organismos encontrados e o seu CT $[u \mathrm{~m}]$. Os organismos estão divididos em seus respectivos morfotipos geométricos e correspondem ao banco de dados da Superfície $(3-5 \mathrm{~m})$. Destaque para o CT (eixo x) apresentado em escala logarítimica $\left(\log _{10}\right)$. 

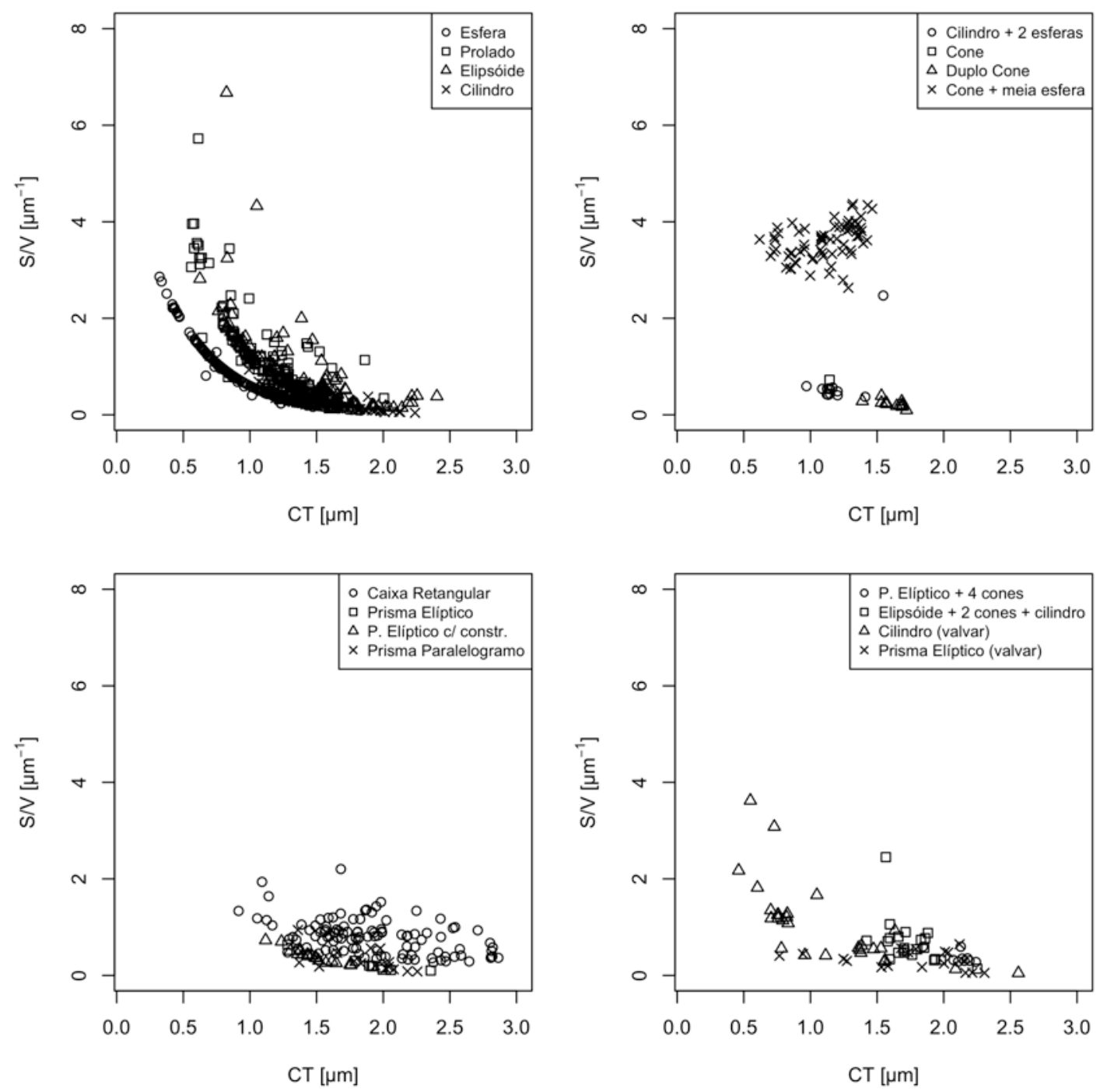

Figura 18: Relação entre a razão $S / V\left[u m^{-1}\right]$ para os organismos encontrados e o seu CT [um]. Os organismos estão divididos em seus respectivos morfotipos geométricos e correspondem ao banco de dados da PFMC (profundidade variável). Destaque para o CT (eixo $\mathrm{x}$ ) apresentado em escala logarítimica $\left(\log _{10}\right)$.

Os resultados mostram grande variabilidade nas razões S/V dentro de um mesmo grupo taxonômico (Figura 19), todavia alguns padrões observados merecem destaque. Na PFMC (Figura 19B), existem intervalos de razões de $S / V$ que são compartilhados por apenas dois grupos (Cocolitoforídeos (CO) e Diatomáceas em Cadeia (DC)) (ANOVA, Tukey posthoc, $\mathrm{p}<0.001, \mathrm{n}=334$ ). Na superfície (Figura 19A), contudo, intervalos na razão S/N são compartilhados entre, pelo menos, 3 grupos distintos. A grande quantidade de "outliers" nas razões S/V de Dinoflagelados Tecados (DT) correspondem ao morfotipo 9-H (Cone + meia esfera), uma vez que o morfotipo apresentou valores na razão S/V maiores que os demais (Figura 
19A e 19B) e sua ocorrência é maior dentre os Dinoflagelados Tecados (Tabela 6).
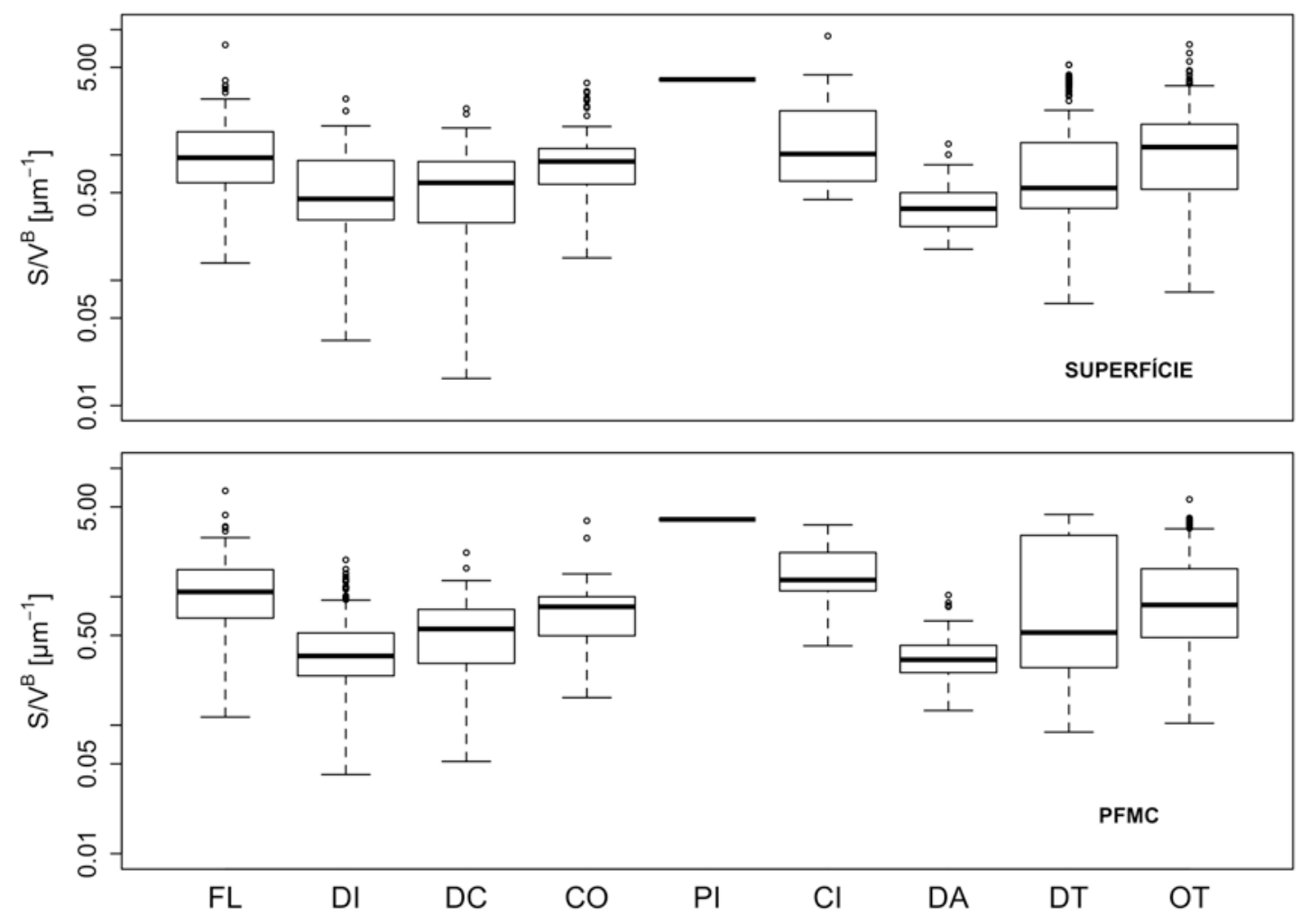

Figura 19: Distribuição da razão Superfície/Volume (S/V) entre os grupos fitoplanctônicos. $\mathrm{FL}=$ Flagelados, $\mathrm{DI}=$ Diatomáceas Isoladas, $\mathrm{DC}=$ Diatomáceas em Cadeia, $\mathrm{CO}=$ Cocolitoforídeos, $\mathrm{Cl}=$ Cianobactérias, $\mathrm{DA}=$ Dinoflagelados Atecados, $\mathrm{DT}=$ Dinoflagelados Tecados, OT=Outras espécies. A razão $S / N$ (eixo y) está representada em escala logarítmica. Os grupos taxonômicos estão alinhados de acordo com sua taxa de crescimento.

A razão S/V apresentou diferença entre alguns morfotipos, entretanto, apenas o morfotipo Cone + meia esfera $(9-\mathrm{H})$ apresentou intervalos de S/V diferente de todos os outros morfotipos nas duas profundidades (ANOVA, p<0.01, Tukey posthoc) (Figura 20A e 20B). A razão S/V média para o morfotipo Cone + meia esfera $(9-\mathrm{H})$ foi de $3.12 \pm 0.33 \mu \mathrm{m}^{-1}$. As formas mais simples (Esfera (1-H), Prolado $(2-\mathrm{H})$ e Elipsóide $(3-\mathrm{H}))$ ocorreram em maior quantidade e em diversas classes de tamanho, o que explica sua alta variabilidade nos valores de S/V (Figura 20A e 20B). 


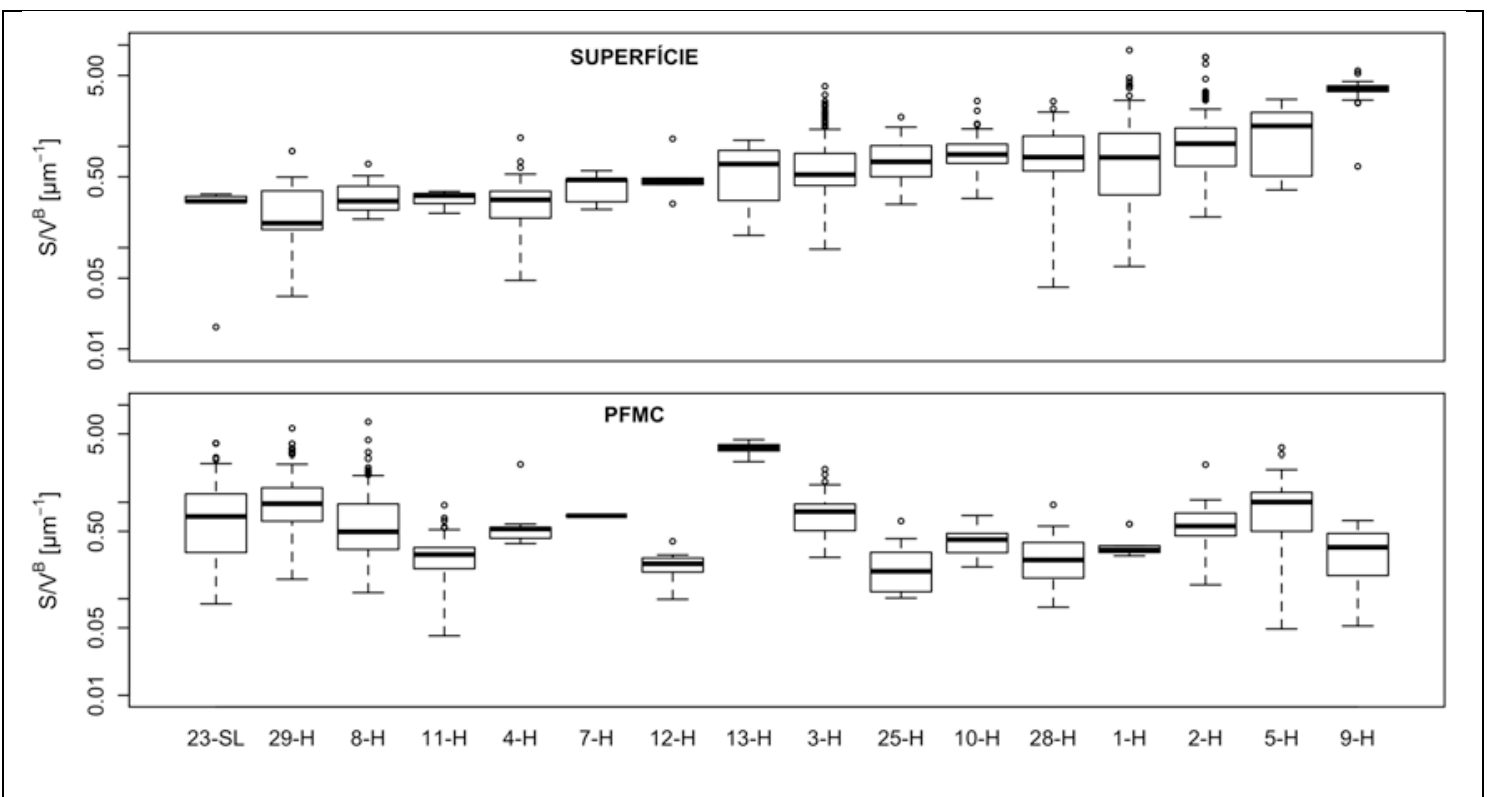

Figura 20: Distribuição da razão Superfície/Volume (S/V) entre os morfotipos geométricos. Os morfotipos estão representados pelos seus símbolos, veja Índice de Símbolos para detalhes. A razão S/V (eixo y) está representada em escala logarítmica. Os morfotipos estão alinhados de acordo com sua razão $S / V$, seguindo os valores de superfície, aumentando da esquerda para a direita do gráfico.

A Biomassa apresentou relação inversa com a razão $S / N^{B}$ na superfície $\left(R^{2}=0.38, p=0.001\right)$ e na PFMC $\left(R^{2}=0.22, p=0.02\right)$. Valores de biomassa acima de $10 \mathrm{mgC} \cdot \mathrm{m}^{-3}$ ocorreram apenas no intervalo de $S / \mathrm{V}^{\mathrm{B}}$ de 0.5 a $1.5 \mu \mathrm{m}^{-1}$ (Figura 21). A estação com $15.27 \mathrm{mgC} \cdot \mathrm{m}^{-3}$ de biomassa foi dominada por Diatomáceas Isoladas, que corresponderam por $78 \%$ da biomassa total. A estação com $11.69 \mathrm{mgC} . \mathrm{m}^{-3}$ de biomassa foi dominada por Dinoflagelados Tecados, que compuseram $42 \%$ da biomassa total da comunidade. As comunidades fitoplanctônicas de plataforma continental apresentaram um intervalo de $S / V^{B}$ entre 0.6 e $3.4 \mu \mathrm{m}^{-1}$ (Figura 20). 


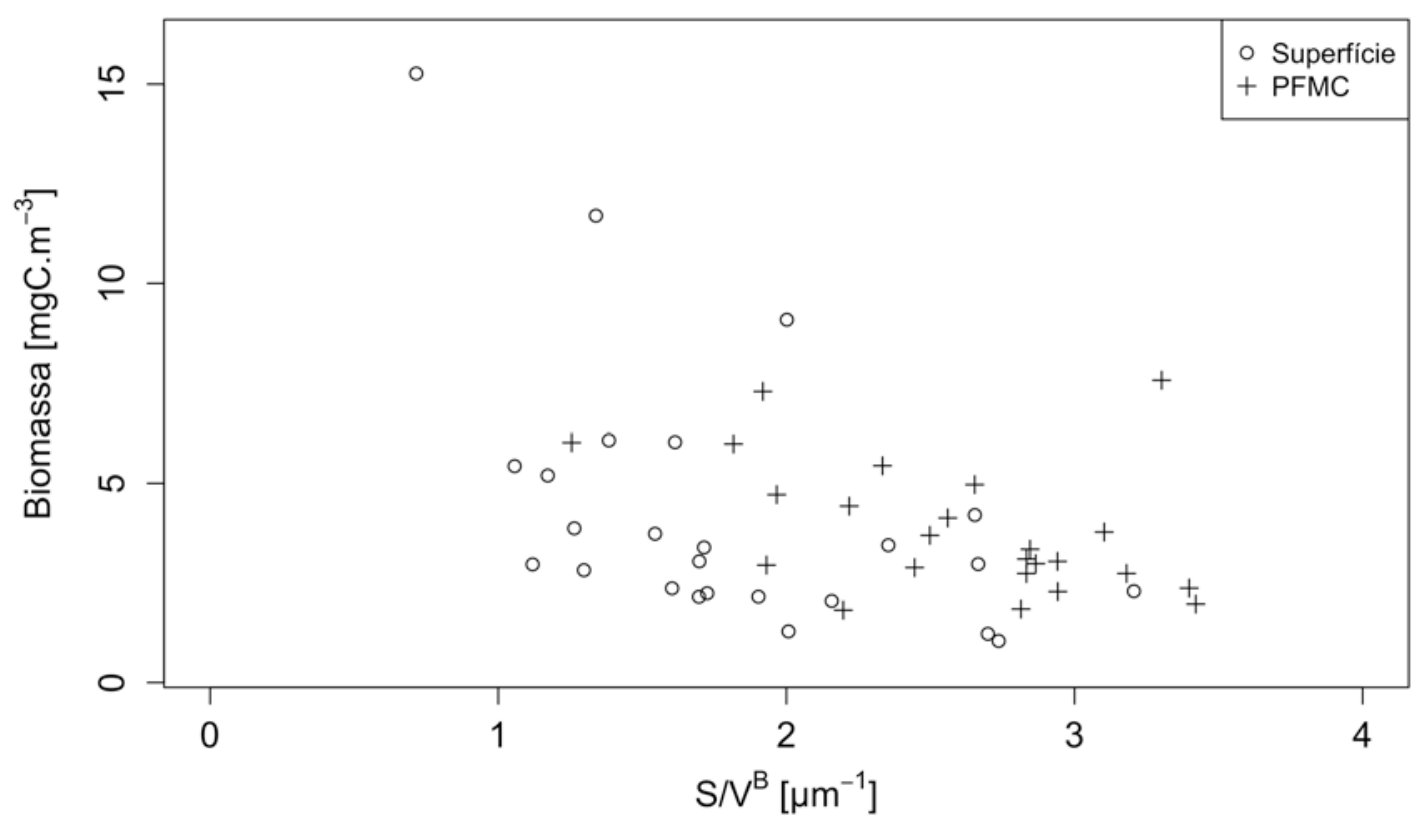

Figura 21: Relação entre a Biomassa e a razão Superfície/Volume ponderada pela biomassa $\left(S / V^{B}\right)$ para a superfície e PFMC.

\subsection{Validação de modelos Bio-óticos}

5.5.1 - Vidussi et al. (2001) e Uitz et al. (2006)

As proporções das classes de tamanho obtidas por meio da concentração de pigmentos marcadores $\left(f_{\text {micro }}, f_{\text {nano }}\right.$ e $\left.f_{\text {pico }}\right)$ e por meio de carbono ( $p_{\text {micro }}$ e $\left.p_{\text {nano }}\right)$ foram comparadas entre a superfície e a PFMC (Tabela 7). A proporção $f_{\text {micro }}$ não apresentou diferença entre as duas profundidades (ANOVA, $\mathrm{p}=0.62, \mathrm{n}=49$ ). Contudo, tanto $f_{\text {nano }}$ e $f_{\text {pico }}$ foram diferentes entre as duas profundidades $(p=0.036$ e $p=0.006$, respectivamente). A proporção $f_{\text {nano }}$ foi maior na PFMC, com valores médios de $0.29 \pm 0.18$, enquanto que $f_{\text {pico }}$ foi maior na superfície, cuja média foi de $0.40 \pm 0.16$ (Tabela 7 ). Por sua vez, $p_{\text {micro }}$ foi diferente entre superfície e PFMC, sendo maior na superfície (Tabela 7 ). Por outro lado, $p_{\text {nano }}$ foi igual entre as duas profundidades (ANOVA, $p=0.89, n=49$ ). Quando as proporções obtidas tanto por pigmentos $\left(f_{\text {micro }}\right.$ e $\left.f_{\text {nano }}\right)$ quanto por carbono $\left(p_{\text {micro }} \mathrm{e}\right.$ $p_{\text {nano }}$ ) são comparadas, observa-se diferença nas estimativas apenas para o microplâncton na PFMC (Tabela 8). 
Tabela 7: Comparação das proporções das classes de tamanho do fitoplâncton entre as duas profundidades de coleta. Os valores nas células correspondem à média e desvio padrão e os valores de $p$ obtidos através de ANOVA.

\begin{tabular}{clll}
\hline & Superfície & PFMC & \\
\hline$f_{\text {micro }}$ & $0.3970 \pm 0.1942$ & $0.4276 \pm 0.2312$ & $\mathrm{p}=0.620, \mathrm{n}=49$ \\
$f_{\text {nano }}$ & $0.1986 \pm 0.0811$ & $0.2854 \pm 0.1782$ & $\mathrm{p}=0.037, \mathrm{n}=49$ \\
$f_{\text {pico }}$ & $0.4044 \pm 0.1616$ & $0.2870 \pm 0.1199$ & $\mathrm{p}=0.006, \mathrm{n}=49$ \\
$p_{\text {micro }}$ & $0.4643 \pm 0.1996$ & $0.2334 \pm 0.1715$ & $\mathrm{p}<0.001, \mathrm{n}=49$ \\
$p_{\text {nano }}$ & $0.1970 \pm 0.1456$ & $0.1921 \pm 0.1220$ & $\mathrm{p}=0.899, \mathrm{n}=49$ \\
\hline
\end{tabular}

Tabela 8: Sumário das comparações entre as proporções das classes de tamanho do fitoplâncton. Realizado ANOVA, com significância de 0.05 .

\begin{tabular}{lll}
\hline & Superfície & PFMC \\
\hline$f_{\text {micro }}$ vs $p_{\text {micro }}$ & $\mathrm{p}=0.255, \mathrm{n}=50$ & $\mathrm{p}=0.018, \mathrm{n}=48$ \\
$f_{\text {nano }}$ vs $p_{\text {nano }}$ & $\mathrm{p}=0.946, \mathrm{n}=50$ & $\mathrm{p}=0.209, \mathrm{n}=48$ \\
\hline
\end{tabular}

\subsection{2 - Ciotti et al. (2002)}

Os valores de $S_{f}$ apresentaram padrões de distribuição distintos para superfície e PFMC (Figura 22). Na superfície, o intervalo de $S_{f}$ em que essas amostras ocorrem restringe-se de 0.2 a 1.0 , sendo os valores de 0.8 a 1.0 exclusivos às amostras da superfície (Figura 22). Os valores de $S_{f}$ para a PFMC, por outro lado, restringiram-se entre 0 e 0.8 , sendo que no intervalo de 0 a 0.2 foram encontradas apenas amostras de PFMC. Os valores de $S_{f}$ foram inversamente proporcionais à [chl] (normalizada em log) na superfície $\left(R^{2}=0.31, p=0.002\right)$ (Figura 22A), enquanto que na PFMC a relação foi marginalmente significativa $\left(R^{2}=0.19, p=0.045\right)$. A Figura 22B demonstra a relação de $S_{f}$ com a biomassa total da comunidade fitoplanctônica. $\mathrm{Na}$ superfície, não houve relação significativa, embora visualmente sigam a tendência esperada de diminuir com o aumento da biomassa. Na PFMC, $S_{f}$ diminui com o aumento de biomassa (normalizada em log), apresentando $\mathrm{R}^{2}$ de $0.21(p=0.034)$. 

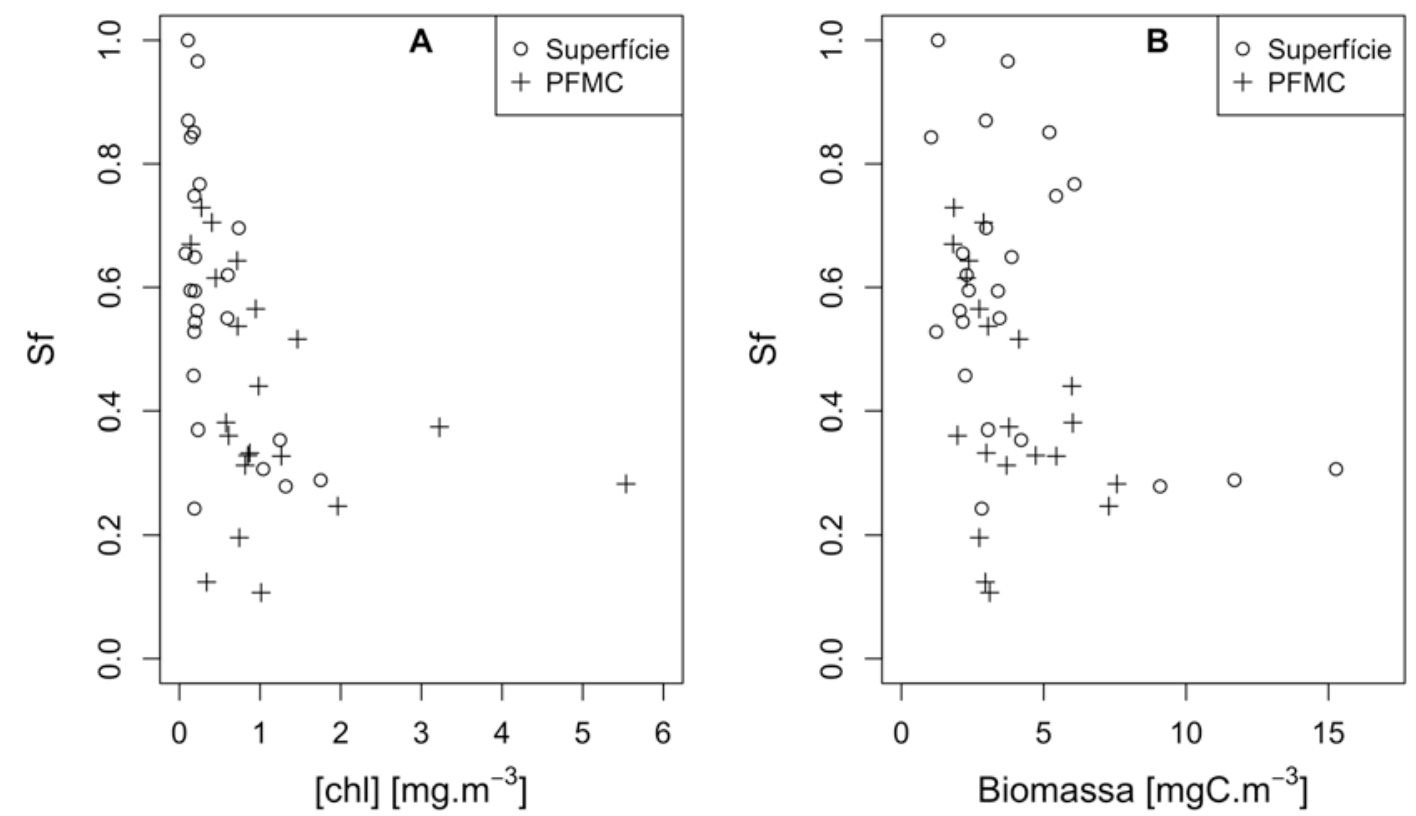

Figura 22: Relação entre $S_{f}$ e a [chl] (A) e a Biomassa (B).

Ao se utilizar $\circ \mathrm{CT}^{\mathrm{B}}$ para validar os valores de $\mathrm{S}_{\mathrm{f}}$, nota-se uma separação (dispersão dos pontos) entre comunidades de superfície e da PFMC (Figura 23). As relações de $S_{f}$ e $\circ C T^{B}$ foram significativas para as duas profundidades e representam a tendência de $S_{f}$ diminuir com o aumento de $C T^{B}$. Na superfície, foi obtido um $R^{2}$ de $0.22(p=0.02)$ e na PFMC um $R^{2}$ de $0.32(p=0.01)$ através das regressões ajustadas aos dados de $C T^{B}$ normalizados (log). 


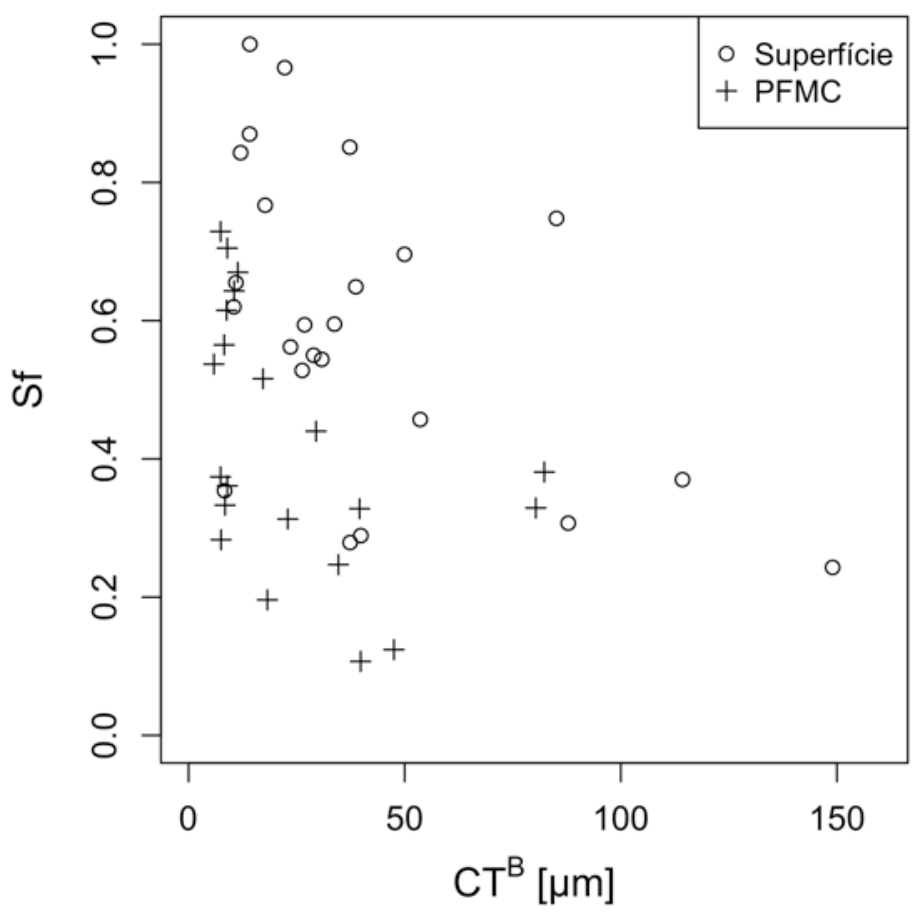

Figura 23: Relação entre $S_{f}$ e o Comprimento Total do organismos ponderado pela Biomassa $\left(\mathrm{CT}^{\mathrm{B}}\right)$

\subsection{Coeficiente de absorção da luz pelo fitoplâncton}

A absorção de luz pelo fitoplâncton média entre os comprimentos de onda de 400 a $700 \mathrm{~nm}$ ( <aph>, $\mathrm{m}^{-1}$ ) é bem explicada pela concentração de clorofila-a e é pouco dependente da profundidade da amostra (Figura 24A). A regressão entre <aph> e [chl] $(\log -\log )$, resulta num $R^{2}$ de $0.82(p<0.001)$, enquanto que para a PFMC, o $\mathrm{R}^{2}$ foi 0.87 , $(p<0.001)$. Todavia, nota-se que os maiores desvios nas tendências centrais de <aph> em função de [chl] ocorrem com o aumento da [chl], sendo esses ainda mais evidentes para as amostras da PFMC (Figura 24A). Na PFMC encontramos os maiores valores de <aph> e [chl] observados. As correlações de <aph> com a biomassa fitoplanctônica em carbono (Figura 24B) foram menores tanto na superfície quanto na PFMC ( $R^{2}=0.34, p=0.002$ e $R^{2}=0.43, p<0.001$, respectivamente). Os maiores valores de <aph> observados ocorreram na PFMC no intervalo de biomassa entre $2.5 \mathrm{mgC} . \mathrm{m}^{-3}$ e $7.5 \mathrm{mgC} . \mathrm{m}^{-3}$ (Figura 24B). 

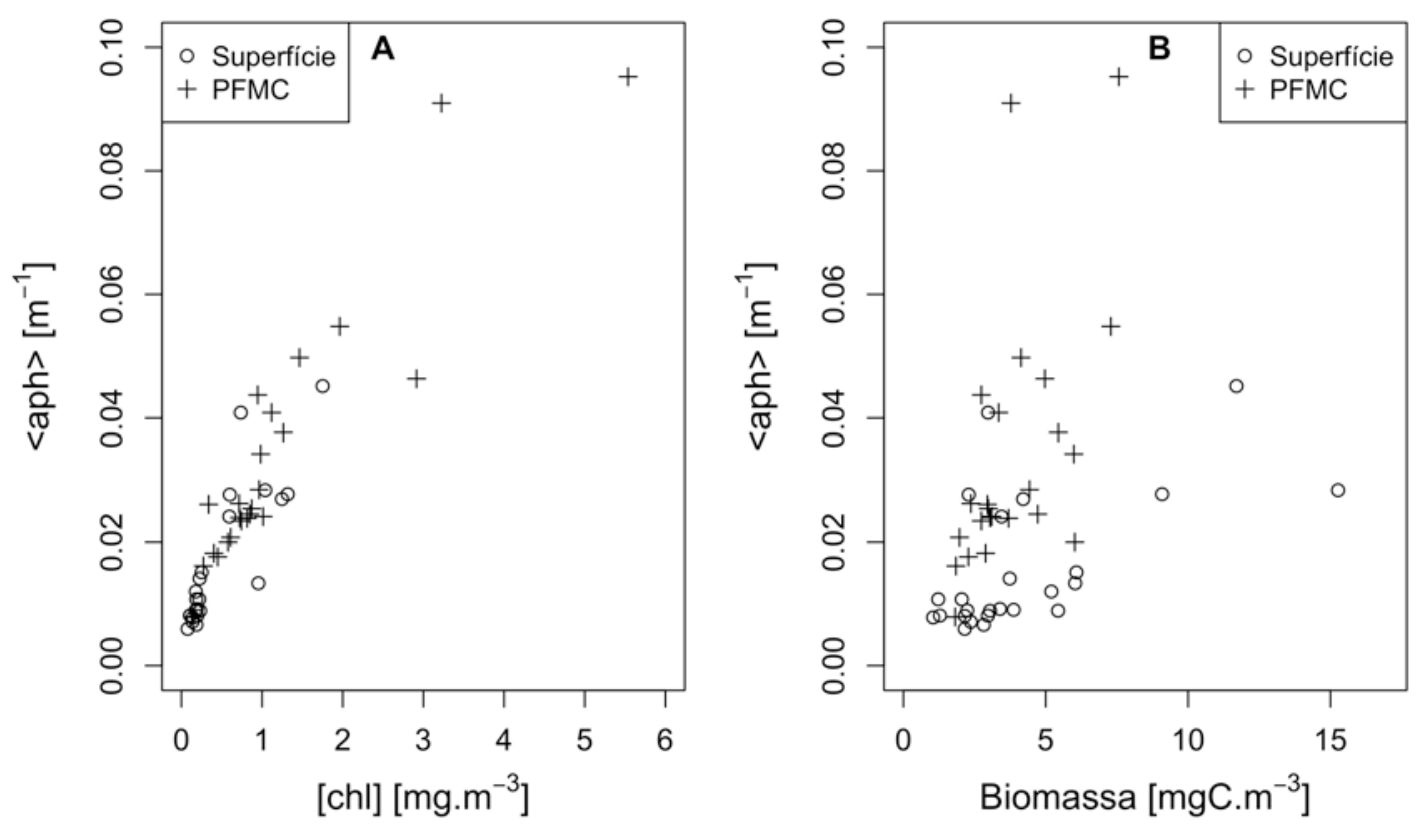

Figura 24: Relação entre <aph> e a [chl] (A) e a Biomassa (B).

Ao contrário do que se esperava, a razão $S / V^{B}$ não explicou as variações observadas em <aph>. Para as duas profundidades analisadas (superfície e PFMC) não foram encontradas relações significativas entre estas duas variáveis (Figura 25). Analisando somente a magnitude da absorção de luz (<aph>), não foi possível estabelecer relações com a razão $S / N^{B}$ da comunidade fitoplanctônica.

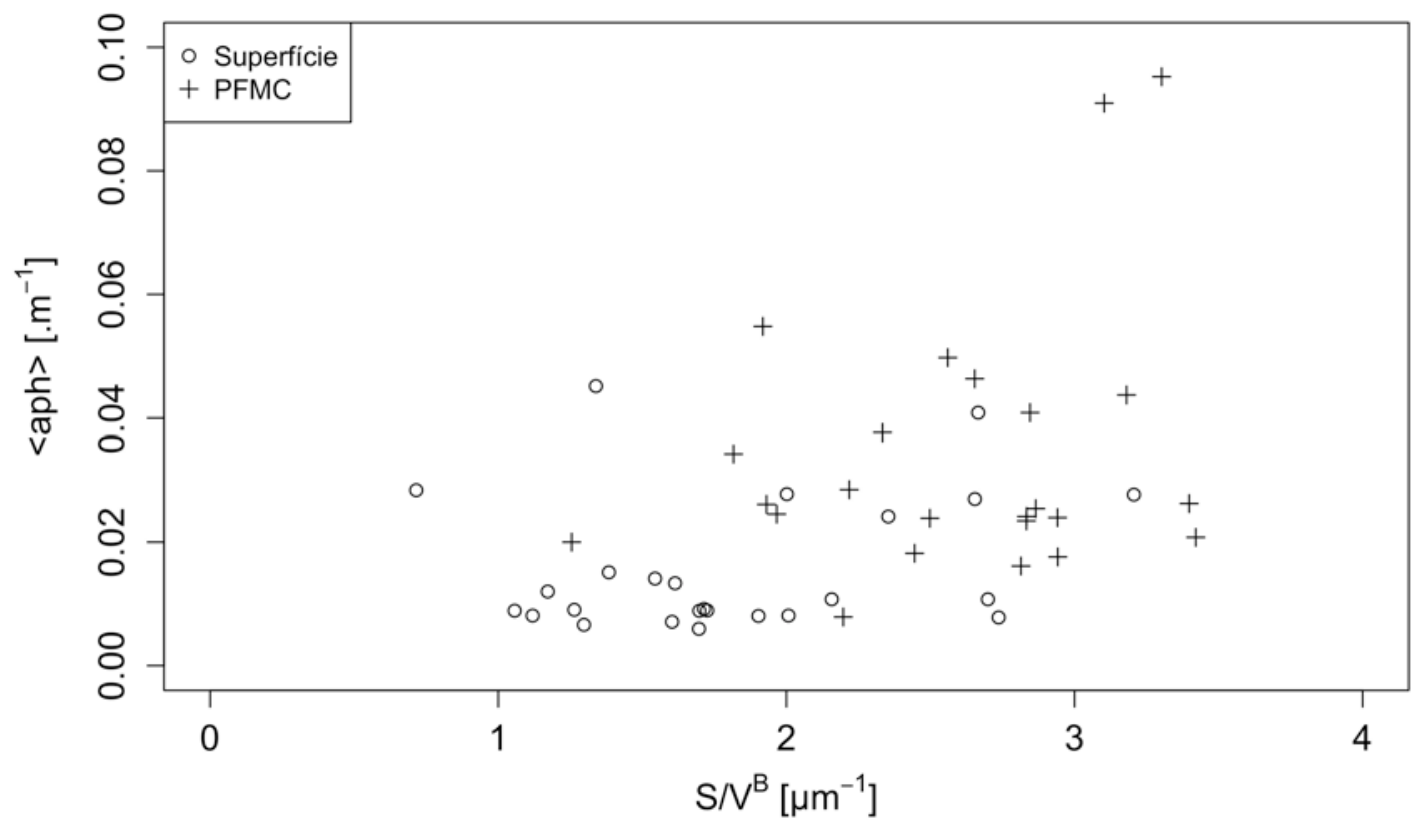


Figura 25: Relação entre <aph> e a razão Superfície/Volume ponderada pela biomassa $\left(\mathrm{S} / \mathrm{V}^{\mathrm{B}}\right)$

Ao utilizar-se as bandas espectrais formadas pelos resíduos do ajuste de Sf, é possível identificar não só influência dos pigmentos, mas também da forma do organismo dominante em biomassa, bem como sua razão $S / V^{B}$. $A$ Tabela 9 sumariza quais pigmentos e morfotipos fitoplanctônicos explicam os resíduos observados no ajuste de $S_{f}$. A análise de AIC permite identificar quais variáveis e modelos lineares explicam melhor as variações observadas em cada banda. Em 475nm, a combinação dos pigmentos Clorofila-b, Fucoxantina e 19'-Butanoiloxifucoxantina explicou $28 \%$ da magnitude do resíduo. Nas bandas da luz vermelha, isto é, 650nm e 665nm, a Clorofila-b foi o pigmento mais importante na magnitude do resíduo observado (Tabela 9).

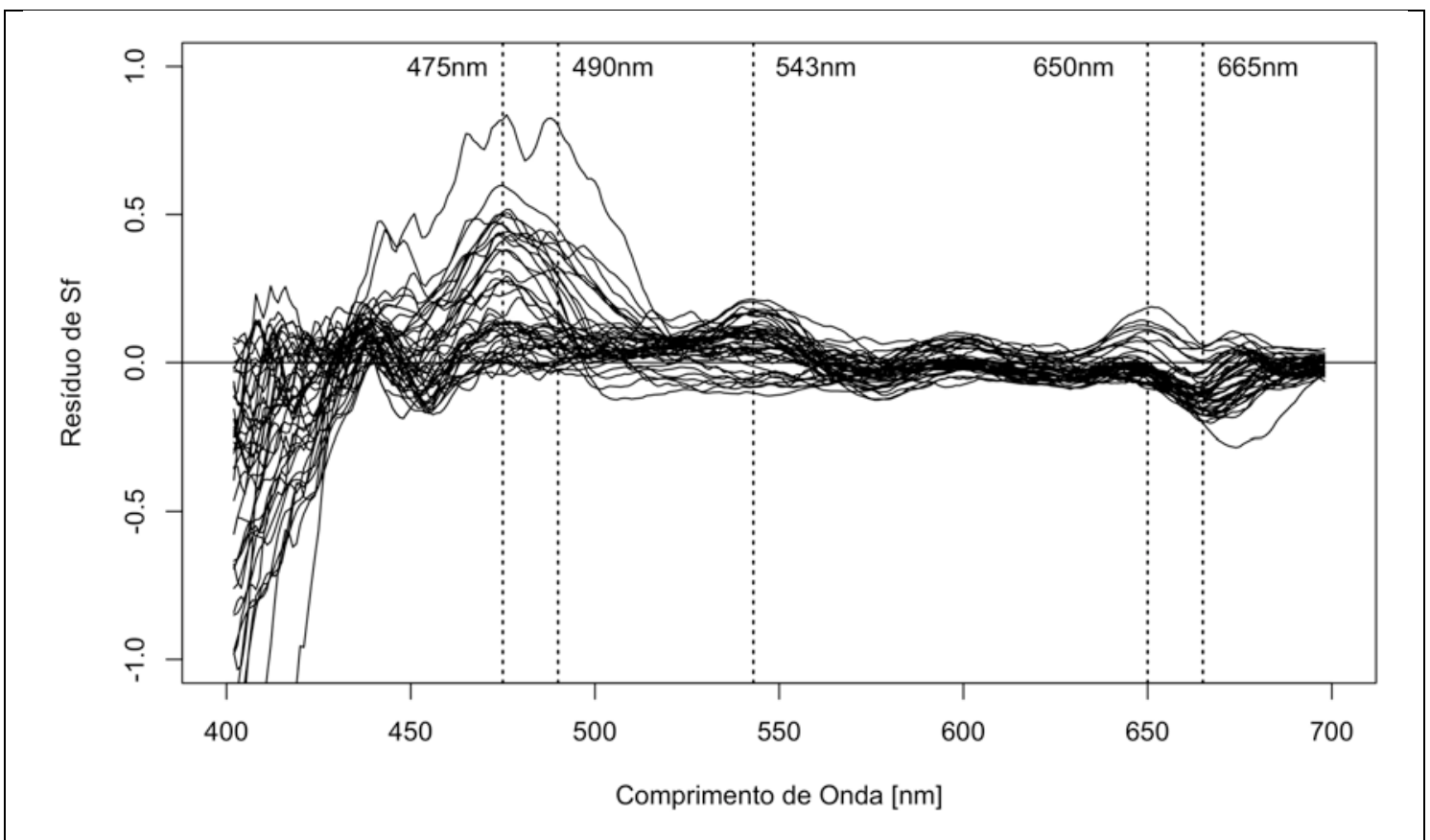

Figura 26: Distribuição dos resíduos de $S_{f}$ de acordo com o comprimento de onda. Em destaque os comprimentos de onda centrais de cada banda de resíduo analisada.

Quanto à influência dos morfotipos fitoplanctônicos e a razão $S / V^{B}$, a mesma só é observada nas bandas acima dos 543nm. A magnitude do resíduo em $543 \mathrm{~nm}$ foi diretamente proporcional à maior presença (em biomassa) de formas planas na comunidade. Já na banda do 650nm, não só a presença das formas planas é importante, como também a razão $S / V^{B}$ da 
comunidade influenciam a absorção de luz nesta banda espectral. Entendese por formas planas aquelas cujo comprimento total é muito maior que as outras dimensões. Exemplos dessas formas são Caixas Retangulares, Cilindros e os Prismas (Elípticos e Paralelogramo). Os resíduos de $\mathrm{S}_{\mathrm{f}}$ em $665 \mathrm{~nm}$, por outro lados, são explicados pela maior proporção de formas robustas na comunidade, além de sua razão $S / V^{B}$. Formas robustas são aquelas onde todas as dimensões apresentam medidas muito similares, exemplos são as Esferas, Prolados, Elipsóides e Cones.

Tabela 9: Relação das bandas de resíduo de $S_{f}$ e os principais pigmentos e formas geométricas que influenciam a magnitude do resíduo de $S_{f}$.

\begin{tabular}{|c|c|c|c|c|}
\hline $\begin{array}{c}\text { Banda } \\
\text { Resíduo }\end{array}$ & Pigmentos & & Forma e $S / V^{B}$ & \\
\hline $475 \mathrm{~nm}$ & $\begin{array}{l}\text { Chl-b + Fuco } \\
+ \text { Hex-Fuco }\end{array}$ & $R^{2}=0.28, p<0.01$ & Sem relação & NA \\
\hline $490 \mathrm{~nm}$ & Sem relação & NA & Sem relação & NA \\
\hline $543 n m$ & Sem relação & NA & Formas Planas & $\mathrm{R}^{2}=0.20, p<0.01$ \\
\hline $650 \mathrm{~nm}$ & Clorofila-b & $R^{2}=0.52, p<0.01$ & $\begin{array}{c}\mathrm{S} / \mathrm{V}^{\mathrm{B}}+\text { Formas } \\
\text { Planas }\end{array}$ & $R^{2}=0.23, p<0.01$ \\
\hline $665 \mathrm{~nm}$ & Clorofila-b & $R^{2}=0.33, p<0.01$ & $\begin{array}{c}S / V^{B}+\text { "Formas } \\
\text { Robustas" }\end{array}$ & $R^{2}=0.28, p<0.01$ \\
\hline
\end{tabular}

É importante salientar que apenas em 650nm e $665 \mathrm{~nm}$ existe a influência tanto de pigmentos, quanto dos morfotipos dos organismos. Nas outras bandas (475nm e 543nm) foi observado a influência isolada dos pigmentos e das formas dos organismos, respectivamente. Contudo, o método utilizado para determinar a concentração de pigmentos (HPLC) não permite a detecção da Ficoeritrina, pigmento comum de cianobactérias e que possuem pico de absorção de luz na banda do 550nm. A Ficoeritrina pode, portanto, influenciar o resíduo de Sf em $543 \mathrm{~nm}$, porém não é possível demonstrar sem os dados de concentração desse pigmento. Ao contrário do esperado, não foi se observou relação do resíduo de Sf em 490nm com a concentração de pigmentos acessórios (Tabela 9). 


\section{Discussão}

\subsection{Biomassa e Razão C:chl}

A análise do carbono exclusivo ao fitoplâncton através da microscopia possui inúmeras fontes de erro, incluindo erros intrínsecos à metodologia (Sournia, 1978). Alterações significativas na determinação da biomassa ocorrem com a utilização de uma equação comum a todos os organismos. Além disso, a preservação das amostras conhecidamente promove mudanças no tamanho celular dos organismos, e essas mudanças serão diferentes de acordo com a espécie (Menden-Deuer et al., 2001; Hawkins et al., 2005) ou com a solução de preservação utilizada, sendo os mais comuns o glutaraldeído (Booth, 1987; Verity et al., 1992), o formaldeído (Olivieri, 1985) e o lugol (Montagnes et al., 1994). Neste trabalho, optamos por não utilizar correções para a determinação do biovolume de organismos preservados, embora essas equações existam (Parsons et al., 1961, Moal et al., 1987; Putt and Stoecker 1989). A utilização de tais correções é intrínseca da interação entre o agente de preservação, sua concentração e a espécie presente (Leakey et al., 1994) e alguns estudos apontam que estas alterações são inferiores a $5 \%$ na determinação do biovolume celular (Menden-Deuer et al., 2001), mas podem chegar a 29\% com o uso de lugol (Montagnes et al., 1994)

A seleção de equações específicas de conversão de biomassa a partir do biovolume mostrou-se necessária para evitar estimativas exageradas da biomassa fitoplanctônica. Embora em nível de organismo essa diferença foi pequena $\left(0.062 \mathrm{mgC} \cdot \mathrm{m}^{-3}\right)$, o cálculo de biomassa fitoplanctônica através de uma equação universal resultou em valores com uma diferença acima de 4 $\mathrm{mgC} \cdot \mathrm{m}^{-3}$. Dessa forma, os algoritmos para análise de imagens de fitoplâncton devem incorporar equações específicas a cada grupos taxonômico.

Nos oceanos, a abundância dos organismos planctônicos (Zubkov, et al. 1998) e a concentração de clorofila-a (Cullen, 1982) estão distribuídos heterogeneamente ao longo da coluna d'água. Entretanto, nem a [chl] ou a abundância dos organismos são equivalentes à biomassa fitoplanctônica em carbono (Claustre e Marty, 1995; Barlow et al., 2002). Nossos resultados 
mostraram que a biomassa exclusiva à comunidade fitoplanctônica foi igual na superfície e na PFMC, sendo resultado da contribuição diferencial de distintos grupos taxonômicos (Chisholm, 1988) bem como de distintas classes de tamanho que ocorrem nas duas profundidades. Além disso, a relação entre a biomassa e a [chl] foram mais robustas na superfície. Nessa profundidade, a quantidade de carbono intracelular e a [chl] variam de maneira similar, guiadas pelo aumento no tamanho dos organismos (Yentsch e Phinney, 1989; Geider et al., 1998). Na PFMC, a fotoadaptação dos organismos às baixas condições de luminosidade promovem um aumento na [chl] (Morel et al., 1995) que não é seguido pela biomassa.

Os valores de C:chl encontrados no presente estudo estão dentro de limites compatíveis de estudos anteriores em comunidades naturais (Eppley, 1968; Eppley et al., 1971, Eppley et al., 1977; Veldhuis e Kraay, 2004). Entretando, nossos valores de C:chl são menores quando comparados aos obtidos por experimentos e cultivos (10 - 90) (Caperon e Meyer, 1972; Thompson e Guo, 1992), como esperado. Embora os efeitos da intensidade luminosa (Thompson e Guo, 1992), da concentração de nutrientes (Eppley e Renger, 1974; Kruskopf e Flynn, 2006) e da temperatura (Thompson e Guo, 1992) na C:chl sejam bem estudados em experimentos com cultivos monoespecíficos, essa variabilidade ainda não é tão compreendida para comunidades naturais. O maior intervalo de $\mathrm{C}$ :chl de experimentos com cultivos monoespecíficos de fitoplâncton em comparação àqueles observados em comunidades naturais pode estar associado às mudanças nas taxas de crescimento (Laws e Bannister, 1980). Os valores mais baixos de C:chl para a PFMC são resultado da adaptação dos organismos à menor luminosidade, produzindo mais [chl] (Falkowski e LaRoche, 1991), já que em geral a PFMC foi identificada entre 30-40 metros de profundidade. Em condições de baixa luminosidade, o fitoplâncton produz uma maior quantidade de pigmentos fotossintéticos, principalmente de clorofila-a (Morel et al., 1995, Dubinsky e Stambler, 2009), reduzindo assim a razão C:chl. De fato, baixos valores de C:chl são observados para comunidades naturais na PFMC (Veldhuis e Kraay, 2004) chegando a representar comunidades distintas daquelas em superfície, formando associações deste ambiente e condições de luminosidade (Smayda, 2002; Babin et al., 1996; Allali et al., 1997; Moore e 
Chisholm, 1999). Contudo, diversos estudos de produção primária, por exemplo, ainda utilizam uma razão C:chl integrada verticalmente na coluna d'água (Armstrong, 2006; Faure et al., 2006), embora variações em ordens de magnitude já tenham sido observadas entre superfície e PFMC na C:chl (Veldhuis e Kraay, 2004).

\subsection{Classificação da Comunidade Fitoplanctônica}

O agrupamento do fitoplâncton em grandes grupos taxonômicos é uma maneira eficiente de associá-lo aos seus papéis ecológicos e em ciclos biogeoquímico (Le Queré et al., 2005; Nair et al, 2008). A utilização destes grandes grupos se mostrou importante para observar as variações na biomassa em unidades de carbono de comunidades naturais. Nas comunidades de plataforma continental, foi possível observar a dominância e covariância de 8 grupos taxonômicos principais de acordo com a biomassa total da comunidade.

O fitoplâncton marinho é um grupo extremamente diverso e pode ser caracterizado por uma grande quantidade de formas (20 - Hillebrand et al, 1999; 31 - Sun e Liu, 2003; Finkel et al, 2010). Em águas de plataforma continental, ainda não foram descritos os principais morfotipos geométricos que ocorrem em comunidades naturais. Este trabalho propõe que, em termos de ocorrência numérica, as comunidades naturais de plataforma continental subtropicais com influência variável de aportes continentais podem ser descritas por 16 morfotipos principais do fitoplâncton. A menor quantidade observada que os morfotipos propostos por Sun e Liu (2003) deve-se ao fato de algumas dessas formas apresentam dependência a um organismo específico ou espécie que não ocorre em águas de plataforma ou condições físico-quimicas diferenciadas.

Além disso, descrever as relações de exclusividade entre grupos taxonômicos e morfotipos tornou-se um passo fundamental nos estudos ecológicos de comunidades naturais do fitoplâncton. A coexistência de organismos diferenciados geometricamente no ambiente pelágico é uma resposta adaptativa às mudanças no ambiente (Margalef, 1978; Reynolds, 2006; Naselli-Flores et al., 2007). Dessa forma, grupos taxonômicos que 
exploram os recursos do ambiente da mesma maneira tendem a apresentar formas geométrica similares. Como identificado, formas geométricas planas são exclusivas às diatomáceas e formas robustas (arredondadas) tendem a ser mais observadas em dinoflagelados. A associação de formas geométricas à grandes grupos taxonômicos é crucial para as novas tecnologias de aquisição de imagem in situ de comunidades naturais (Olson e Sosik, 2007; Moberg e Sosik, 2012). Imagens obtidas por estes sistemas naturalmente ainda não possuem informações taxonômicas (Sieracki et al., 1998), apenas a forma do organismo fotografado. Desenvolver modelos que associem a forma do organismo observado a um grupo taxonômico sem a necessidade da identificação humana, permite melhores estimativas da biomassa e caracterização da comunidade (Carpentier et al., 1999; Congestri et al., 2000).

\subsection{Descritores de Comunidade e Tamanho ponderado}

Diversos estudos apontam que a abundância dos organismos pequenos (Campbell e Vaulot, 1993; Zubkov et al., 1998) e concentração de clorofila-a pertencente a este grupo (Marañón et al., 2001) é maior na superfície e diminui em direção à PFMC. Dessa forma, é esperado que o tamanho médio da comunidade seja guiado de forma a seguir este padrão. Entretanto, ao analisar o tamanho dos organismos de acordo com sua importância em termos de carbono (biomassa), notou-se um padrão inverso. Neste trabalho, as comunidades de superfície apresentaram maior tamanho de organismo. Estes resultados, inéditos no sentido de serem analisados a partir da importância do carbono, são condizentes com resultados encontrados por outros trabalhos analisando a concentração de clorofila-a dividida em classes de tamanho (Lutz et al., 2003; Taguchi et al., 1988; Pérez et al., 2006).

Tanto a dominância numérica, quanto a concentração de clorofila-a em classes de tamanho não refletem a verdadeira distribuição de tamanho dos organismos na comunidade nem de sua biomassa (Claustre e Marty, 1995; Veldhuis e Kraay, 2004). Fato este, que a concentração de clorofila-a não apresentou relação com o tamanho ponderado por carbono nas comunidades 
analisadas. A utilização do tamanho, por outro lado, pode resultar em boas estimativas de carbono, principalmente para a superfície, onde as relações entre essas duas variáveis foram mais robustas.

Espera-se que a maior contribuição para a biomassa da comunidade fitoplanctônica esteja associada à ocorrência de organismos de maior tamanho (Yentsch e Phinney, 1989), principalmente diatomáceas (e.g. Sathyendranath et al., 2001). Observamos para a região de estudo, que a contribuição em biomassa dos dinoflagelados é alta e ocorre quando a presença de diatomáceas é baixa. A alternância na biomassa de diatomáceas e dinoflagelados está associado às estratégias adaptativas destes organismos às diferentes condições ambientais (Margalef, 1978; Cullen, 2002). Em ambientes costeiros e de plataforma, processos de mistura vertical (Cushing, 1989), formação de vórtices (Falkwoski et al., 1991) e a proximidade com as fontes de nutrientes terrestres promovem maior capacidade suporte para organismos grandes se desenvolverem. Exatamente as estações dominadas por diatomáceas ou dinoflagelados e, portanto, com maior biomassa, estão próximas à costa na região sul (cruzeiro MCT-2) e sudeste (MCT-1). A forma como o organismo explora os recursos definirá seu sucesso em relação aos outros organismos da comunidade. As diatomáceas apresentam uma alta taxa de crescimento (Fahnenstiel et al., 1995) e rapidamente dominam a biomassa da comunidade em condições favoráveis. Entretanto, em condições de estratificação vertical, as diatomáceas são substituídas por organismos móveis, como dinoflagelados e flagelados (Reynolds, 2006; Padisák et al., 2003).

$\mathrm{Na}$ região de estudo, a contribuição relativa da biomassa pelos diferentes morfotipos foi guiada principalmente pelas formas Elipsóide e Esfera, tanto em superfície quanto na PFMC. Infelizmente, estes morfotipos não são exclusivos de nenhum grupo taxonômico.

\subsection{Razão S/V}

É esperado que a razão $S / V$ apresentada por diferentes grupos taxonômicos influencie em suas taxas de crescimento (Banse, 1976), de forma que grupos com elevada S/V tenderiam a ter mais sucesso tanto na 
absorção de luz como nutrientes. Contudo, a variabilidade observada em S/V em cada grupo taxonômico foi alta e grande parte dos grupos apresentou intervalos similares de S/V. Isso comprova a flexibilidade dos grupos taxonômicos em resposta as condições ambientais, que acaba delimitando os valores máximos e mínimos de $\mathrm{S} / \mathrm{V}$ que as espécies apresentam na natureza (Lewis, 1976). Alguns autores apontam, ainda, que a razão S/V do organismos possui relação negativa com a temperatura (Margalef, 1954) e positiva com a concentração de nutrientes no ambiente (Fogg, 1965; Smith e Kalff, 1982). Os resultados também sugerem que valores de S/V estão limitados por um intervalo de tamanho dependendo do morfotipo, aonde se destacam formas planas (Prismas) que mantém uma razão S/V constante por cerca de duas ordens de magnitude de tamanho, a partir de 10 $\mu \mathrm{m}$. Adaptações morfológicas do fitoplâncton, como o alongamento celular e o achatamento das células são bem conhecidos (Reynolds, 2006), de modo a manter uma razão S/V favorável ao ambiente, mas que podem ter papel importante para minimizar a predação pelo zooplâncton (Van Donk, 1997).

A análise comprovou o esperado teórico, de que o morfotipo 9-H tende a manter uma razão S/V relativamente constante com o tamanho celular, e sempre alta em comparação às demais formas de mesmo tamanho. Entretanto, a contribuição de biomassa desse morfotipo foi sempre baixa, o que sugere que relações entre tamanho e acúmulo de biomassa de um determinado morfotipo não são triviais.

\subsection{Validação de modelos Bio-óticos}

\subsection{1 - Vidussi et al. (2001) e Uitz et al. (2006)}

Estimativas de classes de tamanho do fitoplâncton a partir de pigmentos marcadores são amplamente utilizadas (Vidussi et al., 2001; Uitz et al., 2006, Brewin et al., 2011; Taylor et al., 2011), embora não existam validações a partir da biomassa exclusiva do fitoplâncton. Algumas comparações entre a concentração de pigmentos acessórios e a abundância de organismos existem para regiões oligotróficas, mostrando que esses modelos tem boa performance (Brotas et al., 2013). Nossos resultados permitem uma validação local e ilustram que o modelo de Vidussi et al., 
(2001) apresentou boa performance para a região de estudo, divergindo do obtido pelo carbono apenas para o microplâncton na PFMC. Essa divergência ocorre pois alguns pigmentos marcadores são compartilhados entre diferentes grupos taxonômicos (Jeffrey et al., 1994; Jeffrey et al, 1997) e alguns grupos taxonômicos podem apresentar um grande intervalo de variação de tamanho. Assim, a utilização do modelo de Vidussi et al. (2001) para área de estudo foi satisfatória, correspondendo a $75 \%$ de acerto da biomassa das classes de tamanho nas diferentes profundidades.

\subsection{2 - Ciotti et al. (2002)}

Espera-se que o efeito do empacotamento aumente com a [chl] seguindo o aumento de tamanho celular de ambientes oligotróficos para eutróficos (Malone, 1980; Yentsch e Phinney, 1989). Nossos dados demonstram, assim como esperado, que $S_{f}$ diminui com o aumento da [chl] e da biomassa. A maior variabilidade de $S_{f}$ com o aumento da clorofila-a é resultado do efeito de empacotamento dos pigmentos (Ciotti et al., 2002), e o modelo foi desenvolvido para uso na primeira profundidade ótica dos oceanos. Fato este que as relações só foram significativas para a superfície. Assim, comparações diretas de $S_{f}$ entre superfície e PFMC como indice de tamanho dominante da comunidade devem ser evitadas, devido aos efeitos de empacotamento de pigmentos da fotoaclimatação (Kiefer et al., 1976; Kitchen e Zaneveld, 1990).

Apesar do parâmetro $S_{f}$ já ter sido utilizada como estimativas de frações de tamanho dominante do fitoplâncton em produtos de sensoriamento remoto (Brewin et al., 2011; Bricaud et al., 2012) até o presente trabalho, não existiam medidas paralelas de $S_{f}$ e do tamanho real dos organismos da comunidade fitoplanctônica. Nossos resultados evidenciam que fora dos valores extremos do modelo $\left(S_{f}=1\right.$ ou $\left.S_{f}=0\right)$ o significado físico de um dado valor de $S_{\mathrm{f}}$, em termos de tamanho celular, depende em grande parte da aclimatação. Todavia, considerando nossa base de dados limitada, e os erros potenciais das medidas em microscópio, as relações entre $S_{f}$ e $\circ$ tamanho médio da comunidade ponderada pela biomassa foram razoáveis. Os ajustes de $S_{f}$ ao $C T^{B}$ corresponderam a $32 \%$ 
na PFMC e a $22 \%$ na superfície. Na PFMC, o intervalo de tamanhos celular médio observado foi menor, e as variações em $S_{f}$ são guiadas de forma mais efetiva pelas diferenças nas concentrações de pigmentos acessórios entre os pontos observados. Todavia, em superfície, $S_{f}$ se aproximou de zero apenas em estações dominadas por diatomáceas e onde o tamanho médio ponderado foi superior a $100 \mu \mathrm{m}$.

\subsection{Coeficiente de absorção da luz pelo fitoplâncton}

Os modelos empíricos apresentados na literatura, aonde a absorção da luz do fitoplâncton em diferentes comprimentos de onda é bem correlacionada com a [chl] (Bricaud, et al., 1995; Bricaud et al., 2004) se aplicam para os nossos resultados. Da mesma forma, a magnitude de <aph> se correlacionou bem com a [chl]. As relações entre <aph> e a biomassa expressa em carbono foram mais dispersas, e como esperado, as diferenças entre as amostras de superfície e da PFMC ficaram mais evidentes, resultado da razão C:chl ter sido significativamente menor na PFMC.

Vários estudos demonstraram que a razão $S / V$ está diretamente relacionada à taxas de incorporação (Smayda, 1970; Sournia, 1982) e acredita-se que o mesmo seja verdadeiro para as taxas de absorção de luz (Kirk, 1994). Todavia, ao contrário do esperado, as relações entre <aph> e a razão $S / V^{B}$ não foram significativas. A adaptação e plasticidade do organismo a outras variáveis ambientais (Reynolds, 2006) pode sobrepor a eficiência na absorção de luz e a interação dessas variáveis só recentemente foram estudadas (Stanca et al., 2013).

Como demonstrado por Ciotti et al. (2002), grande parte da variabilidade espectral do coeficiente de absorção da luz pelo fitoplâncton é explicado pelo seu tamanho celular. Os ajustes de $S_{f}$ em curvas de $a_{p h}(\lambda)$ corresponderam a cerca de $90 \%$ da variação observada em $a_{p h}(\lambda)$. A análise dos resíduos desse ajuste permite explorar informações taxonômicas e de pigmentos. Nossos resultados apontam que a concentração de pigmentos acessórios está diretamente associada à magnitude dos resíduos de $S_{f}$ em determinadas bandas. Da mesma forma, a forma geométrica do organismo, indicada através da sua proporção em relação à biomassa total da 
comunidade, e sua razão S/V também estão relacionadas aos resíduos de Sf. As relações dos resíduos de $S_{f}$ com a concentração de pigmentos acessórios, principalmente aqueles que não ocorrem nos vetores utilizados por Ciotti et al. (2002) já eram esperados (Bidigare et al., 1990; Hoepffner e Sathyendranath, 1991). Dentre estes pigmentos, a clorofila-b é o mais significativo (Jeffrey et al., 1997; Wright, 2005) e foi o que apresentou relação em todas as bandas onde o efeito dos pigmentos foi significativo. Além disso, a presença da ficoeritrina, pigmento característico de cianobactérias, pode estar relacionada aos altos resíduso de Sf em 543nm. Contudo, este pigmento não é obtido por meio de HPLC devido à sua solubilidade em água e não em solvente orgânico (Kirk, 1994). 


\section{Conclusões}

- Comunidades fitoplanctônicas da plataforma continental sul e sudeste do Brasil podem ser explicadas por 8 grupos taxonômicos e 16 morfotipos geométricos. Padrões de exclusividade entre estes morfotipos e os grupos taxonômicos foram observados e podem auxiliar na análise de imagens obtidas in-situ dos organismos.

- O tamanho dominante de acordo com o carbono de uma comunidade natural é melhor relacionado com a sua biomassa e não com a concentração de clorofila-a. Estudos sobre comunidades fitoplanctônicas devem incorporar medidas de tamanho e biomassa em suas rotinas, e não apenas a concentração de clorofila-a

- A biomassa e a razão S/V não apresentaram diferença entre os grupos taxonômicos e os morfotipos celulares. As variações em S/V podem estar diretamente relacionadas com as condições ambientais, principalmente em definir os limites de variação de S/V entre os grupos taxonômicos. Estudos sobre adaptações morfológicas frente às variáveis ambientais devem ser realizados

- A biomassa não apresenta relação com a razão S/V. Diferentes condições ambientais ou interações tróficas devem reger o sucesso evolutivo do organismo em acumular biomassa, e não apenas a sua razão S/V

- A utilização de modelos baseados na composição de pigmentos para a estrutura de tamanho da comunidade são indicados para a área de estudo. As proporções das classes de tamanho obtidas pelo modelo foram condizentes com a real estrutura de tamanho das comunidades em termos de biomassa na maioria dos casos. A validação local do modelo não apresentou boa performance apenas para o microplâncton na PFMC.

- As variações observadas em <aph> são mais explicadas pela concentração de clorofila-a embora informações complementares podem ser observadas com o uso da biomassa nas relações de <aph>.

- Sf apresenta intervalos característicos entre a superfície e a PFMC e é explicado pelo tamanho médio ponderado por carbono da comunidade. Contudo, os efeitos da fotoaclimatação prejudica as relações observadas. 
- A concentração de pigmentos acessórios, principalmente a Clorofila-b, a forma do organismo e sua razão S/V influenciam o comportamento espectral da absorção da luz pelo fitoplâncton. 


\section{Referências Bibliográficas}

ALLALI, K.; BRICAUD, A.; CLAUSTRE, H. Spatial variations in the chlorophyll-specific absorption coefficients of phytoplankton and photosynthetically active pigments in the equatorial Pacific. Journal of Geophysical Research v. 102, n. 12, p. 413-12,423, 1997.

ALVAIN, S.; MOULIN, C.; DANDONNEAU, Y.; BRÉON, F.M. Remote sensing of phytoplankton groups in case 1 waters from global SeaWiFS imagery, Deep Sea Research Part I: Oceanographic Research Papers, v. 52, n. 11, p. 1989-2004, 2005.

ANAGNOSTIDIS, K.; KOMÁREK, J. Modern approach to the classification system of cyanophytes (Oscillatoriales). Arch. Hydrobiol. Suppl, v. 80, n. 3, p. 327- 472, 1988.

ANDERSON, T. R. Plankton functional type modelling: running before we can walk? Journal of Plankton Research, v. 27, p. 1073-1081, 2005.

ARMSTRONG, R. A. Optimality-based modeling of nitrogen allocation and photoacclimation in photosynthesis, Deep Sea Research Part II: Topical Studies in Oceanography, v. 53, n. 5-7, p. 513-531, 2006.

BABIN, M.; MOREL, A.; CLAUSTRE, H. Nitrogen- and irradiance-dependent variations of the maximum quantum yield of carbon fixation in eutrophic, mesotrophic and oligotrophic marine systems. Deep-Sea Research, v. 43, p. 1241-1272, 1996.

BALECH, E. Los Dinoflagelados del Atlantico Sudoccidental.

Publicaciones Especiales. Instituto Español de Oceanografia, vol. 1, p. 309, 1988.

BANSE, K. Determining the Carbon-to-Chlorophyll Ratio in Natural Phytoplankton. Marine Biology, v. 41, p. 199-212, 1977.

BANSE, K. Rates of growth, respiration and photosynthesis of unicellular algae as related to cell-size-a review. Journal of Phycology, v. 12, p. 135-140, 1976.

BARLOW, R. G.; AIKEN, J.; HOLLIGAN, P. M.; CUMMINGS, D. G.; MARIOTENA, S.; HOOKER, S. Phytoplankton pigment and absorption 
characteristics along meridional transects in the Atlantic Ocean. DeepSea Research I, v. 49, p. 637-660, 2002.

BARRE, N.; PROVOST, C.; SARACENO, M. Spatial and temporal scales of the Brazil-Malvinas Current confluence documented by simultaneous MODIS Aqua 1.1-km resolution SST and color images. Advances in Space Research, v. 37, p. 770-786, 2006.

BIDIGARE, R. R.; ONDRUSEK, M. E.; MORROW, J. H.; KIEFER, D. A. In vivo absorption properties of algal pigments. Opt. Eng., v. 1302, p. 290-302, 1990.

BOOTH, B. C. The use of autofluorescence for analyzing oceanic phytoplankton communities. Botanic Marine, v. 30, p. 101-108, 1987.

BRACHER, A.; VOUNTAS, M.; DINTER, T.; BURROWS, J. P.; RÖTTGERS, R.; PEEKEN, I. Quantitative observation of cyanobacteria and diatoms from space using PhytoDOAS on SCIAMACHY data. Biogeoscience, v. 6, p. 751-764, 2009.

BRAGA, E. S.; NIENCHESKI, L.F.H. Composição das massas de água e seus potenciais produtivos na área entre o Cabo de São Tomé (RJ) e o Chuí (RS). In: ROSSI-WONGTSCHOWSKI, CLDB \& LSP MADUREIRA. O Ambiente Oceanográfico da Plataforma Continental e do Talude na Região Sudeste-Sul do Brasil. EDUSP, p. $161-218,2006$.

BRAGA, E.S.; CHIOZZINI, V.C.; BERBEL, G.B.B.; MALUF, J.C.C.; AGUIAR, V.M.C.; CHARO, M.; MOLINA, D.; ROMERO, S.I.; EICHLER, B.B. Nutrient distributions over the Southwestern South Atlantic continental shelf from Mar Del Plata (Argentina) to Itajaí (Brazil): Winter-summer aspects. Continental Shelf Research, v. 28, n. 13, p. 1649-1661, 2008. doi:10.1016/j.csr.2007.06.018.

BREWIN, R. J. W.; HARDMAN-MOUNTFORD, N. J.; LAVENDER, S. J.; RAITSOS, D. E.; HIRATA, T.; UITZ, J.; DEVRED, E.; BRICAUD, A.; CIOTTI, A; GENTILI, B. An intercomparison of bio-optical techniques for detecting dominant phytoplankton size class from satellite remote sensing. Remote Sens. Environ., v. 115, p. 325-339, 2011.

BRICAUD, A.; BABIN, M.; MOREL, A.; CLAUSTRE, H. Variability in the chlorophyll-specific absorption coefficients of natural phytoplankton 
Analysis and parameterization. Journal of Geophysical Research, v. 100, n. 13, p. 321-13,332, 1995.

BRICAUD, A.; CIOTTI, A. M.; GENTILI, B. Spatial-temporal variations in phytoplankton size and colored detrital matter absorption at global and regional scales, as derived from twelve years of SeaWiFS data (19982009). Global Biogeochemical Cycles, v. 26, GB1010, 2012.

BRICAUD, A.; CLAUSTRE, H.; RAS, J.; OUBELKHEIR, K. Natural variability of phytoplanktonic absorption in oceanic waters: Influence of the size structure of algal populations, J. Geophys. Res., v. 109, C11010, 2004.

BRICAUD, A.; STRAMSKI, D. Spectral absorption coefficients of living phytoplankton and nonalgal biogenous matter: A comparison between the Peru upwelling area and the Sargasso Sea. Limnology and Oceanography, v. 35, p. 562-582, 1990.

BROTAS, V.; BREWIN, B.; SÁ, C.; BRITO, A.; SILVA, A.; MENDES, R.; DINIZ, T.; KAUFMANN, M.; TARRAN, G.; GROOM, S.; PLATT, T.; SATHYENDRANATH, S. Deriving phytoplankton size classes from satellite data: validation along a trophic gradient in the Eastern Atlantic. Remote Sensing of Environment, v. 134, p. 66-77, 2013.

CALADO, L. Dinâmica da interação da atividade de meso-escala da Corrente do Brasil como fenômeno da ressurgência costeira ao largo de Cabo Frio e Cabo de São Tomé, RJ. Tese de Doutorado. Instituto Oceanográfico. São Paulo, Universidade de São Paulo, p. 1$184,2006$.

CAMPBELL, L.; VAULOT, D. Photosynthetic picoplankton community structure in the subtropical North Pacific Ocean near Hawaii (station ALOHA). Deep-Sea Research I, v. 40, p.2043-2060, 1993.

CAMPOS, E.J.D.; IKEDA, Y.; CASTRO, B.M.; GAETA, S.A.; LORENZZETTI, J.A.; STEVENSON, M.R. Experiment Studies Circulation in the Western South Atlantic. EOS, Transactions, Am. Geophys. Union, v. 77, n. 27, p. 253,259, 1996.

CAPERON, J.; MEYER, J. Nitrogen-limited growth of marine phytoplankton -

I. Changes in population characteristics with steady-state growth rate. Deep Sea Res., v. 19, p. 601-618, 1972. 
CARON, D. A.; DAM, H. G.; KREMER, P.; LESSARD, E. J.; MADIN, L. P.; MALONE, T. C.; NAPP, J. M.; PEELE, E. R.; ROMAN, M. R.; YOUNGBLUTH, M. J. The contribution of microorganisms to particulate carbon and nitrogen in surface waters of the Sargasso Sea near Bermuda. Deep Sea Res., v. I, n. 42, p. 943-972, 1995.

CARPENTIER, C.; KETELAARS, H.; WAGENVOORT, A.; PIKAARSCHOONEN, K. Rapid and versatile routine measurements of plankton biovolumes with BACCHUS. J. Plankton Res., v. 21, p. 1877-1889, 1999.

CASTELAO, R. M.; CAMPOS, E. J. D.; MILLER, J. L.. A modeling study of coastal upwelling driven by wind and meanders of the Brazil Current. J. Coastal Res., v. 20, n. 3, p. $662-671,2004$.

CASTRO F. O.; LORENZZETTI, J. A.; SILVEIRA, I. C. A.; MIRANDA, L. B. Estrutura termohalina e circulação na região entre o Cabo de São Tomé (RJ) e o Chuí (RS). In: C.L.D.B. Rossi-Wongtschowski \& L.S-P. Madureira. (eds.). 0 ambiente oceanográfico da plataforma continental e do talude na região sudeste-sul do Brasil, São Paulo, EDUSP - Editora da Universidade de São Paulo, p. 11-120, 2006.

CASTRO, B.M. Correntes e Massas de água da Plataforma Continental Norte de São Paulo. Tese de Livre Docência, Instituto Oceanográfico da Universidade de São Paulo, São Paulo, SP, p. 194, 1996.

CHISHOLM, S. W.; OLSON, R. J.; YENTSCH, C. M. Flow cytometry in oceanography: Status and prospects. EOS, v. 69, n. 18, 1988.

CIOTTI, A. M.; CULLEN, J.J.; LEWIS, M. R. A semi-analytical model of the influence of phytoplankton community structure on the relationship between light attenuation and ocean color. Journal of Plankton Research, v. 104: 1559-1578, 1999.

CIOTTI, A. M.; GARCIA, C. A. E.; JORGE, D. S. F. Temporal and meridional variability of Satellite-estimates of surface chlorophyll concentration over the Brazilian continental shelf. PANAMJAS, v. 5, p. 236-253, 2010.

CIOTTI, A. M.; LEWIS, M. R.; CULLEN, J. J. Assessment of the relationships between dominant cell size in natural phytoplankton communities and spectral shape of the absorption coefficient. Limnology and Oceanography, v. 47, p. 404-417, 2002. 
CIOTTI, A. M.; ODEBRECHT, C.; FILLMANN, G.; MOLLER JR., O. Freshwater outflow and Subtropical Convergence influence on the phytoplankton biomass in southern brazilian continental shelf. Cont. Shelf. Res., v. 15, p. 1737-1756, 1995.

CLAUSTRE, H. E.; MARTY, J. C. Specific phytoplankton biomasses and their relation to primary production in the tropical North Atlantic, v. 42 , n. 8 , p. 1475-1493, 1995.

CLAUSTRE, $\mathrm{H}$. The trophic status of various oceanic provinces as revealed by phytoplankton pigment signatures. Limnol. Oceanogr., v. 39, p. 1206-1210, 1994.

CONGESTRI, R.; FEDERICI, R.; ALBERTANO, P. Evaluating biomass of Baltic filamentous cyanobacteria by image analysis. Aquat. Microb. Ecol.,v. 22, p. 283-290, 2000.

CULLEN, J. J. The deep chlorophyll maximum: comparing vertical profiles of chlorophyll a, Canadian Journal of Fisheries and Aquatic Sciences, v. 39, p. 791-803, 1982.

CULLEN, J.J.; FRANKS P.J.S.; KARL D.M.; LONGHURST A.R. Physical influences on marine ecosystem dynamics. pp. 297-336. In: A.R. Robinson, J.J. Mccarthy and B.J. Rothschild (eds.). The Sea Biological-Physical Interactions in The Ocean., v. 12, p. 662, 2002.

CUPP, E.E. Marine Plankton Diatoms of the West Coast of North America. In: Sverdrup, H.U., Fleming, R.H., Miller, L.H., Zobell, C.E. (eds.), Bulletin of the Scripps Institution of Oceanography of the University of California La Holla, v. 5, p. 238, 1943.

CUSHING, D. H. A difference in structure between ecosystems in strongly stratified waters and in those that are only weakly stratified. J. Plankton Res; v. 11, p. 1-13, 1989.

DOURADO, M. S.; OLIVEIRA, A. P.. Observational description of the Atmospheric and Oceanic Boundary Layers over the Atlantic Ocean. Brazilian. Journal of Oceanography, v. 49, n. 1/2, p. 49-59, 2001.

DUBINSKY, Z.; STAMBLER, N. Photoacclimation processes in phytoplankton: mechanisms, consequences, and applications. Aquat Microb Ecol, v. 56, p. 163-176, 2009. 
DUYSENS, L. N. M. The flattening of the absorption spectrum of suspensions as compared to that of solutions. Biochim. Biophys. Acta, v. 19, p. 1$12,1956$.

EPPLEY, R. W. An incubation method for estimating the carbon content of phytoplankton in natural samples. Limnology Oceanography, v. 13 p. 574-582, 1968

EPPLEY, R. W. e RENGER, E. H. Nitrogen assimilation of an oceanic diatom in nitrogen-limited continuous culture. J. Phycol., v. 10, 15-23, 1974.

EPPleY, R. W., CARLUCCI, A. F., HOLM-HANSEN, O., KIEFER, D., MCCARTHY, J. J., VEMICK, E., WILLIAMS, P. M. Phytoplankton growth and composition in shipboard cultures supplied with nitrate, ammonium, or urea as the nitrogen source. Limnol. Oceanogr., v. 16, p. 741-751, 1971.

EPPLEY, R. W.; HARRISON, W. G.; CHISHOLME, S. W.; STEWART, E. Particulate organic matter in surface water off Southern California and its relationship to phytoplankton. J. Mar. Res., v. 35, p. 671-696, 1977.

FAHNENSTIEL, G. L.; MCCORMICK, M. J.; LANG, G. A.; REDALJE, D. G.; LOHRENZ, S. E.; MARKOWITZ, M.; WAGONER, B.; CARRICK, H. J. Taxon-specific growth and loss rates for dominant phytoplankton populations from the northern Gulf of Mexico. Marine Ecology Progress Series, v. 117, p. 229-239, 1995

FALKOWSKI, P. G.; LAROCHE, J. Acclimation to spectral irradiance in algae. J. Phycol., v. 27, p. 8-14, 1991.

FALKOWSKI, P. G.; LAWS, E. A.; BARBER, R. T.; MURRAY, J. W. Phytoplankton and their role in primary, new, and export production, in: Ocean biogeochemistry: the role of the ocean carbon cycle in global change. Springer, p. 99-121, 2003.

FALKOWSKI, P. G.; ZIEMANN, D.; KOLBER, Z.; BIENFANG, P. K. Role of eddy pumping in enhancing primary production in the ocean. Nature, v. 352, p. 55-58, 1991.

FAURE, V.; PINAZO, C.; TORRETON, J. P.; DOUILLET, P. Relevance of various formulations of phytoplankton chlorophyll a : carbon ratio in a 3D marine ecosystem model, C. R. Biol., v. 329, p. 813-822, 2006. 
FILLMANN, G. Caracterização química das massas de ǵua da plataforma continental do Sul do Brasil. Tese de mestrado da Universidade Federal do Rio Grande - RS, p. 133, 1990.

FINKEL, Z. V.; BEARDALL, J.; FLYNN, K. J.; QUIGG, A.; REES, T. A. V. e RAVEN, J. A. Phytoplankton in a changing world: cell size and elemental stoichiometry. Journal of Plankton Research, v. 32: 119137, 2010.

FOGG, G. E.; NALEWAJKO, C.; WATT, W.D. Extracellular products of phytoplankton photosynthesis. Proc. R. Sot. Lond., v. 162, p. 517-534, 1965.

GAETA, S. A.; BRANDINI, F. P. Produção primária do fitoplâncton na região entre o Cabo de São Tomé (RJ) e o Chuí (RS). In: 0 ambiente oceanográfico da Plataforma Continental e do Talude na região Sudeste-Sul do Brasil. Eds. Rossi-Wongtschowski, C.L. \& Madureira, L., p. 219-264, 2006

GARCIA, C. A. E.; GARCIA, V. M. T. Variability of chlorophyll a from ocean color images in the La Plata continental shelf region. Continental Shelf Research, v. 28, p. 1568-1578, 2008.

GEIDER, R. J.; MACINTYRE, H. L.; KANA, T. M. A dynamic regulatory model of phytoplankton acclimatation to light, nutrients and temperature. Limnology Oceanography, v. 43, p. 679-694, 1998.

GEIDER, R. J.; MACINTYRE, H. L.; KANA, T. M. Dynamic model of phytoplankton growth and acclimation: responses of the bal- anced growth rate and the chlorophyll a:carbon ratio to light, nutrient-limitation and temperature. Marine Ecology Progress Series, v. 148, p. 187-200, 1997.

GIANNINI, M. F. C; GARCIA, C. A. E.; TAVANO, V. M.; CIOTTI, A. M. Effects of low-salinity and high-turbidity waters on empirical ocean colour algorithms: An example for Southwestern Atlantic waters. Continental Shelf Research, v. 59, p. 84-96, 2013.

GOERICKE, R.; MONTOYA, J. P. Estimating the contribution of microalgal taxa to chlorophyll a in the field - variations of pigments ratios under nutrient - and light-limited growth. Mar. Ecol. Prog. Ser., v. 169, p. 97$112,1998$. 
GRAHAM, H. W.; BRONIKOWSKY, N. The genus Ceratium in the Pacific and North Atlantic Oceans. Pulil. Carnegie Int. Wash., v. 565, n.5, p. 185, 1944.

GROB, C.; ULLOA, O.; CLAUSTRE, H.; HUOT, Y.; ALARCÓN, G.; MARIE, D. Contribution of picoplankton to the total particulate organic carbon concentration in the eastern South Pacific, Biogeosciences, v. 4, p. 837-852, 2007.

HASLE, G. R.; SYVERTSEN, E. E. Marine Diatoms.. In: Thomas, C.R. (ed.). Identifying Marine Phytoplankton. Academic Press, p. 5-385, 1997.

HAWKINS, P. R.; HOLLIDAY, J.; KATHURIA, A.; BOWLING, L. Change in cyanobacterial biovolume due topreservation by Lugol's lodine. Harmful Algae, v. 4, p. 1033-1043, 2005.

HEIMDAL, B.R. Modern coccolithophorids.. In: Tomas, C.R. (ed.). Identifying Marine Phytoplankton. Academic Press, p. 731-858, 1997.

HERBLAND, A.; LEBOUTEILLER, A.; RAIMBAULT, P. Size structure of phytoplankton biomass in the equatorial Atlantic Ocean. Deep-Sea Research A, v. 32, n. 7, p.819-836, 1985.

HILLEBRAND, H.; DÜRSELEN, C. D.; KIRSCHTEL, D.; POLLINGHER, U.; ZOHARY, T. Biovolume calculation for pelagic and benthic microalgae. Journal of Phycology, v. 35, p. 403-424, 1999.

HOEPFFNER, N.; SATHYENDRANATH, S. Effect of pigment composition on absorption properties of phytoplankton. Mar. Ecol. Prog. Ser, v. 73, p. 11-23, 1991.

HOLM-HANSEN, O. Algae: amounts of DNA and organic carbon in single cells. Science, v. 163, p. 87-88, 1969.

HURET, M.; DADOU, I.; DUMAS, F.; LAZURE, P.; GARCON, V. Coupling physical and biogeochemical processes in the Rio de la Plata plume. Continental Shelf Research, v. 25, p. 629-653, 2005.

HUSTEDT, F. Die Kieselalgen Deutschlands, Österreichs und der Schweiz. In: Dr. L. Rabenhorst's Kryptogamenflora von Deutschland, Österreichs und der Schweiz. Akademische Verlagsgesellschaft M.B.H. Leipzig, p. 1-920, 1930. 
JEFFREY, S. W.; MANTOURA, R. F. C.; WRIGHT, S. W. Phytoplankton pigments in oceanography: Guidelines to modern methods. Paris: UNESCO, P.447, 1997.

JEFFREY, S. W.; WRIGHT, D S. W. Photosynthetic pigments in the haptophyta, In: J. C. Green and B. S. C. Leadbeater [eds.], The haptophyte algae. Claredon Press, p. 111-132, 1994.

JONGE, V. N. Fluctuations in the organic carbon to chlorophyll a ratios for estuarine benthic diatom populations. Marine Ecology Progress Series, v. 2, p. 345-353, 1980.

KIEFER, D.; OLSON, R.; HOLM-HANSEN, O. Another look at the nitrite and chlorophyll maxima in the central North Pacific. Deep Sea Res. I, v. 23, p.1199-1208, 1976

KIRK, J. T. O. Light and Photosynthesis in Aquatic Ecosystems. Cambridge University Press, Melbourne. 1994.

KITCHEN, J. C.; ZANEVELD, J. R. V. On the non-correlation of the vertical tructure of light scattering and chlorophyll a in case 1 waters. J. Geophys. Res. , v. 95, n. 20, p. 237-20,246, 1990.

KOMÁREK, J.; ANAGNOSTIDIS, K. Modern Approach to the Classification System of Cyanophytes (Nostocales). Archiv Fuer Hydrobiologie. Supplementband Monographische Beitraege, v. 82, p. 247-345, 1989.

KOMÁREK, J.; ANAGNOSTIDIS, K. Oscillatoriales. In: Büdel, B.; Krienitz, L.; Gärtner, G.; Schagerl, M. (eds.). Süsswasserflora von Mitteleuropa. Elsevier/Spektrum, v. 1, p. 759, 2005.

KRUSKOPF, M.; FLYNN, K. Chlorophyll content and fluorescence responses cannot be used to gauge reliably phytoplankton biomass, nutrient status or growth rate. New Phytologist, v. 169, p. 525-536, 2006.

LAWS, E. A., BANNISTER, T. T. Nutrient- and light-limited growth of Thalassiosira fluviatilis in continuous culture with implications for phytoplankton growth in the ocean. Limnol. Oceanogr, v. 25, n. 3, p. 457-473, 1980.

LE QUÉRÉ, C.; HARRISON, S.P.; PRENTICE, C.I; BUITENHUIS, E.T.; AUMONT, O.; BOPP, L.; CLAUSTRE, H.; CUNHA, L.C.; GEIDER, R.; GIRAUD, X.; KLAAS, C.; KOHFELD, K.E.; LEGENDRE, L.; MANIZZA, M.; PLATT, T.; RIVKIN, R.B.; SATHYENDRANATH, S.; UITZ, J.; 
WATSON, A.J. e WOLF-GLADROW, D. Ecosystem dynamics based on plankton functional types for global ocean biogeochemistry models. Global Change Biology, v. 11, p.2016-2040, 2005.

LEAKEY, R. J. G.; BURKHILL, P. K.; SLEIGH, M. A. A comparison of fixatives for the estimation of abundance and biovolume of marine plankton ciliate populations. J. Plankton Res., v. 16, p. 375-389, 1994.

LEWIS, W. M. Surface/volume ratio: implications for phytoplankton morphology. Science, v. 192, p. 885-887, 1976.

LIMA, I.D.; GARCIA, C.A.E.; MÖLLER, O.O. Ocean surface processes on the southern Brazilian shelf: characterization and seasonal variability. Continental Shelf Research, v. 16, n. 10, p. 1307-1317, 1996.

LUTZ, V.A.; SATHYENDRANATH, S.; HEAD, E.J.H.; LI, W.K.W. Variability in pigment composition and optical characteristics of phytoplankton in the Labrador Sea and the Central North Atlantic. Marine Ecology Progress Series, v. 260, p. 1-18, 2003.

MACINTYRE, H. L.; KANA, T. M.; ANNING, T.; GEIDER; R. J. Photoacclimation of photosynthesis irradiance response curves and photosynthetic pigments in microalgae and cyanobacteria. J. Phycol., v. 38, p. 17-38, 2002.

MALONE, T. C. Algal size. In: I. Morris [ed.], The physiological ecology of phytoplankton. Univ. of California Press, p. 433-463, 1980.

MANN, K. H.; LAZIER, J. R. Dynamics of Marine Ecosystems: Biological Physical Interactions in the Oceans, Blackwell, Malden, Mass., 1991. MARAÑóN, E.; HOLLIGAN, P.M.; BARCIELA, R.; GONZÁLEZ, N.; MOURIÑO, B.; PAZÓ, M.J.; VARELA, M. Vertical distribution of phytoplankton biomass, production and growth in the Atlantic subtropica gyres. Marine Ecology Progress Series, v. 216, p.43-56, 2001.

MARGALEF, R. Life forms of phytoplankton as survival alternatives in an unstable environment. Oceanol. Acta, v. 1, p. 493-509, 1978.

MARGALEF, R. Modifications induced by different temperatures on the cells of Scenedexmus obliquus (Chlorophyceae). 1954.

MARTINEZ, G.; BRUGNOLI, E.; HERNÁNDEZ, J.; FROUIN, R.; VIZZIANO, D. How valid is the SeaWiFS estimation of chlorophyll-a at the Río de 
la Plata estuary and its area of influence? In: SPIE Conference 2005Active and Passive Remote Sensing of the Oceans. Frouin, R.J.; Kawamura, H.; Pan, D. (Eds). SPIE, Honolulu, HI, p. 54-65, 2005. doi:10.1117/1112.582665.

MEI, Z. P.; LEGENDRE, L.; GRATTON, Y.; TREMBLAY, J. É.; LEBLANC, B.; KLEIN, B.; GOS-SELIN, M. Phytoplankton production in the North Water Polynya: size-fractions and carbon flux. Marine Ecology Progress Series, v. 256, p.13-27, 2003.

MENDEN-DEUER, S.; LESSARD, E. J. Carbon to volume relationships for dinoflagellates, diatoms, and other protist plankton. Limnology Oceanography, v. 45, n. 3, p. 569-579, 2000.

MENDEN-DEUER, S.; LESSARD, E. J.; SATTERBERG, J. Effect of preservation on dinoflagellate and diatom cell volume, and consequences for carbon biomass predictions. Marine Ecology Progress Series, v. 222, p. 41-50, 2001.

MENDES C.R.B.; CARTAXANA P.; BROTAS V. HPLC determination of phytoplankton and microphytobenthos pigments: comparing resolution and sensitivity of a C18 and a C8 method. Limnology and Oceanography: Methods, v. 5, p. 363-370, 2007.

METZleR, P. M.; GILBERT, P.M.; GAETA, S. A.; LUBLAN, J. M. New and regenerated production in the South Atlantic off Brazil. Deep-Sea Res., v. 4 , p. $363-384,1997$.

MITCHELL, B. G. Algorithms for determining the absorption coefficient of aquatic particulates using the quantitative filter technique (QFT). SPIE, Ocean Optics X, v. 1302, p. 137-148, 1990.

MITRA, A.; FLYNN, K.J.; FASHAM, M.J.R.; Accounting correctly for grazing dynamics in Nutrient-Phytoplankton-Zooplankton models. Limnology and Oceanography, v. 52, p. 649-661. 2007.

MOAL, J.; MARTIN-JEZEQUEL, V.; HARRIS, R. P.; SAMAIN, J.F.; POULET, S. A. Interspecific and intraspecific variability of the chemical composition of marine phytoplankton. Oceanol. Acta, v. 10, p. 339-346, 1987. 
MOBERG, E. A.; SOSIK, H. M. Distance maps to estimate cell volume from plankton images. Limnology Oceanography: Methods, v. 10, p. 278288, 2012.

MÖLLER Jr. O.; PIOLA, A.R.; FREITAS, A.C.; CAMPOS, E.J.D. The effects of river discharge and seasonal winds on the shelf off southeastern South America. Continental Shelf Research, v. 28, p. 1607-1624, 2008.

MONTAGNES, D. J. S.; BERGES, J. A.; HARRISON, P. J.; TAYLOR, F. J. R. Estimating carbon, nitrogen, protein, and chlorophyll a from volume in marine phytoplankton. Limnology Oceanography, v. 39, n. 5, p. 10441060, 1994.

MOORE, L. R.; CHISHOLM, S. W. Photophysiology of the marine cyanobacterium Prochlorococcus: ecotypic differences among cultured isolates. Limnology and Oceanography, v. 44, p. 628-638, 1999.

MOREL, A.; BRICAUD, A. Theoretical results concerning the optics of phytoplankton, with special references to remote sensing applications.. In Oceanography from space. COSPAR/SCOR/IUCRM Symp. Plenum. p 313-327, 1981.

MOREL, A.; PRIEUR, L. Analysis of variation in ocean color. Limnology Ocenaography, v. 22, p. 709-722, 1977.

MOREL, A.; VOSS, K.J.; GENTILI, B. Bidirectional reflectance of oceanic waters: A comparison of modeled and measured upward radiance fields. Journal of Geophysical Research, v. 100, n. 13, p. 143-13 , 1995.

MORRISON, J.R.; SOSIK, H.M. Inherent optical properties in New England coastal waters: decomposition into contributions from optically important constituents. Proceedings of Ocean Optics, v. XVI, p. 10, 2002.

MULLIN, M. M.; SLOAN, P. R.; EPPLEY, R. W. Relationship between carbon content, cell volume and area in phytoplankton. Limnol. Oceanogr., v. 11, p. 307-311, 1966.

NAIR, A.; SATHYENDRANATH, S.; PLATT, T.; MORALES, J.; STUART, V.; FORGET, M.; DEVRED, E. e BOUMAN, H. Remote sensing of plankton functional types. Remote Sensing of Environment, v. 112, p.3366-3375, 2008. 
NASELLI-FLORES, L.; PADISÁK, J.; ALBAY, M. Shape and size in phytoplankton ecology: do they matter? Hydrobiologia, v. 578, p.157161, 2007.

NIENCHESKI, L.F.H.; WINDOM, H.L.; MOORE, W. S.; JAHNKE, R. A.. Submarine groundwater discharge of nutrients to the ocean along a coastal lagoon barrier, Southern Brazil. Mar. Chem., v. 106, p. $546-$ 561, 2007.

ODEBRECHT, C.; GARCIA, V. M. T. Ambientes Costeiros e Marinhos e sua Biota - Fitoplâncton. In: Os Ecossistemas Costeiro e Marinho do Extremo Sul do Brasil. Seeliger, U., Odebrecht, C. \& Castello J.P. (Eds). Rio Grande, RS, p. 104-106, 1998.

OLENINA, I.; HAJDU, S.; EDLER, L.; ANDERSON, A.; WASMUND, N.; BUSCH, S.; GÖBEL, J.; GROMISZ, S.; HUSEBY, S.; HUTTUNEN, M.; JAANUS, A.; KOKKONEN, P.; LEDAINE, I.; NIEMKIEWICZ, E. Biovolumes and size-classes of phytoplakton in the Baltic Sea. HELCOM Balt. Sea Environ. Proc., v. 106, p. 144, 2006.

OLIVIERI, E. T. Feasibility of estimating phytoplankton size and biomass in fresh and preserved samples from Benguela Current with a Coulter Counter. S. Afr. J. Mar. Sci., v. 3, p. 99-110, 1985.

OLSON, R. J.; SOSIK, H. M. A submersible imaging-in- flow instrument to analyze nano- and microplankton: Imaging FlowCytobot. Limnol. Oceanogr. Methods, v. 5, p. 195- 203, 2007.

PADISÁK, J.; SORÓCZKI-PINTÉR, É.; REZNER, Z. Sinking properties of some phytoplankton shapes and the relation of form resistance to morphological diversity of plankton - an experimental study. Hydrobiologia , v. 500, p. 243-257, 2003.

PARSONS, T. R.; STEPHENS, K.; STRICKLAND, J. D. H. On the chemical composition of eleven species of marine phytoplankters. J. Fish. Res. Board Can., v. 18, p. 1001-1016, 1961.

PARSONS, W. T. R.; STRICKLAND, J. D. H. The proximate analysis of marinestanding crops. Nature, v.184, p.2038, 1959

PÉREZ, V.; FERNÁNDEZ, E.; MARAÑÓN, E.; MORÁN, X. A. G.; ZUBKOV, M. V. Vertical distribution of phytoplankton biomass, production and growth in the Atlantic subtropica gyres. Deep-Sea Research I, v. 53, 
p.1616-1634, 2006.

PETERSON, R.G.; STRAMMA, L. Upper-level circulation in the South Atlantic

Ocean. Progress in Oceanography, v. 26, p. 1-73, 1991.

PIOLA, A.R.; CAMPOS, E.J.D.; MOLLER, O.O.; CHARO, M. MARTINEZ, C. Subtropical shelf front off eastern South America , Journal Geophysical Research, v. 105, p. 6566-6578, 2000.

PIOLA, A.R.; ROMERO, S.I.; ZAJACZKOVSKI, U. Space-time variability of the Plata plume inferred from ocean color. Continental Shelf Research, v. 28, p. $1556-1567,2008$.

POMEROY, L. R. The ocean's food web, a changing paradigm. Bioscience, v. 24, p. 499-504, 1974.

PREISENDORFER, R.W. Application of radiative transfer theory to light measurement in the sea. Int. Union Geod. Geophys. Monogr., v. 10, p. 11-30, 1961.

PREZELIN, B. B. Light reactions in photosynthesis. In Platt.T. (ed.), Physiological Bases of Phytoplankton Ecology. Can. BulL Fish., p. 1- 43, 1981.

PRÉZELIN, B. B.; HOFMANN E. E.; MENGELT C.; KLINCK J. M. The linkage between Upper Circumpolar Deep Water (UCDW) and phyto- plankton assemblages on the west Antarctic Peninsula continental shelf, J. Mar. Res., v. 58, n. 2, p. 165-202, 2000.

PRIEUR, L.; SATHYENDRANATH, S. An optical classification of coastal and oceanic waters based on the specific spectral absorption curves of phytoplankton pigments, dissolved organic matter, and other particulate materials. Limnol. Oceanogr., v. 26, n.4, p. 671-689, 1981.

PUTT, M., STOECKER, D. K. An experimentally determined carbon,volume ratio for marine 'oligotrichous' ciliates from estuanne and coastal waters. Limnol Oceanogr., v.34. p.1097-1110, 1989.

REYNOLDS, C. S. The Ecology of Freshwater Phytoplankton. Cambridge University Press, Cambridge 2006.

RICARD, M. Atlas du Phytoplancton Marin. Diatomophycées. CNRS, v. 2, p. $297,1987$.

SATHYENDRANATH, S.; COTA G.; STUART V.; MAASS H.; PLATT T. Remote sensing of phytoplankton pigments: A comparison of empirical 
and theoretical approaches, Int. J. Remote Sens., v. 22 n. 2-3, p. 249273, 2001.

SIERACKI, C. K.; SIERACKI M. E.; YENTSCH C. S. An imaging-in-flow system for automated analysis of marine microplankton. Mar. Ecol. Prog. Ser., v. 168, p. 285-296, 1998.

SILVEIRA, I.C.A.; SCHMIDT, A.C.K.; CAMPOS, E.J.D.; GODOI, S.S.; IKEDA, Y. A Corrente do Brasil ao Largo da Costa Leste Brasileira. Revista Brasileira de Oceanografia, v. 48, n. 2, p. 171-183, 2000.

SINCLAIR, M.; KEIGHAN, E.; JONES, J. ATP as a measure of living phytoplankton carbon in estuaries. J. Fish. Res. Bd. Can., v. 36, p. 180$186,1979$.

SMAYDA, T. J. Adaptive ecology, growth strategies and the global bloom expansion of dinoflagellates. Journal of Oceanography, v. 58, p.281294, 2002.

SMAYDA, T. J. The suspension and sinking of phyto- plankton in the sea. Oceanography and Marine Biology: An Annual Review, v. 8, p 353414, 1970.

SMAYDA, T.J.; REYNOLDS, C.S. Community assembly in marine phytoplankton: application of recent models to harmful dinoflagellate blooms. Journal of Plankton Research, v. 23, p. 447-461, 2001.

SMETACEK, V.; HENDRIKSON, P. Composition of particulate organic matter in Kiel Bight in relation to phytoplankton succession. Oceanol. Acta, v. 2, p. 287-298, 1979.

SMITH, R. E. H.; KALFF, J. Size-dependent phosphorus uptake kinetics and cell quota in phytoplankton. Journal of Phycology, v.18, p. 275-284, 1982.

SOSIK, H. M.; OLSON, R. J. Automated taxonomic classification of phytoplankton sampled with imaging-in- flow cytometry. Limnol. Oceanogr. Methods, v. 5, p. 204-216, 2007.

SOURNIA, A. Form and function in marine phytoplankton. Biological Reviews, v. 57, p. 347-394, 1982.

SOURNIA, A. Phytoplankton Manual. Unesco, p. 337, 1978.

SOUZA R. B., ROBINSON, I S. Satellite and Lagrangian observations of the Brazilian Coastal Current. Cont. Shelf Res. v. 24, p.241-262, 2004 
STANCA, E.; CELLAMARE, M.; BASSET, A. Geometric shape as a trait to study phytoplankton distribution in aquatic ecosystems. Hydrobiologia, v. 701, p. 99-116, 2013.

STEEMANN-NIELSEN, E. The use of radio-active carbon (14C) for measuring organic production in the sea. Journal du Conseil International pour Exploration de la Mer, v.18, p. 117-140. 1952.

STEIDINGER, K. A.; TANGEN, K. Dinoflagellates. pp. 387-584. In: Tomas, C.R. (ed.). Identifying Marine Phytoplankton. Academic Press, San Diego, p. 861, 1997.

STRATHMANN, R. R. Estimating the organic carbon content of phytoplankton from cell volume or plasma volume. Limnol. Oceanogr., v. 12, p. 411418, 1967.

SUN, J.; LIU, D. Geometric models for calculating cell biovolume and surface area for phytoplankton. Journal of Plankton Research, v. 25, n. 11, p. 1331-1346, 2003.

TAGUCHI, S.; DITULLIO, G.R.; LAWS, E.A. Physiological characteristics and production of mixed layer and chlorophyll maximum phytoplankton populations in the Caribbean Sea and western Atlantic Ocean. DeepSea Research A, v. 35, n.8, p.1363-1377, 1988.

TAKANOHASHI, R. A. Distribuição de nutrientes e clorofila-a ao longo da plataforma continental e talude do estado do Rio de Janeiro. Monografia da Universidade do Estado do Rio de Janeiro, p. 108, 2012.

TASSAN, S.; FERRARI, G. M. An alternative approach to absorption measurements of aquatic particles retained on filters. Liminology Oceanography, v. 40, n. 8, p. 1358-1368, 1995.

TAYLOR, A. G.; LANDRY, M. R.; SELPH, K. E.; YANG, E. J. Biomass, size structure and depth distribution of the microbial community in the eastern equatorial Pacific. Deep-Sea Research II, v. 58, p. 342-357, 2011.

TAYLOR, F. Dinoflagellates from the International Indian Ocean Expendition a Report on Material Collected by the R.V. "Anton Bruun 1963-1964", Stuttgart, E. Schweizerbart'sche Verlagsbuchhandlung (Ngele u. Obermiller) (Stuttgart), p. 234, 1976. 
THOMPSON, P.A.; GUO, M. Effects of variation in temperature. I. On the biochemical composition of eight species of marine phytoplankton. Journal of Phycology, v. 28, p. 481-488, 1992.

TREES, C. C.; CLARK, D. K.; BIDIGARE, R. R.; ONDRUSEK, M. E.; MUELLER, J. L. Accessory pigments versus chlorophyll a concentrations within the photic zone: A ubiquitous relationship. Limnology Oceanography, v. 45, n. 5, p. 1130-1143, 2000.

UITZ, J.; CLAUSTRE, H.; MOREL, A.; HOOKER, S. B. Vertical distribution of phytoplankton communities in open ocean: An assessment based on surface chlorophyll. Journal of Geophysical Research, v. 111, C08005, 2006.

UTERMÖHL, VON H. Zur Vervollkommung der quantitativen PhytoplanktonMethodik. Mitt. Int. Verein. Theor. Angew. Limnol., v. 9, p. 1-38, 1958.

VADRUCCI, M. R.; CABRINI, M.; BASSET, A. Biovolume determination of phytoplankton guilds in transitional water ecosystems of Mediterranean Ecoregion. Transitional Waters Bulletin, v. 2, p. 83-102, 2007.

VALENTIN, J.L. The Cabo Frio Upwelling System, Brazil. In: Seeliger, U., Kjerfve, B. (Eds.). Coastal Marine Ecosystems of Latin America, p. 97-105, 2001.

VALENTIN, J.L.; ANDRÉ, D.L.; JACOB, A.S. Hydrobiology in the Cabo Frio (Brazil) upwelling: two-dimensional structure and variability during a wind cycle. Cont. Shelf. Res., 7: $77-88,1987$

VAN DE HULST, H. C. Light scattering by small particles. Wiley, New York, 1957.

VAN DONK, E. Defenses in phytoplankton against grazing induced by nutrient limitation, UV-B stress and infochemicals. Aquatic Ecology, v. 31, p. 53-58, 1997.

VELDHUIS, M. J.W.; KRAAY, G.W. Phytoplankton in the subtropical Atlantic Ocean: towards a better assessment of biomass and composition. Deep Sea Res. I, v. 51, p. 507-530, 2004.

VENRICK, E.L. Phytoplankton species structure in the central North Pacific, 1973-1996; variability and persistence. Journal of Plankton Research, v. 21, p. 1029-1042, 1999.

VENRICK, E.L. Phytoplankton species structure in the central North Pacific, 
1973-1996: variability and persistence. Journal of Plankton Research, v. 21, n. 6, p. 1029-1042, 1999.

VERITY, P. G.; LANGDON, C. Relationships between lorica volume, carbon, nitrogen, and ATP content of tintinnids in Narragansett Bay. Journal of Plankton Research, v. 66, p. 859-868, 1984.

VERITY, P.G.; ROBERTSON, C.Y.; TRONZO, C.R.; ANDREWS, M.G.; NELSON, J.R.; SIERACKI, M.E. Relationship between cell volume and carbon and nitrogen content of marine photosynthetic nanoplankton. Liminology Oceanography, v. 37, n. 1434-1446, 1992.

VIDUSSI, F.; CLAUSTRE, H.; MANCA, B. B.; LUCHETTA, A.; MARTY, J. C. Phytoplankton pigment distribution in relation to upper thermocline circulation in the eastern Mediterranean Sea during winter, J. Geophys. Res., v. 106, n. C9, 19, p. 939-19,956, 2001

VOLLENWEIDER, R. A. A manual on methods for measuring primary production in aquatic environments. Int. Biol. Program Handbook 12. Oxford Blackwell Scientific Publications, p. 1-213, 1969.

WATERBURY, J.B.; WATSON, S.W.; VALOIS, F.W. e FRANKS, D.G. Biological and ecological characterizations of the marine unicellular cyanobacterium Synechococcus. Can. Bull. Fish. Aquat. Sci., v. 214, p. 71-120, 1986.

WILLIAMS, P. J. B.;. Thomas, D. N.; Reynolds, C. S. Phytoplankton Productivity - Carbon Assimilation in Marine and Freshwater Ecosystems, P.J. le B. Williams, D.N. Thomas, and C.S. Reynolds [eds.]. Blackwell Science Ltd. 2002.

WOOD, E.J.F. Dinoflagellates of the Caribbean Sea and Adjacent Areas. University of Miami Press, Miami, p. 1-142, 1968.

WOSZNIAK, B.; OSTROWSKA, M. Optical absorption properties of phytoplankton in various seas, Oceanologia, v. 29, p. 117-146, 1990.

WRIGHT, S. W. Analysis of phytoplankton populations using pigment markers. Workshop on pigment analysis of Antarctic microorganisms: University of Malaya June 29-July 1, 2005.

YENTSCH, C. S.; PHINNEY, D. A. A bridge between ocean optics and microbial ecology. Liminology Oceanography, v. 34, n. 8, p. 1694-1705, 1989. 
ZAPATA, M.; RODRÍGUEZ, F.; GARRIDO, J. L. Separation of chlorophylls and carotenoids from marine phytoplankton: a new HPLC method using a reversed phase C8 column and pyridine-containing mobile phases. Marine Ecology Progress Series, v. 195, p. 29-45, 2000.

ZUBKOV, M. V.; SLEIGH, M. A.; TARRAN, G. A.; BURKILL, P. H.; LEAKEY, R. J. G. Picoplankton community structure on an Atlantic transect from $50^{\circ} \mathrm{N}$ to $50^{\circ} \mathrm{S}$. Deep-Sea Research I, v. 45, p. 1339-1355, 1998. 


\section{Anexos}

\section{Anexo A}

Tabela 10: Lista das estações oceanográficas realizadas e suas respectivas profundidades e coordenadas geográficas.

\begin{tabular}{|c|c|c|c|c|c|c|}
\hline \multirow{2}{*}{$\begin{array}{c}\text { Cruzeiro } \\
\text { MCT-1 }\end{array}$} & \multicolumn{2}{|c|}{ Data e Hora (GMT) } & \multirow{2}{*}{$\frac{\text { Estação }}{30}$} & \multirow{2}{*}{$\begin{array}{c}\begin{array}{c}\text { Profundidade de } \\
\text { Coleta }\end{array} \\
3 \mathrm{~m} \text { [sup.] }\end{array}$} & \multirow{2}{*}{$\begin{array}{c}\text { Latitude } \\
23^{\circ} 28.68 \mathrm{~S}\end{array}$} & \multirow{2}{*}{$\begin{array}{c}\text { Longitude } \\
044^{\circ} 38.05 \mathrm{~W}\end{array}$} \\
\hline & $30 / 06 / 2010$ & $18: 11$ & & & & \\
\hline МСТ-1 & $30 / 06 / 2010$ & $18: 11$ & 30 & 25m [PFMC] & $23^{\circ} 28.68 \mathrm{~S}$ & $044^{\circ} 38.05 \mathrm{~W}$ \\
\hline MCT-1 & $30 / 06 / 2010$ & $20: 34$ & 31 & $3 m$ [sup.] & $23^{\circ} 20.48 \mathrm{~S}$ & $044^{\circ} 22.66 \mathrm{~W}$ \\
\hline МСТ-1 & $30 / 06 / 2010$ & $20: 34$ & 31 & 25m [PFMC] & $23^{\circ} 20.48 \mathrm{~S}$ & $044^{\circ} 22.66 \mathrm{~W}$ \\
\hline MCT-1 & $30 / 06 / 2010$ & $23: 53$ & 32 & $3 m$ [sup.] & $23^{\circ} 14.23 \mathrm{~S}$ & $046^{\circ} 56.09 \mathrm{~W}$ \\
\hline MCT-1 & $30 / 06 / 2010$ & $23: 53$ & 32 & 26m [PFMC] & $23^{\circ} 14.23 \mathrm{~S}$ & $046^{\circ} 56.09 \mathrm{~W}$ \\
\hline MCT-1 & $01 / 07 / 2010$ & $02: 24$ & 33 & $3 m$ [sup.] & $23^{\circ} 10.30 \mathrm{~S}$ & $043^{\circ} 38.89 \mathrm{~W}$ \\
\hline MCT-1 & $01 / 07 / 2010$ & $02: 24$ & 33 & 32m [PFMC] & $23^{\circ} 10.30 \mathrm{~S}$ & $043^{\circ} 38.89 \mathrm{~W}$ \\
\hline MCT-1 & $01 / 07 / 2010$ & $04: 25$ & 34 & $3 \mathrm{~m}$ [sup.] & $23^{\circ} 09.93 \mathrm{~S}$ & $043^{\circ} 25.32 \mathrm{~W}$ \\
\hline МСТ-1 & $01 / 07 / 2010$ & $04: 25$ & 34 & 25m [PFMC] & $23^{\circ} 09.93 \mathrm{~S}$ & $043^{\circ} 25.32 \mathrm{~W}$ \\
\hline MCT-1 & $01 / 07 / 2010$ & 07:02 & 35 & $3 m$ [sup.] & $23^{\circ} 05.55 \mathrm{~S}$ & $043^{\circ} 06.71 \mathrm{~W}$ \\
\hline MCT-1 & $01 / 07 / 2010$ & 07:02 & 35 & $36 \mathrm{~m}$ [PFMC] & $23^{\circ} 05.55 \mathrm{~S}$ & $043^{\circ} 06.71 \mathrm{~W}$ \\
\hline MCT-1 & $01 / 07 / 2010$ & 09:27 & 36 & $3 \mathrm{~m}$ [sup.] & $23^{\circ} 03.01 \mathrm{~S}$ & $042^{\circ} 55.01 \mathrm{~W}$ \\
\hline MCT-1 & $01 / 07 / 2010$ & $09: 27$ & 36 & 15m [PFMC] & $23^{\circ} 03.01 \mathrm{~S}$ & $042^{\circ} 55.01 \mathrm{~W}$ \\
\hline MCT-1 & $01 / 07 / 2010$ & $11: 42$ & 37 & $3 \mathrm{~m}$ [sup.] & $23^{\circ} 01.13 \mathrm{~S}$ & $042^{\circ} 41.04 \mathrm{~W}$ \\
\hline MCT-1 & $01 / 07 / 2010$ & $11: 42$ & 37 & $15 \mathrm{~m}$ [PFMC] & $23^{\circ} 01.13 \mathrm{~S}$ & $042^{\circ} 41.04 \mathrm{~W}$ \\
\hline MCT-1 & $01 / 07 / 2010$ & $14: 05$ & 38 & $3 \mathrm{~m}$ [sup.] & $22^{\circ} 59.92 \mathrm{~S}$ & $042^{\circ} 25.03 \mathrm{~W}$ \\
\hline MCT-1 & $01 / 07 / 2010$ & $14: 05$ & 38 & 12m [PFMC] & $22^{\circ} 59.92 \mathrm{~S}$ & $042^{\circ} 25.03 \mathrm{~W}$ \\
\hline MCT-1 & $01 / 07 / 2010$ & $17: 08$ & 39 & $3 m$ [sup.] & $22^{\circ} 59.00 \mathrm{~S}$ & $042^{\circ} 11.03 \mathrm{~W}$ \\
\hline MCT-1 & $01 / 07 / 2010$ & $17: 08$ & 39 & 15m [PFMC] & $22^{\circ} 59.00 \mathrm{~S}$ & $042^{\circ} 11.03 \mathrm{~W}$ \\
\hline MCT-2 & $06 / 12 / 2010$ & $20: 25$ & 04 & $3 \mathrm{~m}$ [sup.] & $34^{\circ} 11.60 \mathrm{~S}$ & $051^{\circ} 51.1 \mathrm{~W}$ \\
\hline MCT-2 & $08 / 12 / 2010$ & $13: 20$ & 13 & $3 \mathrm{~m}$ [sup.] & $33^{\circ} 01.40 \mathrm{~S}$ & $050^{\circ} 45.3 \mathrm{~W}$ \\
\hline MCT-2 & $08 / 12 / 2010$ & $16: 12$ & 14 & $3 m$ [sup.] & $32^{\circ} 51.20 \mathrm{~S}$ & $051^{\circ} 00.8 \mathrm{~W}$ \\
\hline MCT-2 & $08 / 12 / 2010$ & $16: 12$ & 14 & $29 \mathrm{~m}$ [PFMC] & $32^{\circ} 51.20 \mathrm{~S}$ & $051^{\circ} 00.8 \mathrm{~W}$ \\
\hline MCT-2 & $08 / 12 / 2010$ & $18: 54$ & 15 & $30 \mathrm{~m}$ [PFMC] & $32^{\circ} 41.00 \mathrm{~S}$ & $051^{\circ} 17.0 \mathrm{~W}$ \\
\hline MCT-2 & $08 / 12 / 2010$ & $18: 54$ & 18 & $3 m$ [sup.] & $32^{\circ} 16.60 \mathrm{~S}$ & $051^{\circ} 54.9 \mathrm{~W}$ \\
\hline MCT-2 & 09/12/2010 & $20: 18$ & 23 & $3 \mathrm{~m}$ [sup.] & $31^{\circ} 43.30 \mathrm{~S}$ & $049^{\circ} 57.2 \mathrm{~W}$ \\
\hline MCT-2 & 09/12/2010 & $20: 18$ & 23 & 90m [PFMC] & $31^{\circ} 43.30 \mathrm{~S}$ & $049^{\circ} 57.2 \mathrm{~W}$ \\
\hline MCT-2 & $11 / 12 / 2010$ & $07: 27$ & 30 & $5 \mathrm{~m}$ [sup.] & $30^{\circ} 27.90 \mathrm{~S}$ & $048^{\circ} 42.2 \mathrm{~W}$ \\
\hline MCT-2 & $11 / 12 / 2010$ & $07: 27$ & 30 & 75m [PFMC] & $30^{\circ} 27.90 \mathrm{~S}$ & $048^{\circ} 42.2 \mathrm{~W}$ \\
\hline MCT-2 & $11 / 12 / 2010$ & $10: 59$ & 31 & $5 \mathrm{~m}$ [sup.] & $30^{\circ} 20.40 \mathrm{~S}$ & $048^{\circ} 55.2 \mathrm{~W}$ \\
\hline MCT-2 & $11 / 12 / 2010$ & $10: 59$ & 31 & 63m [PFMC] & $30^{\circ} 20.40 \mathrm{~S}$ & $048^{\circ} 55.2 \mathrm{~W}$ \\
\hline MCT-2 & $11 / 12 / 2010$ & $15: 25$ & 33 & $5 \mathrm{~m}$ [sup.] & $30^{\circ} 05.10 \mathrm{~S}$ & $049^{\circ} 24.3 \mathrm{~W}$ \\
\hline MCT-2 & $11 / 12 / 2010$ & $15: 25$ & 33 & $65 \mathrm{~m}$ [PFMC] & $30^{\circ} 05.10 \mathrm{~S}$ & $049^{\circ} 24.3 \mathrm{~W}$ \\
\hline MCT-2 & $11 / 12 / 2010$ & $18: 35$ & 34 & 25m [PFMC] & $29^{\circ} 52.80 \mathrm{~S}$ & $049^{\circ} 47.7 \mathrm{~W}$ \\
\hline MCT-2 & $12 / 12 / 2010$ & 05:59 & 35 & $7 \mathrm{~m}$ [sup.] & $28^{\circ} 41.50 \mathrm{~S}$ & $048^{\circ} 48.0 \mathrm{~W}$ \\
\hline MCT-2 & $12 / 12 / 2010$ & $08: 33$ & 36 & $54 \mathrm{~m}$ [PFMC] & $28^{\circ} 51.60 \mathrm{~S}$ & $048^{\circ} 30.3 \mathrm{~W}$ \\
\hline MCT-2 & $20 / 12 / 2010$ & $20: 41$ & 64 & $5 \mathrm{~m}$ [sup.] & $25^{\circ} 19.00 \mathrm{~S}$ & $045^{\circ} 37.9 \mathrm{~W}$ \\
\hline MCT-2 & $20 / 12 / 2010$ & $20: 41$ & 64 & $84 \mathrm{~m}$ [PFMC] & $25^{\circ} 19.00 \mathrm{~S}$ & $045^{\circ} 37.9 \mathrm{~W}$ \\
\hline MCT-2 & $21 / 12 / 2010$ & $02: 46$ & 65 & $5 \mathrm{~m}$ [sup.] & $25^{\circ} 03.10 \mathrm{~S}$ & $045^{\circ} 25.6 \mathrm{~W}$ \\
\hline MCT-2 & $21 / 12 / 2010$ & $02: 46$ & 65 & 40m [PFMC] & $25^{\circ} 03.10 \mathrm{~S}$ & $045^{\circ} 25.6 \mathrm{~W}$ \\
\hline MCT-2 & $21 / 12 / 2010$ & 08:38 & 66 & $5 \mathrm{~m}$ [sup.] & $24^{\circ} 13.00 \mathrm{~S}$ & $045^{\circ} 12.2 \mathrm{~W}$ \\
\hline MCT-2 & $21 / 12 / 2010$ & $08: 38$ & 66 & $35 \mathrm{~m}$ [PFMC] & $24^{\circ} 13.00 \mathrm{~S}$ & $045^{\circ} 12.2 \mathrm{~W}$ \\
\hline MCT-2 & $21 / 12 / 2010$ & $13: 00$ & 67 & $5 \mathrm{~m}$ [sup.] & $23^{\circ} 52.00 \mathrm{~S}$ & $044^{\circ} 39.8 \mathrm{~W}$ \\
\hline MCT-2 & $21 / 12 / 2010$ & $13: 00$ & 67 & 38m [PFMC] & $23^{\circ} 52.00 \mathrm{~S}$ & $044^{\circ} 39.8 \mathrm{~W}$ \\
\hline MCT-2 & $21 / 12 / 2010$ & $17: 15$ & 68 & $5 \mathrm{~m}$ [sup.] & $23^{\circ} 31.40 \mathrm{~S}$ & $044^{\circ} 07.7 \mathrm{~W}$ \\
\hline MCT-2 & $21 / 12 / 2010$ & $17: 15$ & 68 & 28m [PFMC] & $23^{\circ} 31.40 \mathrm{~S}$ & $044^{\circ} 07.7 \mathrm{~W}$ \\
\hline MCT-2 & $22 / 12 / 2010$ & 01:07 & 69 & $5 \mathrm{~m}$ [sup.] & $23^{\circ} 10.10 \mathrm{~S}$ & $043^{\circ} 33.4 \mathrm{~W}$ \\
\hline MCT-2 & $22 / 12 / 2010$ & 01:07 & 69 & 32m [PFMC] & $23^{\circ} 10.10 \mathrm{~S}$ & $043^{\circ} 33.4 \mathrm{~W}$ \\
\hline
\end{tabular}




\section{Anexo B}

\section{Condições oceanográficas e Estado Trófico}

A descrição das variáveis oceanográficas de cada cruzeiro não fazem parte dos obejtivos do presente trabalho e, assim, descreveremos apenas algumas variáveis mais importantes para que a variabilidade encontrada na biomassa fitoplânctonica nas amostras utilizadas seja justificada. As duas regiões amostradas divergem em seus regimes oceanográficos de maneira marcante, e possuem diferentes graus de sazonalidade para a contribuição de massas de água costeira e padrões de circulação (Peterson e Stramma, 1991).

\section{MCT-1}

Durante a campanha oceanográfica MCT-1, a porção leste da plataforma continental do Rio de Janeiro foi dominada por águas quentes, indicando a influência da Corrente do Brasil (Figura 27A e 27B). Na porção ao sul da paltaforma continental, já no estado de São Paulo, evidencia-se a presença de um vórtice ciclônico, devido às temperaturas mais baixas $\left(18.8^{\circ} \mathrm{C}\right)$ na superfície. Os maiores valores de temperatura foram encontrados na superfície $\left(23.7^{\circ} \mathrm{C}\right.$ ) (Figura $\left.27 \mathrm{~A}\right)$, enquanto que os menores valores foram encontrados na PFMC $\left(18.4^{\circ} \mathrm{C}\right)$ (Figura 27B). Os valores mais baixos de salinidade foram observados próximos à costa e na porção sul da plataforma continental (Figura 27C e 27D), atingindo 35.1 na superfície (Figura 27C). $O$ padrão de distribuição espacial dos valores de temperatura e salinidade foram semelhantes entre a superfície e a PFMC, sugerindo uma camada de mistura vertical eficiente.

$\mathrm{Na}$ superfície, os valores de [chl] mantiveram-se, em sua maioria, abaixo de $1 \mathrm{mg} \cdot \mathrm{m}^{-3}$, caracterizando essa porção da plataforma continental brasileira como um ambiente oligotrófico (Figura 27E). Na PFMC, os valores de [chl] para a maioria das estações foram abaixo de de $4 \mathrm{mg} \cdot \mathrm{m}^{-3}$ (Figura $27 \mathrm{~F}$ ). Os valores elevados de [chl] ocorreram apenas nas estações mais costeiras, especialmente nas proximidades da Baia de Guanabara (RJ) (Figura 27E e 27F), com o máximo de $20 \mathrm{mg}^{-\mathrm{m}^{-3}}$ na PFMC. 
O cruzeiro MCT-1 foi realizado no inverno, quando se espera influência reduzida da ACAS devido à menor intensidade da ressurgência costeira em Cabo Frio (RJ), e maior influência de Água Tropical, promovendo condições meso-oligotróficas. Os máximos de clorofia-a foram costeiros, fato influenciado pelo desenho experimental que incluiu amostragens em pontos próximos à desembocadura de baias costerias (Takanohashi, 2012). Gradientes horizontais da [chl] entre ambientes de plataforma continental e o oceano aberto são esperados, seguindo o aporte de nutrientes na costa (Malone, 1980).

\section{MCT-2}

Nas coletas realizadas durante o cruzeiro oceanográfico MCT-2 na plataforma continental sul e sudeste do Brasil, observou-se um gradiente zonal de temperatura superficial da água (Figura 28A). A porção sul da plataforma continental sudeste apresentou as maiores temperaturas, entre $24^{\circ} \mathrm{C}$ e $26^{\circ} \mathrm{C}$, enquanto que os menores valores de temperatura (abaixo de $20^{\circ} \mathrm{C}$ ) ocorreram no extremo sul da plataforma continental brasileira. As maiores temperaturas ao norte seguem o padrão esperado para o verão. Esse padrão é mantido pela Corrente do Brasil, característica por possuir águas mais quentes que fluem em direção ao sul do país pela porção externa da plataforma continental. Na PFMC (Figura 28B), os valores de temperatura foram mais baixos que da superfície, e no extremo sul da plataforma continental brasileira foram encontrados mínimos de $14.1^{\circ} \mathrm{C}$. As menores temperaturas ao sul do Brasil correspondem ao ramo norte da Corrente das Malvinas, que flui em direção ao norte pela plataforma continental interna brasileira. Durante o verão, a influência deste ramo da Corrente das Malvinas é limitado à plataforma continental sul brasileira.

A salinidade, tanto na superfície (Figura 28C) quanto na PFMC (Figura 28D), apresentou um gradiente entre costa e talude continental, sendo mais evidente na superfície. Os menores valores de salinidade (abaixo de 34) estão limitados à plataforma continental interna. Os mínimos de salinidade ocorreram na desembocadura da Lagoa dos Patos (RS) e foram observados tanto na superfície quanto na PFMC. Embora a plataforma continental sul 
receba grande influência de aportes continentais durante o inverno e primavera (Ciotti et al., 1995, Giannini et al., 2013), sua ocorrência no verão ainda é significativa.

A [chl] foi maior na costa, especialmente próximo à desembocadura da Lagoa dos Patos (Figura 28E). O mesmo padrão espacial foi observado para a [chl] na PFMC (Figura 28F). Contudo, a maior parte das estações do cruzeiro MCT-2 possuíram [chl] menores que $1 \mathrm{mg} \cdot \mathrm{m}^{-3}$, sendo o máximo de $5.2 \mathrm{mg} \cdot \mathrm{m}^{-3}$ encontrado na PFMC na plataforma continental sudeste. $\mathrm{Na}$ plataforma sul do Brasil, o verão é a estação do ano com as menores concentrações anuais de clorofila-a (Ciotti et al., 2010), porém a contribuição de água doce são ainda evidentes na costa do Rio Grande do Sul (Campos et al., 1996), propiciando aporte de nutrientes e maiores condições de crescimento para o fitoplâncton.

Em ambas as campanhas oceangráficas, foram observados, como esperado (Cullen, 1982), picos subsuperficiais nos perfis verticais de fluorescência da clorofila-a na grande maioria das estações, o que permitiu as análises comparativas entre a superficie e a PFMC. Picos de fluorescência, ou de [chl], são resultado tanto de um aumento do número de organismos nessa profundidade, quanto à maior concentração intracelular de pigmentos dos organismos ali presentes. 

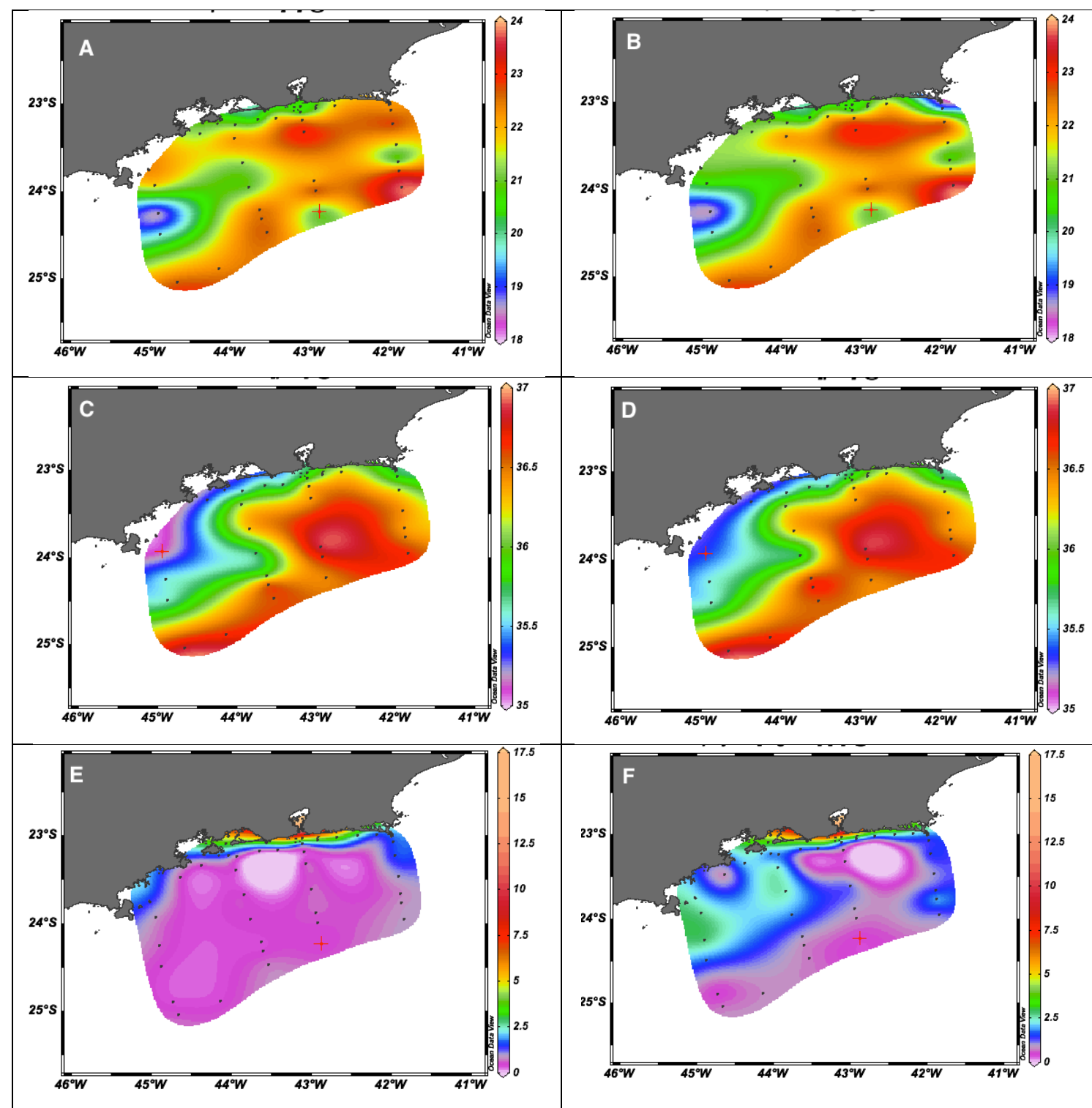

Figura 27: Distribuição espacial da temperatura da água na superfície (A) e na PFMC (B), da salinidade na superfície (C) e PFMC (D) e da concentração de clorofila-a superficial (E) e na PFMC (F) para o cruzeiro MCT-1. 


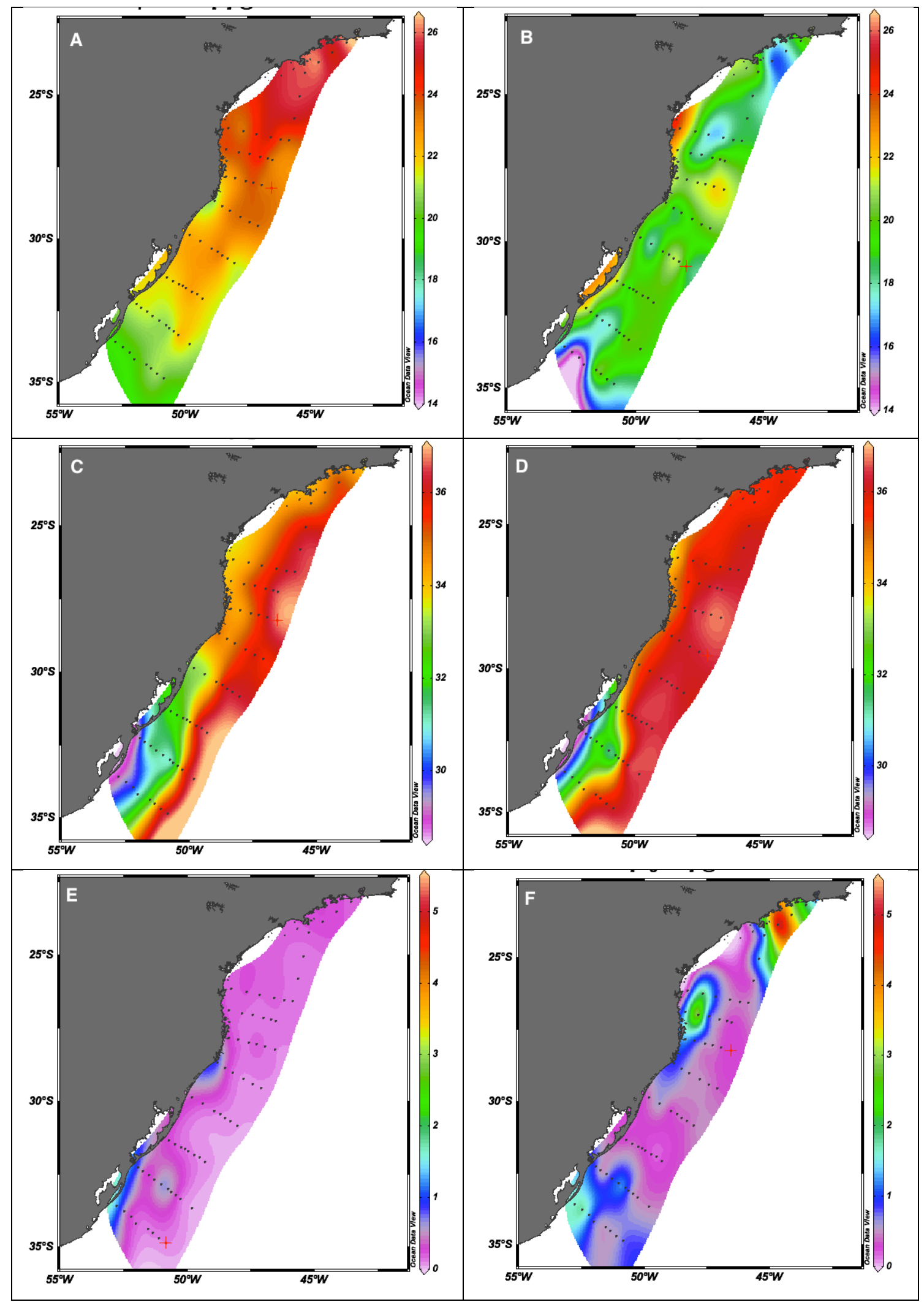

Figura 28: Distribuição espacial da temperatura da água na superfície (A) e na PFMC (B), da salinidade na superfície (C) e PFMC (D) e da concentração de clorofila-a superficial (E) e na PFMC (F) para o cruzeiro MCT-2. 


\section{Anexo C}

Tabela 11: Descrição dos morfotipos fitoplanctônicos observados, seus códigos e sua representação geométrica. Adaptado de Sun e Liu (2003).

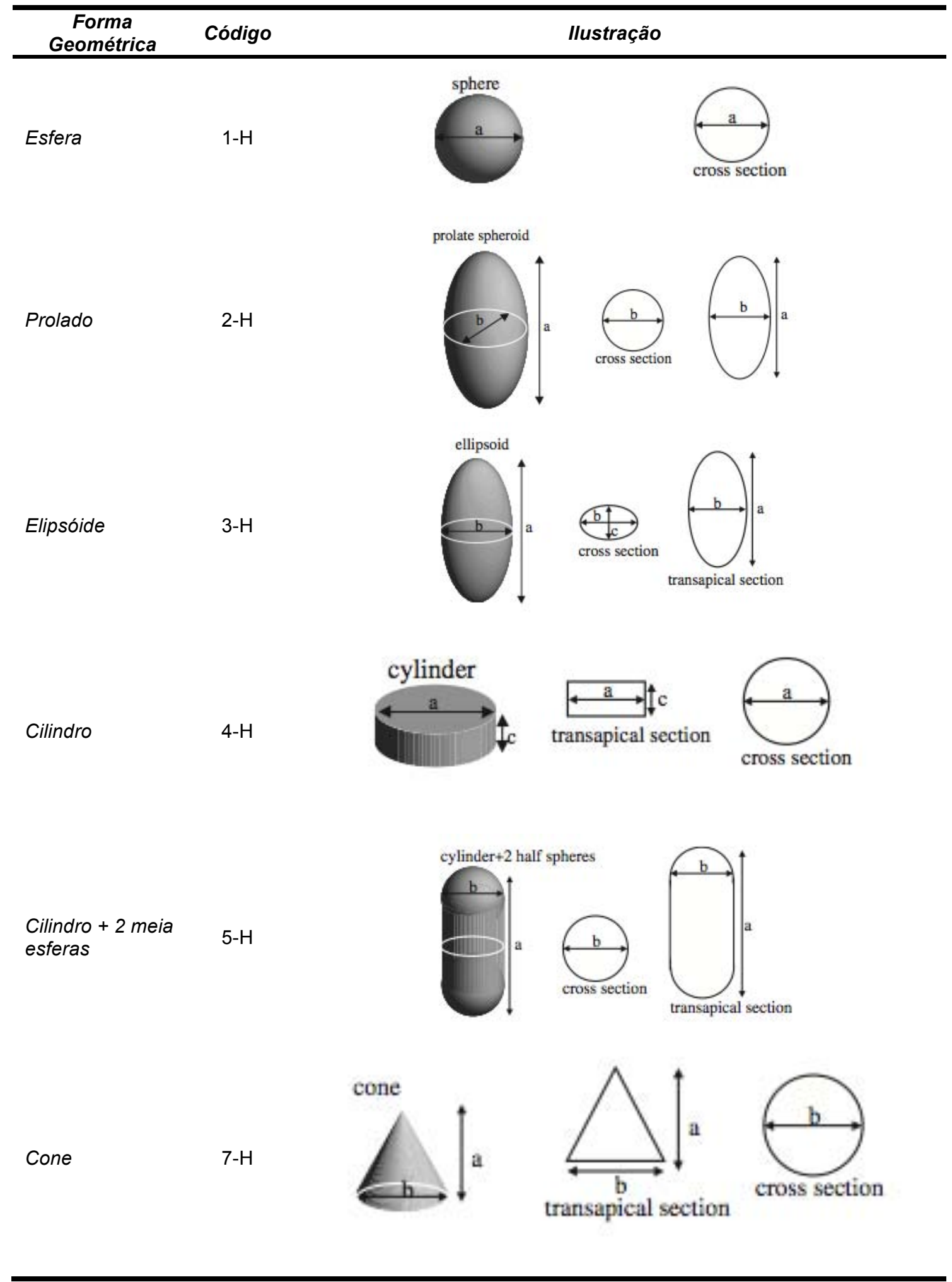




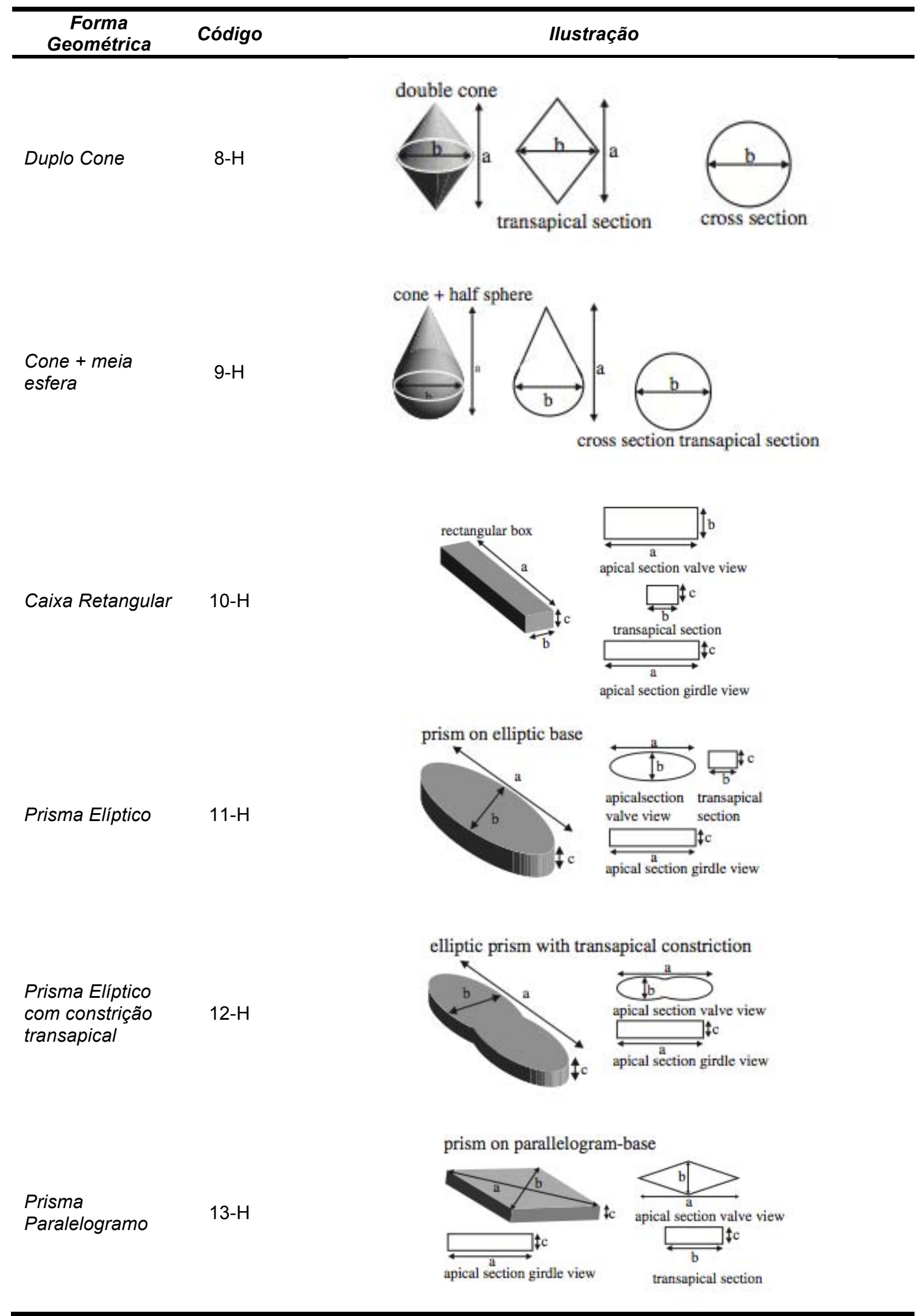




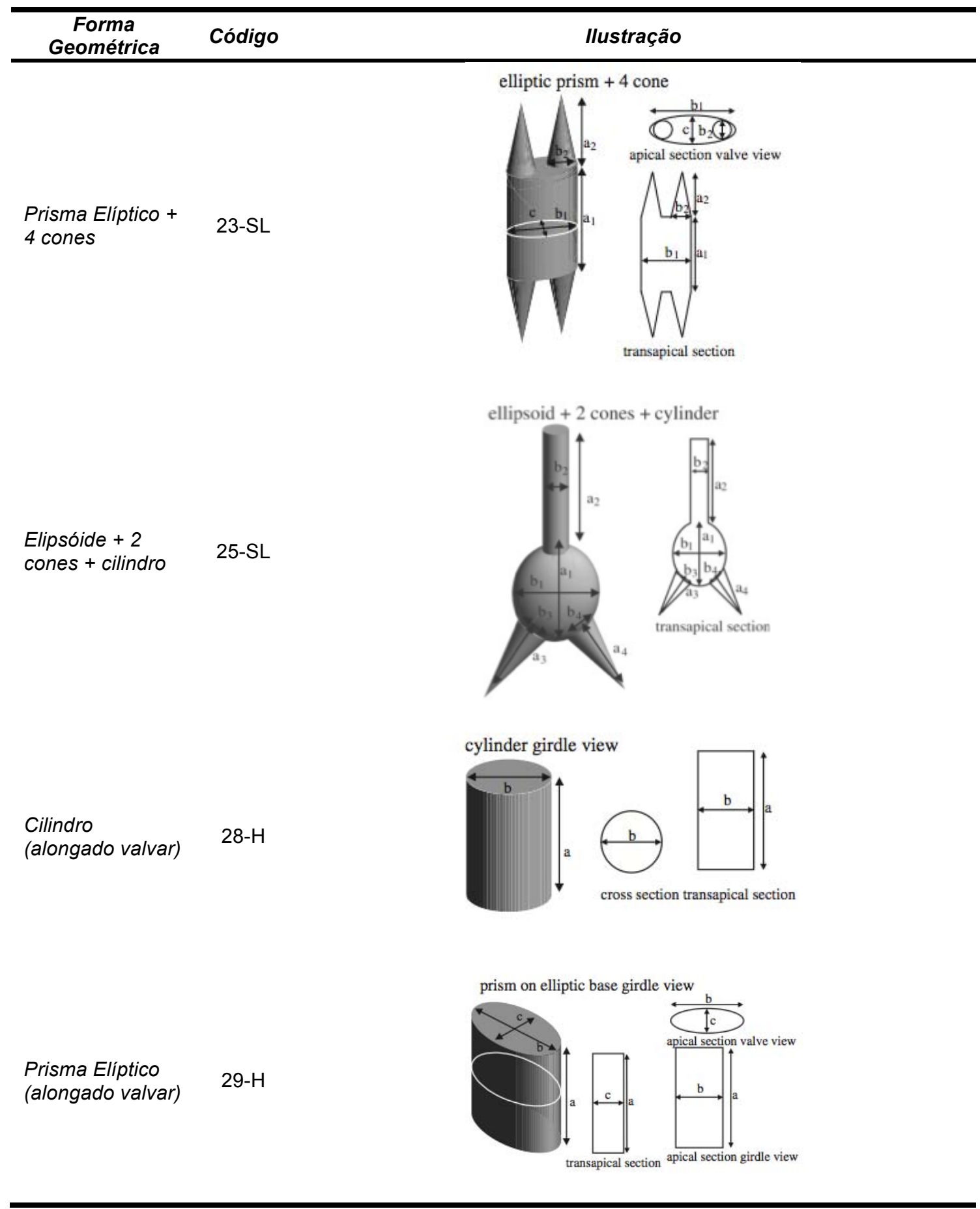

